\title{
Pacific Northwest Laboratory Annual Report for 1991 to the DOE Office of Energy Research
}

\section{Part 3 Atmospheric and Climate Research}

Staff Members of Pacific Northwest

Laboratory

May 1992

Prepared for

the U.S. Department of Energy

under Contract DE-AC06-76RLO 1830

Pacific Northwest Laboratory

Richland, Washington 99352

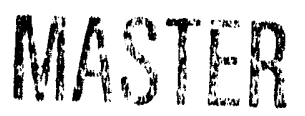




\section{PREFACE}

This 1991 Annual Report from Pacific Northwest Laboratory (PNL) to the U.S. Department of Energy (DOE) describes research in environment and health conducted during fiscal year 1991. This year the report consists of four parts, each in a separate volume.

The four parts of the report are oriented to particular segments of the PNL program, describing research performed for the DOE Office of Heatth and Environmental Research in the Office of Energy Research. In sorne instances, the volumes report on research funded by other DOE components or by other governmental entities under interagency agreements. Each part consists of project reports authored by scientists from several PNL research departments, reflecting the multidisciplinary nature of the research effort.

The parts of the 1991 Annual Report are:

Pari 1: Biomedical Sciences
Program Manager: J. F. Park
J. F. Park, Report Coordinator

S. A. Kreml, Editor

Part 2: Environmental Sciences
Program Manager:
R. E. Wildung
D. A. Perez, Editor

Part 3: Atmospheric Sciences

Program Manager: W. R. Barchet $\quad$ L. K. Grove, Editor

Part 4: Physical Sciences

Frogram Manager: L. H. Toburen $\quad$ L. H. Toburen, Report Coordinator

R. C. Pedersen, Editor

Activitiss of the scientisis whose work is described in this annual report are broader in scope than the articles indicate. PNL staff have responded to numerous requests from DOE during the year for planning, for service on various task groups, and for special assistance.

Credit for this anmual report goes to the many scientists who performed the research and wrote the individual project reports, to the program managers who directed the research and coordinated the technical progress reports, to the editors who edited the individual project reports and assembled the four parts, and to Ray Baalman, editor in chief, who directed the total effort.

T. S. Tenforde

Health and Environmental Research Program 
Previous reporis in this series:

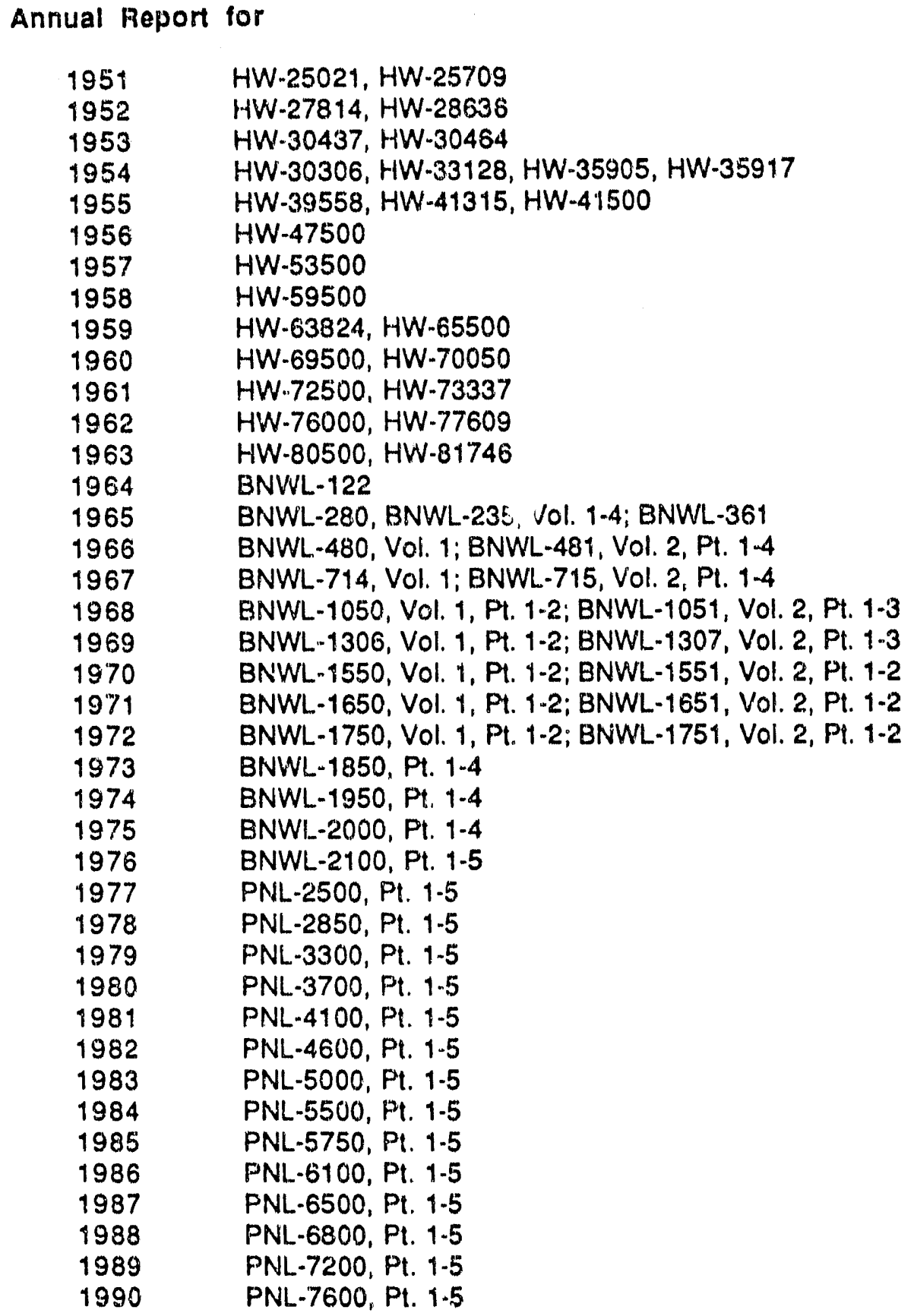




\section{FOREWORD}

Within the U.S. Department of Energy's (DOE'S) Office of Health and Environmental Research (OHER), the atmospheric sciences and ca, hon dioxide research programs are part of the Environmental Sciences Division (ESD). One of the central missions of the division is to provide the DOE with scientifically defensible information on the local, regional, and global distributions of energy-related pollutants and their effects on climate. This information is vital to the definition and implementation of a sound national energy strategy. This volume reports on the progress and status of all OHER atmospheric science and climate research projects at the Pacific Northwest Laboratory (PNL).

PNL has had a long history of technical leadership in the atmospheric sciences research programs within OHER. Within the ESD, the Atmospheric Chemistry Program (ACP) continues DOE's long-term commitment to study the continental and oceanic fates of energy-related air pollutants. Research through direct measurement, numerical modeling, and laboratory studies in the ACP emphasizes the long-range transport, chemical transformation, and removal of emitted pollutants, oxidant species, nitrogen-reservoir species, and aerosois. The Atmospheric Studies in Complex Terrain (ASCOT) program continues to apply basic research on density-driven circulations and on turbulent mixing and dispersion in the atmospheric boundary layer to the micro- to mesoscale meteorological processes that affect air-surface exchange and to emergency preparedness at DOE and other facilities.

Research at PNL provides basic scientific underpinnings to DOE's program of global climate research. Research projects within the core carbon dioxide and ocean research programs are now integrated with those in the Atmospheric Radiation Measurements (ARM), the Computer Hardware, Advanced Mathematics and Model Physics (CHAMMIP), and quantitative links programs to form DOE's contribution to the U.S. Global Change Research Program. Climate research in the ESD has the common goal of improving our understanding of the physical, chemical, biological, and social processes that influence the Earth system so that national and international policymaking relating to natural and human-induced changes in the Earth system can be given a firm scientific basis.

The description of ongoing atmospheric and climate research at PNL is organized in two broad research areas:

- Atmospherlc Research

- Cllmate Research

This report describes the progress in FY 1991 in each of these areas. A divider page summarizes the goals of each area and lists the projects that support research activities. 


\section{CONTENTS}

PREFACE $\ldots \ldots \ldots \ldots \ldots \ldots \ldots \ldots \ldots \ldots \ldots \ldots \ldots \ldots \ldots \ldots \ldots \ldots \ldots \ldots \ldots \ldots \ldots$

FOREWORD $\ldots \ldots \ldots \ldots \ldots \ldots \ldots \ldots \ldots \ldots \ldots \ldots \ldots \ldots \ldots \ldots \ldots$

ATMOSPHERIC RESEARCH $\ldots \ldots \ldots \ldots \ldots \ldots \ldots \ldots \ldots \ldots \ldots \ldots \ldots$

DOE Almospheric Chemistry Program Direction, J. M. Hales ...................... 3

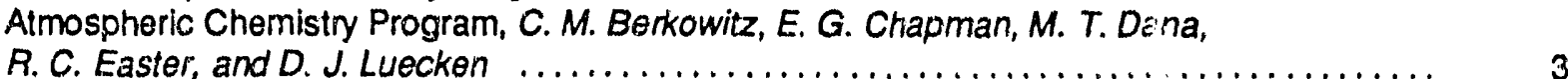

PNL Aircraft Measurements in the Kuwait Oil-Fire Plume, K. M. Busness,

P. H. Daum, J. M. Hales, C. M. Berkowitz, S. D. Tomich, R. V. Hannigan,

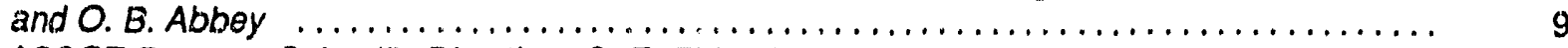

ASCOT Program Scientific Direction, C. E. Elderkin ............................ 12

Coupling/Decoupling of Synoptic and Valley Circulations, C. D. Whiteman,

K. J. Allwine, and J. M. Hubbe ...................................... 16

Atmospheric Diffusion in Complex Terrain, J. C. Doran ........................ 20

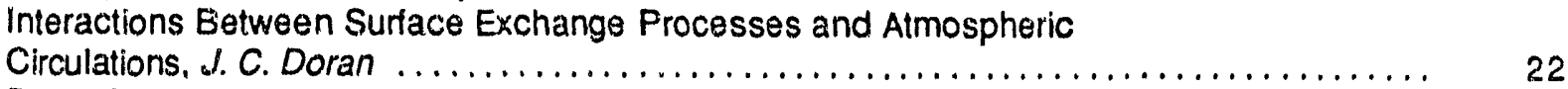

Direct Simulation of Atmospheric Turbulence, f. C. Doran $\ldots \ldots \ldots \ldots \ldots \ldots \ldots \ldots \ldots . \ldots 22$

The Fith International Conference on Precipitation Scavenging and

Atmosphere-Surface Exchange Processes, W. R. Barchet, W. G. N. Slinn,

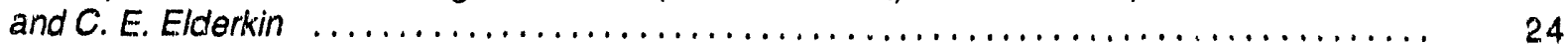

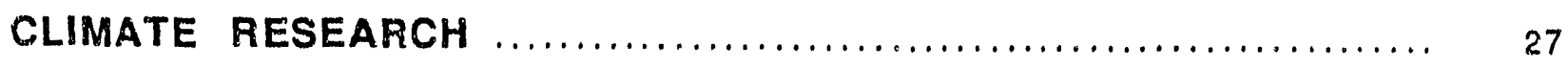

The Atmospheric Radiation Measurement (ARM) Program: Field Measurements

for Radiation Forcing and Feedbacks in General Circulation Models, G. M. Siokes

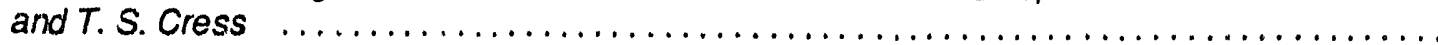

Tethered-Balioon Sounding System for Obtaining Vertical Radiation Profiles,

C. D. Whiteman, J. M. Alzheimer, G. A. Anderson, M. R. Garnich, and W. J. Shaw ........ 35

Point-Area Relationships for Global Climate Models, J. C. Doran .................... 39

Characterization of Cloud/Aerosol Interactions with Solar and Long-Nave

Radiation, N. S. Laulainen, J. J. Michalsky, L. C. Harrison, N. R. Larson,

and J. L. Berndt ..............................................

The Computer Hardware, Advanced Mathematics and Model Physics

(CHAMMP) Climate Modeling Program, D. C. Bader, M. C. MacCracken,

and R. C. Malone

Carbon Dioxide Ocean Research, J. P. Downing, W. E. Asher, D. W. Denbo,

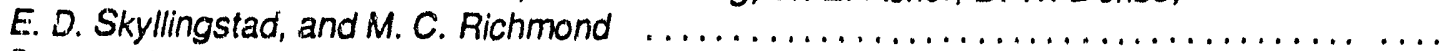

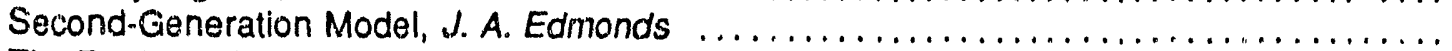

The Regional Effects of Climate Change and $\mathrm{CO}_{2}$ Fertilization on the Natural

and Human Environment: the MINK Study, M. J. Scott $\ldots \ldots \ldots \ldots \ldots \ldots \ldots \ldots \ldots \ldots$

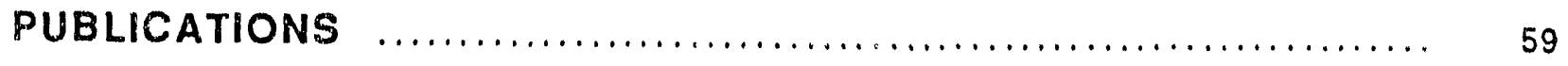

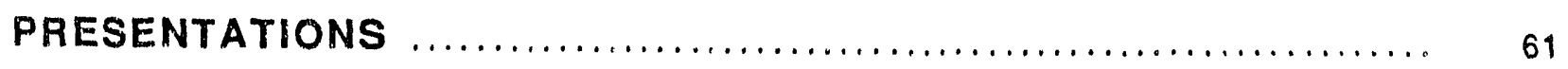

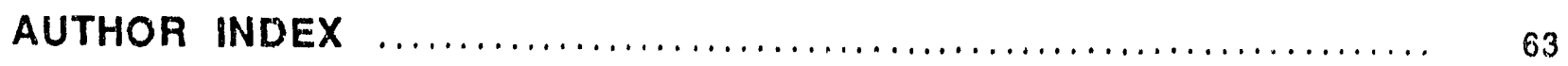

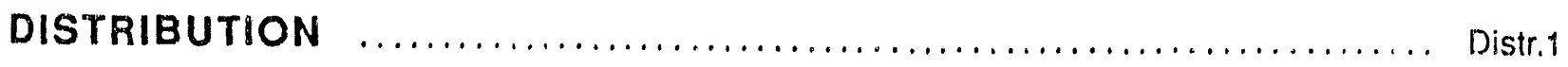


Atmospheric Research 


\section{ATMOSPHERIC RESEARCH}

Atmospheric research at the Pacific Northwest Laboratory (PNL) focuses primarily on two areas: the flow of air in complex terrain and the fate of emissions as they are transported and processed in the atmosphere. Analyses of airflow in complex terrain investigate what roles energy exchange, terrain configuration, and scale interactions for coupled flows (e.g., slope, valley, and gradient) play in developing and destroying boundary-layer circulations and in dispersing contaminants. Analyses of the regional-scale transport of ernissions address the physical and chemical processes that occur within cloud and precipitation systems, including the inflow and outtlow dynamic microphysical, chemical, and scavenging properties of clouds, regional wet deposition patterns, and the climatology of storm chemistry.

Research activities include field experiments, data analysis, and modeling simulations. Field experiments provide data for analysis in both aifflow and emission processing research, and modeling simulations provide a tool for predicting airflow and emission transpont and mitigating their effects. In FY 1991, two field experiments were performed, analysis of data from previous experiments continued, and model development was advanced both in the examination of airflow in complex terrain and in the transport and processing of pollutants.

The two field programs supported by projects whose progress is summarized in this report were a multilaboratory measurement program adjacent to Colorado's Front Range near the U.S. Department of Energy's (DOE's) Rocky Flats Plant and an aircraft study of the characteristics of the smoke plume from the Kuwait oil-well fires. The two-week-long Colorado field study at the end of January and beginning of February obtained an initial characterization of the complex meteorological features that may influence the fate of atmospheric contaminants released in the region. As one of several aircraft measurement programs in the Persian Gulf region coordinated by the World Meteorological Organization, PNL. used its Gulfstream-1 aircraift during July and August to measure several physical, chemical, and radiative properties of the oil-fire plume.

Numerical computer models are used to help analyze the results of measurement programs and to carry out numerical experiments that extend the range of conditions being studied. Models under development at PNL include some that simulate mesoscale airflow in complex terrain and some that simulate the transport and removal of pollutanis through deposition or reaction on regional and global scales. These inve stigations are systematically increasing the reliability of theoretical descriptions and models. Such mo Jels hold the promise of translating descriptive and forecasting capabilities to the great number of locations where boundary-layer flow and contaminant dispersicn and removal are significantly influenced by terrain features, surface energy exchange, and regional characteristics of meteorology and atmospheric chemistry.

The following articles present summaries of the progress in FY 1991 under these research tasks:

- Atmospheric Chemistry Program Management and Coordination

- Nonlinearlty/Acla Preclpltation Processing

- Research Alrcraft Operations

- ASCOT Program Management

- Atmospheric Boundary-Layer Studles

- Atmospheric Diffusion in Complex Terraln

- Coupling/Decoupling of Synoptlc and Valley Circulations. 


\section{Atmospheric Research}

\section{DOE Atmospheric Chemistry Program Direction}

\section{J. M. Hales}

Efforts in FY 1991 were addressed to a major restructuring of the Atmospheric Chemistry Program (ACP), based on the need to consolidate the overall effort within a reduced financial base. As currently composed, the program involves five DOE laboratories and one National Oceanic and Atmospheric Administration (NOAA) affiliate:

- Argonne National Laboratory (ANL)

- Brookhaven National Laboratory (BNL)

- Lawrence Berkeley Laboratory (LBL)

- Oak Aidge National Laboratory (ORNL)

- Pacific Northwest Laboratory (PNL)

- NOAA's Atmospheric Turbulenc 7 and Diffusion Division (ATDD).

Consolidation has beenl largely accomplished. It is being documented, along with a five-year research plan, in the ACP Operations Plan, which will be published early in 1992. Other significant events in FY 1991 include the following:

- The National Academy of Sciences Atmospheric Chemistry Committee has published its detailed review of the ACP.(a) This review encouraged the continuation of ACP and supported its development along with the proposed focus on DOE's Nationa: Energy Strategy. The ACP Operations Plan is being written with strong guidance taken from the NAS report.

- The ACP initiated its University Grants Program with the selection of five university proposals for funding. The projects selected are

- Pamela Aker, University of Wisconsin at Milwaukee: Characterization of Gas-Aerosol Interaction Kinetics Using MorphologyDependent Stimulated Ramarı Scattering.

(a) National Research Council. 1991. The Department of Energy's Atmospheric Chemistry Program, A Critical Review. National Acadenny Press, Washington, D.C.
- Paul Davidovitz, Boston College: Measurement of Gas/Water Uptake Coefficients for Trace Gases Active in the Marine Environment.

- William Marlow, Texas A\&M: Atmospheric Aerosol Microphysics: Formation, Characterization, and Interaction.

- Peter McMurray, University of Minnesota: Uitrafine Aerosol Size Distributions and Sulfuric Acid Vapor Pressures: Implications of New Particle Formation in the Atmosphere.

- Judith Weinstein-Lloyd, SUNYIOId Westbury: Atmospheric Peroxides.

- The ACP conducted i special aircraftmeasurement project in the Kuwait oil-fire plume. The Gulfstream-1 operated by PNL was deployed to the Persian Gulf region for these measurements and was operated by ACP personnel from PNL and BNL. Flight operations were supported by forecast model output from Lawrence Livermore National Laboratory (LLNL) and NOAA's Atmospheric Research Laboratory (ARL). The data have undergone initial processing and are being summarized in a formal DOE report.

Activities of the individual ACP laboratcries are being reported continuously in the ACP's Monthly Update, which is distributed by PNL. Persons interested in receiving the Monthly Update should contact

J. M. Hales, ACP Science Director

Pacific Northwest Laboratony

P.O. Box 999, MS K1.74

Richland, Washington 99352

\section{Atmospheric Chemistry Program}

C. M. Berkowitz, E. G. Chapman, M. T. Dana, R. C. Easter, and D. J. Luecken

The overall objective of the Atmospheric Chemistry Program is to conduct research that furthers our understanding of atmospheric processes relevant to the effects of energy-related 
pollutants on the global atmospheric environment. This research combines field observations and modeling studies to provide needed information for implernenting DOE's National Energy Strategy and for guiding how DOE develops air pollutionrelated constraints.

Precipitation and cloud fields have a measurable effect on the chemical climatology of the troposphere. Past studies by PNL have verified that production of hydrogen peroxide increases in the vicinity of cloud's and have establistied that sulfate wet removal rates are dependent on precipitation rates. Dynamic cloud models, scphisticated chemical kinetic packages, and new methods of computer visualization have ncreased our understanding of the complexities of these atmospheric cleansing processes.

3esearch during FY 1991 included studies that modeled several aspects of tropospheric chemistry and a five-week field study of the plume resultirig from oil fires in Kuwait. The modeling studies and an instrument development program are described here; the field study is described in a separate section. Specific objectives addressed during FY 1991 were to

- Investigate transport of suliur species over the northern Atlantic Ocean, using a global-scale chemical model that contains an explicit description of removal processes in clouds,

- evaluate the impact of anthropogenic sulfate aerosols on the planet's radiation balance, via both their direct rolo in scattering and their potential effect on cloud albodo and cloud lifetime,

- Investigate conditions under which boundary layer aerosols can be transported aloft via convective cloud circulation,

- examine the sensitivity of wet deposition to chemical inflow conditions for several types of storms, using previously collected field data as a base case for the analysis, and

- modify the trace atmospheric gas analyzer for use aboard the Gulfstream-1 aircraft operated by PNL.

Key results from this research are summarized in the following sections.

\section{Transatlantlc Transport of Sulfur}

Sulfur plays an important role in atmospheric chemistry. It can be oxidized to form sulfate zerosol, which in turn affects the acidity of precipitation. It has been estimated that a large fraction of the total sulfate aerosol can act as cloud condensation nuclel, and recent work by Charison et al. (1991) has implicated sulfate as a major factor for determining the global-scale albedo.

To investigate the role of sulfur in global-scale processes, PNL performed a number of simula. tions using a three-dimensional global-scale Eulerian model to evaluate the transatlantic transport of sulfur. This Global Chemistry Model (GChM) simulates emissions, transport, chemical transformations, and wet and dry deposition. Unique to GChM is its explicit parameterization of removal processes in clouds. Details are given by Luecken et al. (1991). One-month winter and summer simulations were performed using meteorological information from a global climate model for a perpetual January and a perpetual July (i.e., simulations were performed with a fixed sea surface temperature and a fixed zenith angle).

Other studies, based on less explicit descriptions of wet removal, havo suggested that the North American contribution to sulfur concentrations and deposition over the Northern Atlantic ocean is greater than those from Europe. The results of this study indicate that European and North American anthropogenic sources of $\mathrm{SO}_{2}$ can contribute equally to sulfur loadings and deposition over the North Atlantic (Figure 1).

\section{Anthropogenic forcing of the Planetary Radlative Budget by Sulfate Aerosols}

Aerosols Impact the natural atmosphere by enhancing cloud albedo. For a fixed amount of water vapor, the addition of cloud condensation nuclel will result in a greater number of small cloud drop. lets. it has been postulated that this reduction in droplet size will be associated with an increase in cloud albedo (Twomey et al. 1984).

Sulfate aerosols generated from antl irogenic $\mathrm{SO}_{2}$ may increase cloud condensation nuclel loading over the western North Atlantic. To Investigate whether these aerosols are enhancing cloud 


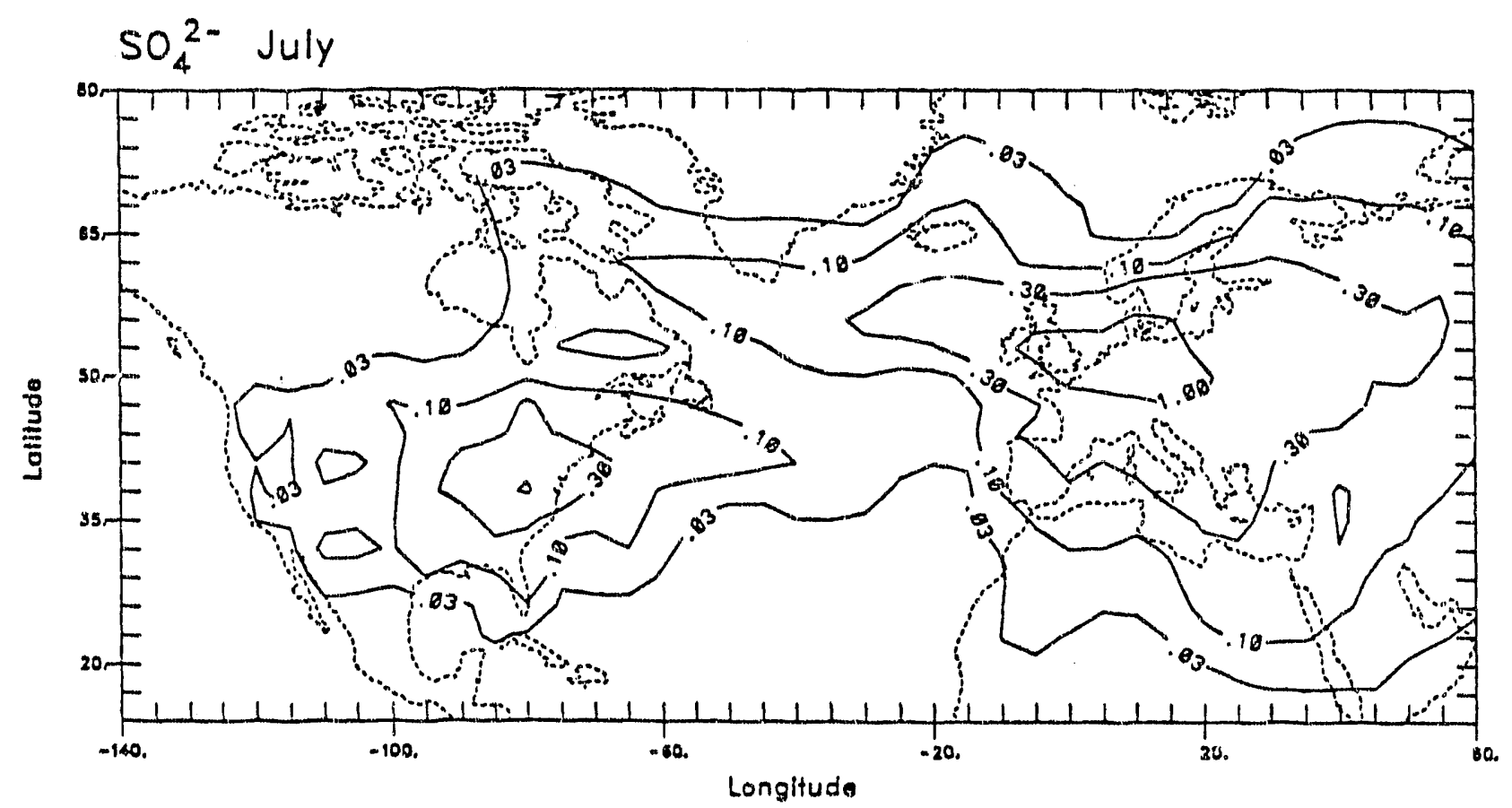

FIGURE 1. Surface-Level Concentrations (in ppb) of Anthropogenic Sulfate for a One-Month (July) Simulation.

albedo, PNL's GChM is being used with meteoron logical data from the European Center for Medium Range Forecasting to identify regions of maximum sulfate concentrations. These simulations will provide guidance to $C$. M. Benkovitz of Brookhaven National Laboratory for detailed study of satellite data.

In addition, Charlson et al. (1991) have argued that, in cloud-free air, sulfate particles scatter sunlight, some of which is lost to space, thereby reducing solar irradiance at the ground. To evaluate this radiative forcing term, previous studies have used climatological values for key pararneters. Preliminary results from the GChM anaivsis indicate that such forcing is only locally significant. The radiative forcing term involves both cloud cover and sulfur emissions, and as a result its spatial distribution is very heterogeneous and not easily characterized by simple scaling arguments.

\section{Transport of Boundary Layer Aerosols to the Free Troposphere}

The fifth Processing of Emissions by Clouds and Precipitation (PRE.CP.V) field experiment in central
Ohio showed water vapor and aerosol number mixing ratio decreasing strongly with altitude between the boundary layer and upper troposphere, with a high correlation between the vertical profiles (Kleinman and Daum 1991). Because global-scale models often treat aerosol removal identically to the removal of water vapor, better understanding of the observations could improve the treatment of aerosols.

A study to examir.e this phenomenon was initiated during FY 1991, using a one-dimensional convective cloud version of the PLUVIUS model (Easter and Luecken 1988). In the simulations, aerosol particles were injected at various heights into simulated convective clouds. Trace quantities of water vapor were also introduced to identify differences in how convective storm systems process aerosols and water.

Preliminary results from this study were reported by Kleinman et al. (1991) and are shown in Fig. ure 2. The effect of in-cioud removal of aerosol particles by precipitation scavenging can be judge by comparing the vertical profiles of soluble 


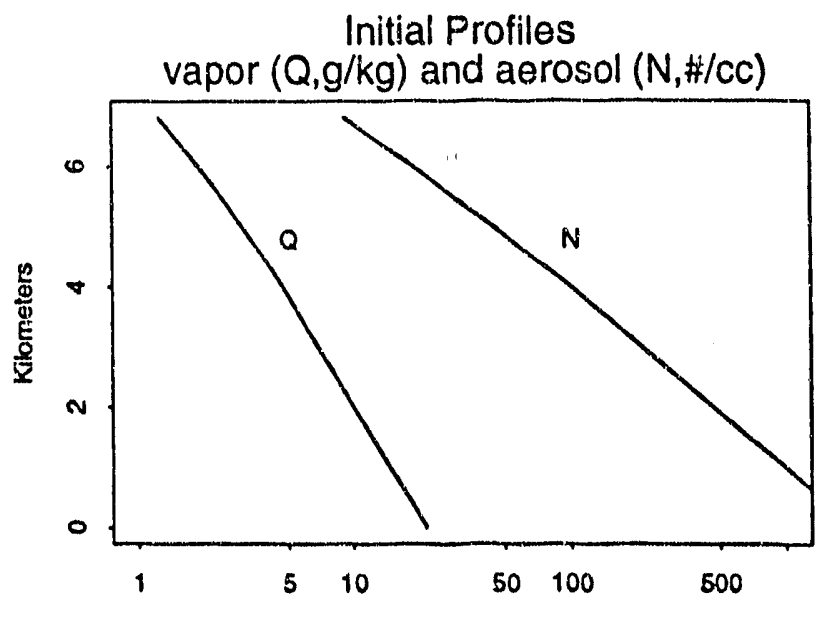

Profiles of N/Q

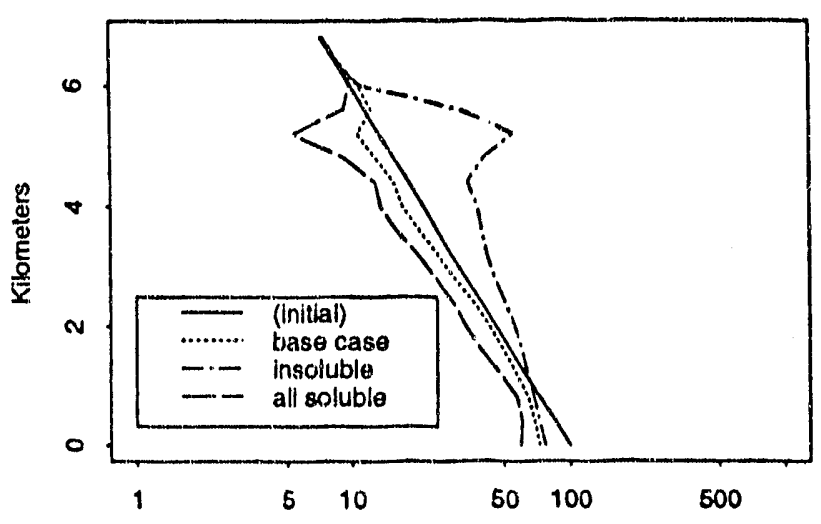

Final Profiles

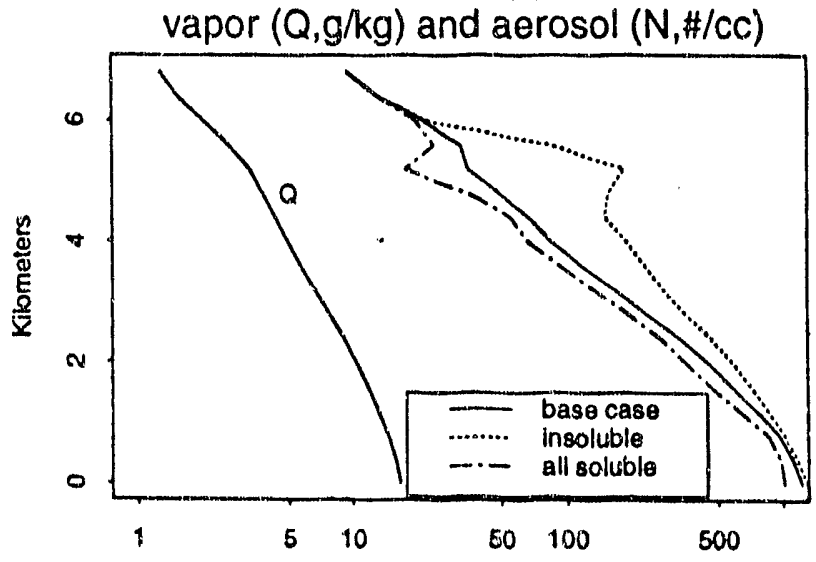

FIGURE 2. Vertical Concentration Profiles at the End of a 60. Minute Convective Cloud Simulation for Three Aerosol Categories: a) All Soluble, b) Partially Soluble, and c) All Insoluble. Also shown is the associated mixing ratio of water vapor. and non-soluble aerosol particles. These results suggest that aerosol particles, even those that are moderately soluble, are removed by scavencing more efficiently than water vapor is. We hypothesize that this occurs because when a cloud droplet is removed, the aerosols contained within that droplet are also removed. This effect is more pronounced lior soluble aerosols, which are transferred to cloud droplets more efficientiy, than for insoluble aerosols. The net effect is that more aerosols are removed than cloud droplets, and the difference in removal rates is a function of aerosol solubility

\section{Sensitlvity of Wet Deposition to Siorm Inflow Conditions}

In another modeling study (Berkowitz 1991), a series of cloud chemistry simulations were performed to evaluate how sensitive sulfate wet removal rates were to changes in the vertical distributions of $\mathrm{SO}_{2}$ and oxidant species. This study was done in part to evaluate how changes in the vertical distributions of chemical pollutants entering different lypes of storms related to changes in surface chemistn. A second purpose of this study was to verify the evaluation of the RADM Scavenging Module's performance in reproducing observations made during the Frontal Boundary Study (Berkowitz et al. 1989).

Key findings were as follows: First, deposition from stratiform storms is more strongly dependent on the initial gas-phase profiles as a function of height than is deposition from convective storms. Differences in the ratio of $\mathrm{SO}_{2}$ to $\mathrm{H}_{2} \mathrm{O}_{2}$ as a function of height can have a large effect on the rate of deposition and hence the nature of the proportionality (linearity) of wet removal in stratiform storms. No similar sensitivity was found for convective systems. Second, the rate of deposition from convective storms is sensitive to the total mass loading of $\mathrm{SO}_{2}$ and $\mathrm{H}_{2} \mathrm{O}_{2}$, with only a weak dependence on the :'ertical profiles. Third, concentrations of sulfate in precipitation were generally insensitive to perturbations in the fine structure of the initial gas-phase profiles. 
Modiflcations to the Trace Atmospherlc Gas Analyzer for Application in the Gulfstream-1 Alrcraft

During the past year, scientists at PNL and at Battelle's Columbus laboratories have been modifying aircraft and instrument systems to provide tandem mass-spectroscopy measurements onboard the Gulfstream-1. The mass spectrome. ter being modified for this application is the Trace Atmospheric Gas Analyzer built by the Sciex Corporation in Canada. The Trace Atmospheric Gas Analyzer applies two quadrupole mass filters in a series configuration to provide unambiguous and highly specific detection of pollutant species. Its large vacuum pump and state-of-the-art ion counting technology combine to provide sensitivities that approach the part-per-trillion level for many species (Table 1). lir addition, the Trace Atmospheric Gas Analyzer can monitor several species simultaneously and responds rapidly: a recent transient-response test at Battelle's Columbus laboratories indicated a response time on the order of $10 \mathrm{~Hz}$.

The Trace Atmospheric Gas Analyzer has a high electrical power demand, is large, and is too cumbersome in its standard configuration for convenient airborne application. These features have induced program scientists to make two major modifications to the existing equipment: First, the gearbox on one engine of the Gulfstream-1 has been customized to accommodate a large auxiliary

TABLE 1. Trace Atmospheric, Gas Analyzer Sensitivities, in Parts Per Trillion, to Selected Species

\begin{tabular}{l} 
Soecies \\
\hline Nitric Acid \\
Nitrous Acid \\
Formic Acid \\
Acotic Acid \\
Dimethyl Sulfide \\
Benzaldehyde \\
Pyridirie \\
Toluerie \\
Sulfuric Acid \\
Sulfur Dioxide \\
Acetone \\
Dimethylnitrosamine \\
Benzonitrile
\end{tabular}

Sensitivity
100
500
500
20
2
10
2
50
10
100
10
10
4

generator, which is intended to fill Trace Atmospheric Gas Analyzer power requirements exclusively. This modification has required a substantial amount of engineering design, fabrication, and testing; a 150-hour ground test of the generator assembly has been completed on a gear-box mock-up, and it has been installed on the Gulfstream-1. Second, the Trace Atmospheric Gas Analyzer itself has been disassembled and rebuilt as three modules. This major reconfiguration allows for convenient installation and removal of the machine from the aircraft.

\section{Further Objectlves}

The most general objective for the Atmospheric Chemistry Program in the future is to work within the objectives of the International Global Atmospheric Chernistry Program (IGAC 1991). By working with other organizations in IGAC, PNL will pool its resources with other research institutions to measure, understand, and eventually to predict changes in the chernistry of the glubal atmosphere. The particular areas within IGAC in which PNL will participate are

1. Natural Variability and Anthropogenic Perturba. tions of the Marine Atmosphere: A field program over the western Pacific is being planned in order to begin development of a chernical climatology tor this region. Such a climatology will be important in evaluating the effects on global-scale air quality of the increasing use of coal in the Pacific Rim countries. The geographical location of PNL. is a very good position for evaluating the perturbations that this expected development will have on the atmosphere over the Pacific Ocean. A second program is planned for the western North Atlantic Ocean and will focus on the transport of pollutants from North America and the effect these pollutants have on the oxidative capacity of the atniusphere.

2. Global Distributions, Transformations, Trends, and Modeling: The efforts will concern the chemical and physical evolution of cloud con. densation nuclei as controllers of cloud properties. 
Our involvernent in this component of IGAC will be a combination of laboratory studies arid modeling. The modeling effort will bs a continuation of the programs described earlier in this contribution. A new laboratory eftort will be initiated by slatf at PNL and Battelle's Columbus laboratories. This new initiative will attempt to derive a relationship bo. tween the number density of sulfate aerosols and the number donsily of cloud condensation nuclel by using a cloud condensation nuclel counter and photochemical smog chambers. Aerosols associated with energy production have long been sus. pected of affecting not only tive clear sky albedo of the planet, but also th cloud drop density in thin clouds. If they do ria a significant impact on droplet number density, it would be expected that they would also hav $z$ an impact on the cloud albedo, ars hence, on the planetary radiation budget and climate. To cate, there have been no defensible arguments relating the functional form of aerusol number density and enthanced cloud condensation nuclei.

The Atmospheric Chemistry Program will attempt to provide such a relation experimentally. The method by which we propose to do this involves combining smog chamber studies with a cloud condensation nuclei courter. A variety of chemical inixes of $\mathrm{SO}_{2}, \mathrm{O}_{3}, \mathrm{H}_{2} \mathrm{O}_{2}$, and other pollutants will be used to initiate the reactions leading to the formation of sulfate. Air will be removed from this mix at selected times and injected into a CCM counter. Although the details are sill being thought out, there is reason to belicve that this novel combination of instruments could answer this fundamental question.

\section{Reforances}

Berkowilz, C. M. 1991, "The Response of Sulfate Linearity and Precipitation Chernistry to Gas-Phase Protiles." Atmospheric Environment 25A:1295. 1311.

Berkowitz, C. M., R. C. Easter, and B. C. Scott. 1989. "Theory and Results from a Cuasi-Steady.
Slate Precipitation-Scavenging Model." Atmospheric Environment 23:1555-1571.

Charlson, R. J., J. Langner, H. Rodhe, C. B. Leovy, and S. G. Warren. 1991. "Perturbation of the Northern Hemisphere Radiative Balanco by Backscattering from Anthropogenic Sultate Aerosurs." Tellus (in press).

Easter, Pr, C., and D. J. Luecken. 1988. "A Simu" lation of Sulfur Wet Deposition and its Dependence on the Inflow of Sulfur Species to Storms." Atmospheric Environment 22:2715-2739.

IGAC. 1991. The International Global Atmospheric Chemistry (IGAC) Programme: A Core Project of the International Geosphere-Biosphere Pro. gramme, ed. I. E. Galbally. Commission on Atmospherle Chemistry and Global Pollution of the International Association of Meteorology and Atmospheric Physics.

Kleinman, L. I., and P. H. Daum. 1991. "Ventical Distribution of Aerosol Particles, Water Vapor, and Insoluble Trace Gases in Convectlvely Mixed Air." Journal of Gsophysical Research 96:991-1005.

Kleinman, L. I., P. H. Daum, and C. M. Berkuwitz. 1991. "Effects of In-Cloud Processes upon the Vertical Distribution of Aerosol Particles: Observations and Numerical Simulations." Paper presented at the Fifth International Conterence on Precipltation Scavenging and AirnosphoricSurtace Exchange Processes, July 15-19, 1991. Richland, Washington. PNI.-SA.19607, Pacific Northwest Laboratory, Richland, Washington.

Luecken, D. J., C. M. Berkowitz, and R. C. Easter. 1991. "Use of a Three.Dimensional CloudChemistry Model to Study the Transatlantic Trans. port of Soluble Sulfur Species." Journal of Geophy'sical Research 96:22,477-22,490.

Twomey, S., M. Piepgrass, and T. L. Wolfe. 1984. "An Assessment of the Impact of Pollution on the Global Cloud Albedo." Tellus 36B:356-366. 


\section{PNL. Alrcraft ifleasurements in the Kuwalt Oll.Fire Plume}

K. M. Busnoss, P. H. Daum, (a) J. M. Hales, C.M. Berkowitz, S. D. Tomich, R. V. Hannigan, and O. B. Abbey

During July and August 1991, PNL., In collaboration with Brookhaven National Laboratory (BNL) and Lawrence Livermipre National Laboratory (LLNL), conducted a field measurement program in the eastern Saudi Arabia region to study the composition and transport of the smoke plume resulting from the burning oil-well fires in Kuwait. The Gulfstream-1 aircraft operated by PNL., the instrumentation, and the scientific crew were deployed to a base in the Middle East, the island state of Bahrain, to measure chemical, radiative, and meteorological properties in the plurne.

The primary objectives of this measurement program were to

- collect information from which the rates of transformation/removal of constituents of the Kuwait oll-fire plume could be evaluated,

- characterize the chemicel and physical properties of the plume over a range of distances from the source, and

- lakn advantage of the one-time opportunity for quantitative evaluation of large-scale atmospheric-chemistry models and associated models of radiant transport through aerosol plumes.

in the future, two DOE global atmospheric chernistry models, LLNL's GranTour and PNL's GChM, "vill be applied to this study, using aircraft data and meteorological observations. Both are time-resolved models capable of incorpurating field results on a mechanistic basis and capable of simulations on large-scaie domains.

Subobjectives to be considered were to

- assemble an optimal descriptive observational and modeling database for assessing the downstream environmental impact of pollutant deposition from the plume,

(a) Brookhaven National Laboratory.
- document how the plume affects the solar energy balance for future applicrtion to assessing hemispheric and global attenuation of solar radiation by anthropogenic aerosols, and

- characterize the radiative absorption properties of the plume and astociated atmospheric motions to determine possible plume-induced perturbations of atmospheric; dynamics and associated feedbacks to the climate.

This was one of several measurement programs conducted in the area as a result of the oil-well fires in Kuwait, and it involved interaction with several International groups, including the National Oceanic and Atrnospheric Administration (NOAA) and government agencies in Blahrain and Saudi Arabia. The U.S. aircraft measulement program in the region was coordinated within an international World Meteorological Organization (WMO) plan, which attempted to provide a continuous monitoring presence in the Persian Gulf region during the oil fires. Other aircralt measurement teams whose work preceded that of the DOE team Included British, German, and Canadian aircraft, as well as aircraft owned by the National Center for Atmospheric Research (NCAR) and the University of Washington uir.der National Science Foundation (NSF) sponsorship. Simultaneous with the early flights of the DOE aircraft, a National Aeronautics and Space Administration (NASA)/Saudi hell. ccoter was operating in Kuwatt to characterize the near-source plume. The results of the DOE meas. urement effort, as part of the large multiagency data collection, will be made available to the scien. tific community at large, for evaluating plume characteristic, determining impact on the environment, and improving large-scale environmental models.

The Gulfstream- 1 departed from Pasco, Washing. ton, on July 21 and arrived in Bahrain, the mideast base of operations, on July 25. After final configuring of the aircraft equipment and extensive coordination with local government agencies, the first sampling mission was flown on July 31 . The Gulistream-1 was extensively reconfigured for chemistry, radiation, particle, and meteorological measurements, as indicated in the summary of instrumentation in Table 1. Additionally, the 
TABLE 1. Summary of Alrcraft Instrumentation

Insiniment.

Aerosol spectrometer probe
Particle spectrometer probe
Total temperature syistem
Pressure systom
Hygrometer
Nephetometer
Ozone analyzer
SO2 analyzer
CO analyzer
COz analyzer
NO2, analyzer
NONNO analyzer
Electrical aerosol analyzer
CCN instrument
Visible and infrared radiation sensors
Canister sampling system
Air sampling system with flowmeters
Loran, global positioning system, inertial navigation system

Maasurement

Airuorne aerosol $0.12-3 \mu \mathrm{m}$

Droplets/particles 2-47 um

Trtalstatic temperature

Ambient pressure

Dewpoint tomperature

Particlo kght scattering (bscat)

Ozone

$\mathrm{SO}_{2}$

co

NOINO

$\mathrm{NO}, \mathrm{NO}_{x}$

Submicron

CCN

Solar radiation

Gas phiase hydrocarbons $/ \mathrm{CO}_{2}$

Integrated gas and aerosol fitters

Positionaircraft attitude aircraft was equipped with specially installed airconditioning equipment in anticipation of the extreme temperatures expected in the region during midsummer. Sampling operations would have been impossible without this equipment, as temperatures approaching $50^{\circ} \mathrm{C}$ and relative humidities of 80 to $90 \%$ were encountered. Even then, a few instruments malfunctioned as a result of the extreme environmental conditions.

Flight planning was conducted onsite daily, using local assistance from the Bahrain meteorology center, torecasts provided by an ARAMCO mete. orology group in Dhahran, Saudi Arabia, and model-generated forecasts iransmitted by fac. simile from LLNL and NOAA. The NOAA forecasts, based on their HY-SPLIT transport and dispersion model produced plume trajectories and 12-hour average soot concentrations. The LLNL ADPIC/MATHEW models produced map contours of plume concentration and plume age predictions. These forecasits served quite well at moderate distances from the plume source, but occasionally suffered inaccuracies at greater distances, not so much as a result of model inade. quacies, but rather because of their reliance on numerically forecast winds over wide regions. Later in the study, missions were shifted to later in the day, to allow satellite data to be incorporated into the flight planning process so that aircraft positioning could be improved.
During the study, prevailing winds were predominantly from the north, generally carrying the plume southward from Kuwait over the eastern Arabian Peninsula and the Persian Gulf. Initial program planning had optimistically called for sampling flights farther downwind from the plume source, as far south as the Arabian Sea, but difficulty in accurately locating the plume at sush extended distances, limited aircraft range, and difficulty in obtaining clearance for flight in southern Saudi airspace pracluded successful sampling so far south.

The DOE team flew 13 sampling missions between July 31 and August 17, mostly near the northeast coast of Saudi Arabia, as shown in Figure 1, which shows the locations of major cross-plume sampling tracks. Missions were designed to intercept the plume at varying distances from the source, in order to sample the plume at different ages. Local meteorological conditions often folled such attempts, however, causing recent and aged recirculated plume to occupy the same airspace. Typically, several traverses were flown along each track at elevations from 500 to $5000 \mathrm{~m}$, to obtain meas. urements throughout the vertical extent of the plume and across its horizontal expanse.

Several integrated samples that were collected on fitter media are undergoing analysis at BNL for a 


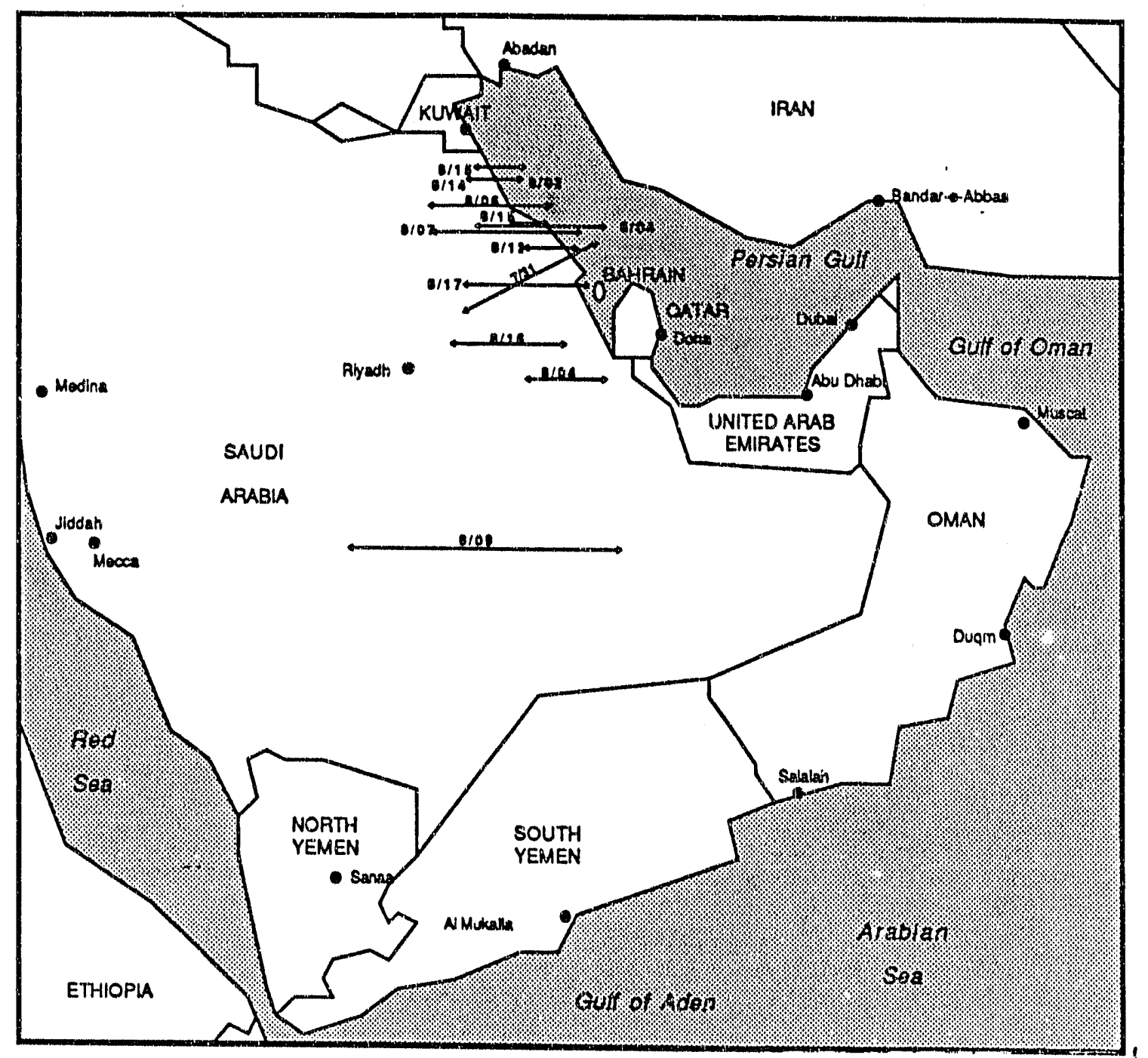

FIGURE 1. Major Plume Cross Sections Flown by Culfistream-1.

number of organic and inorganic species, including $\mathrm{SO}_{2}, \mathrm{HNO}_{3}$, condensed volatile organic compounds, $\mathrm{SO}_{4}, \mathrm{NO}_{3}$, and several forms of carbon, and for aerosol light-absorption coefficient and aerosol mass. 'Janister samples are being analyzed at Battelle's Columbus laboratories to determine the light and heavy hydrocarbon contents of the plume and to provide backup indications of $\mathrm{CO}_{2}$ concentrations. Processing of real-time tapes from the aircraft data acquisition system has begun.

\section{Preliminary FIndings}

When all analysis tasks have been completed, a detailed data report will be prepared and data will be made available for inclusion in the WMO database. At this time, analysis tasks are under way, but none are yet completed. Preliminary indications from flight notes and real-time charts show widely varying concentrations of gas species and particulates, depenaing on plume age and distance from the source, as would be expected. 
Near-source levels of $\mathrm{SO}_{2}$ exceeded $200 \mathrm{ppb}$, the upper range limit of the instrument used. Levels of NO/NO $x$ were several parts per billion, but substanthally less than levels of $\mathrm{SO}_{2}$; ozone levels were generally in the range of 50 to $70 \mathrm{ppb}$. Aerosol light scattering (bscat) readings often exceeded the instrument's full scale, $10^{-3} \mathrm{~m}^{-1}$. Particle counts, as observed by optical counting probes, frequently exceeded $2000 / \mathrm{cc}$, and similar counts obtained by a CCN counter operating at about $0.6 \%$ supersaturation level indicate that a high percentage of the particles in the plume are capable of forming condensate and, hence, are likely to be scavenged by precipitation. Plume height was not observed to be greater than about $5000 \mathrm{~m}$, and it appears that, except at near-source distances where some self-lifting may have occurred, macroscopic atmospheric mixing processes were the dominant factors in elevating the plume. This agrees with findings noted by other teams and reinforces speculation that long-range transport of the plurre will not occur, limiting climate modification to the near-source region. Specific data concerning plume radiative properties are not yet available, but it was quite evident from light extinction observed during flights into the plume that effects on solar flux will be significant.

\section{ASCOT Program Sclentific Direction}

\section{E. Elderkin}

\section{Overall Objective}

Scientific research activities at the primary DOE laboratories participating in the Atmospheric Studies in Complex Terrain (ASCOT) program are coordinated by the ASCOT Program Scientific Direction project, which also arranges for collaborations with other supporting laboratories and university groups. The project leads the program in defining a scientific focus for the ASCOT program, representing the consolidated interests of the participants, and pursuing significant scientific challenges to the boundary layer community. At the same time it links scientific outputs with DOE's mission-related needs.

\section{Objectives for FY 1991}

During the past year, the objectives of the project were to
- conduct the ASCOT experimental program in the Front Range area of the Colorado Rockies, focusing on its multivalley drainage and multilayered flows,

- begin planning long-range experimental and modeling investigations of interactions between mesoscale circulations in the boundary layer and larger regional- and synoptic-scale circulations,

- begin transforming ASCOT measurement technology to a technology based primarily on remote sensing, and

- build a stronger link between the basic scientific output of the ASCOT program and the emergency preparedness needs of DOE, especially through cooperation with the Rocky Flats Plant.

\section{Accompllshments}

The primary accomplishments of the ASCOT Scientific Direction project in FY 1991 were to

- lead the planning and implementation of winter nighttime experiments along the Front Range of the Colorado Rockies; coordinate ASCOT meteorological measurements in these experiments with tracer releases in the EG\&G/Rocky Flats Winter Validation Study;

- provide guidance and incremental funding for Argonne National Laboratory to adapt and install two minisodars measuring detailed three. component wind profiles and eight Lawrence Livermore National Laboratory towers measuring near-surface winds, temperatures, and net radiation in the Front Range area; their continuous operation was promoted as a part of the intensive winter experiment and as the beginning of a mesoscale measurement network integrating in situ and remote-sensing technology;

- provide a "first look" analysis of one of the Front Range winter experiments, i.e., that of the night of February 4-5, 1991, as a demonstration of integrating the various $t, j e s$, locations, and times of measurements to describe the complex, evolving meteorology within the experiment domain; an example analysis was inrluded in an ASCOT summary report of the experimental series;

- organize and chair a Planning and Advisory Panel (PAP) meeting, which included ASCOT 
program leaders from DOE laboratories and participating National Oceanic and Atmospheric Administration laboratories, DOE/Office of Health and Environmental Research staff, and EG\&G/Rocky Flats staff; the meeting was held to establish the scope of future multiyear research in the Front Range area, its scientific objectives, and its linkage with the emergency preparedness needs of DOE in general and site studies at the Rocky Flats Plant in particular; and

- conduct an ASCOT science meeting in November 1991, involving all (approximately 40) scientists contributing to the ASCOT program, to present their latest findings from earlier experiments on the western slopes of the Rockies, their recent analysis and modeling results from research in the Tennessee Valley around Oak Ridge National Laboratory in ASCOT-90, and their initial observations from the Front Range ASCOT-91 experiments; a follow-on workshop with the meeting participants was organized, to define the principal scientific questions, and program objectives for the next four years of research in the Front Range.

\section{Case Study: A Meteorologlcal Descrip- tIon of the ASCOT-91 Experiment}

In FY 1991, the ASCOT program initiated research on transport and dispersion in the Front Range area of the Rocky Mountains, around DOE's Rocky Flats Plant. In January and February 1991, ASCOT winter nighttime meteorological experiments were conducted in conjunction with the tracer releases of EG\&G/Rocky Flats' Winter Validation Study.

As a focus for the 1991 ASCOT field measurement, two hypotheses were investigated:

- The major canyons in the area (Coal Creek and Eldorado) provide a significant fration of the nocturnal cold air draining from the mountains over the Rocky Flats region, and thus play a major role in determining the nocturnal transport and diffusion in this area.

"In the first $10 \mathrm{~km}$ from the mountains, the structure of the cold air drainage evoives significantly with distance, including pronounced changes in the flow depth, speed, and the height of the wind speed maximum.
To address these hypotheses with necessary measurements in the near field, the ASCOT program deployed instruments on towers in the foothills and at mountain sites as described in Table 1 , and installed profiling instrumentation, as described in Table 2. Figure 1 shows the location of each measurement site.

In the past, very few measurements of meteorological variables have been taken on a regular basis within a radius of $10 \mathrm{~km}$ of the Rocky Flats Plant. Thus, there is little documentation or understanding of air flows out of the Rocky Mountains and over the foothills immediately surrounding Rocky Flats. Only a 60-m tower on the Rocky Flats Plant site provides data for estimating flow features responsible for transport and diffusions in the near field. The NOAA PROFS network provides cata at greater distances ( 15 to $50 \mathrm{~km}$ ) surrounding the site but only at the surface. Two radar profilers, one at Stapleton airport and one at Platteville, provide a measure of vertical variability in the wind field, but at too great a distance to define drainage and near-surface flows over the Rocky Flats Plant and populated areas nearby. Thus, both surface and vertical profiling measurements needed significant augmentation for the intensive field campaign.

Surface distributions and vertical profiles of nocturnal winds and temperatures were measured in the mountains and at the exits of the Coal Creek

TABLE 1. Lawrence Livermore National Laboratory Tower Network.

\begin{tabular}{llcc} 
Codelal & \multicolumn{1}{c}{ Location } & Instrumentation(o) & Elevation (m) \\
\cline { 2 - 4 } BR & Bartletts Ranch & 1,3 & 1667 \\
PF & Pat's Flat & 1, & 1875 \\
JR & Jim's Ranch & 1,3 & 2029 \\
OR & l.ois' Ranch & 1 & 2096 \\
CC & Unda's Ranch & 1,3 & 2004 \\
PP & Paul's Peak & 2473 \\
PR & Rim Rock & 1,3 & 2330 \\
TO & Tolland & 1 & 2708
\end{tabular}

(a) Codes relate to figure.

(b) $1=2$ levels wind speed, wind direction, $\sigma_{0}$, temperature, and $\Delta T$. Instrument lovels are 6.1 and $17.68 \mathrm{~m}$.

$2=1$ level wind speod, wind direction, $\sigma_{0}$, and temperature instrument level is $8.83 \mathrm{~m}$.

$3=$ Net radiometer. 
TABLE 2. Profile Measurement Equipment Operating in the Near Field.

\begin{tabular}{|c|c|c|c|c|}
\hline Sodera & Location & Instrumentation & ASCOI_Laboratory(b) & Elevation (m) \\
\hline CC & Coal Creek Canyon & $\begin{array}{l}\text { Minisodar" } \\
\text { Tethersonde }\end{array}$ & $\begin{array}{l}\text { ANL } \\
\text { UNL }\end{array}$ & 2004 \\
\hline PV & Plainview & $\begin{array}{l}\text { Tethersonde and } \\
\text { weather station }\end{array}$ & ATDD & 1970 \\
\hline MT & Masa Trailhead & $\begin{array}{l}\text { Minisodar (mobile) } \\
\text { Tethersonde (primary) }\end{array}$ & $\begin{array}{l}\text { ANL } \\
\text { WPL }\end{array}$ & 1800 \\
\hline $\begin{array}{l}E C \\
F V\end{array}$ & $\begin{array}{l}\text { El Doredo Canyon } \\
\text { Flatirons Vista Trailhead }\end{array}$ & $\begin{array}{l}\text { Tethersonde (secondary) } \\
\text { Tethersonde (secondary) }\end{array}$ & & $\begin{array}{l}1765 \\
1713\end{array}$ \\
\hline FP & Filtration Plant & Airsonde & PNL & 1684 \\
\hline RF & Rocky Flats Plant Tower & $\begin{array}{l}\text { Rawinsonde } \\
\text { Radar profiler } \\
\text { RASS }\end{array}$ & $\begin{array}{l}\text { LANL } \\
\text { WPL }\end{array}$ & 1849 \\
\hline BR & Bartett's Ranch & Minisodar & PNL & 1670 \\
\hline$\|$ & Indiana St/Hiway 128 & Doppler lidar & WPL & 1784 \\
\hline $\begin{array}{l}\text { (a) } \\
\text { (b) }\end{array}$ & $\begin{array}{ll}\text { Aes nelate to figure. } \\
\text { Argonne National L } \\
\text { iL } \\
\text { Lawrence Livermor } \\
\text { OD } & \text { Atmospheric Turbu } \\
\text { Wave Propagation } \\
\text { Wacific Northwest L } \\
\text { il } & \text { Los Alamos Nation }\end{array}$ & $\begin{array}{l}\text { ratory, Argonne, Minois. } \\
\text { lational Laboratory, Liverm } \\
\text { co and Diffusion Division, } 0 \\
\text { soratory, Boulder, Colorado. } \\
\text { oratory, Richland, Washing } \\
\text { aboratory, Los Alamos, Ne }\end{array}$ & $\begin{array}{l}\text { e, California. } \\
\text { Ridge, Tennessee. } \\
\text { Mexico. }\end{array}$ & \\
\hline
\end{tabular}

and Eldorado canyons, on slopes between these two canyons, and on the plains east of the Front Range.

- The eight-tower network measured hourlyaveraged wind and temperature at 6 and $18 \mathrm{~m}$, plus net radiation on four of the towers.

- Three minisodars (two fixed and one mobile) each provided three components of wind and turbulence to a height of about $200 \mathrm{~m}$ at $8 \mathrm{-m}$ increments; winds were measured continu. ously at 1-minute intervals and averaged over 15-minute time segments.

- Three tethersondes measured wind, temperature, humidity, and pressure each hour to about the $600 \mathrm{~m}$ height, nominally at intervals of 4 to $12 \mathrm{~m}$, on balloon ascent and descent.

- An airsonde sampled wind, temperature, hurnidity, and pressure through the troposphers once every two hours. Height intervals of 30, 50 , and $100 \mathrm{~m}$ were used for sampling winds to
$300 \mathrm{~m}, 3 \mathrm{~km}$, and above $3 \mathrm{~km}$, respectively (temperature and humidity measurements were more frequent).

- A rawinsonde took wind, temperature, humidity, and pressure measurements through the troposphere every two hours, typically to an altitude of $7 \mathrm{~km}$ ( $400 \mathrm{mb}$ ) above sea level (MSL) at height intervals of about $25 \mathrm{~m}$ through most of the sounding (i.e., to about $4 \mathrm{~km} \mathrm{MSL}$ ) and larger intervals above $4 \mathrm{~km}$.

Multiple scales of profiling were necessary because little is known of the detailed vertical structure or the depth of drainage layers and their linkages with one another and with synoptic flow fields. Definition of the changing vertical and horizontal structure was aided by Doppler lidar scans that mapped winds flowing out of the two canyons and off the slopes. Their evolution as they moved out over the plains was characterized by scans taken several times eash hour through the night. 


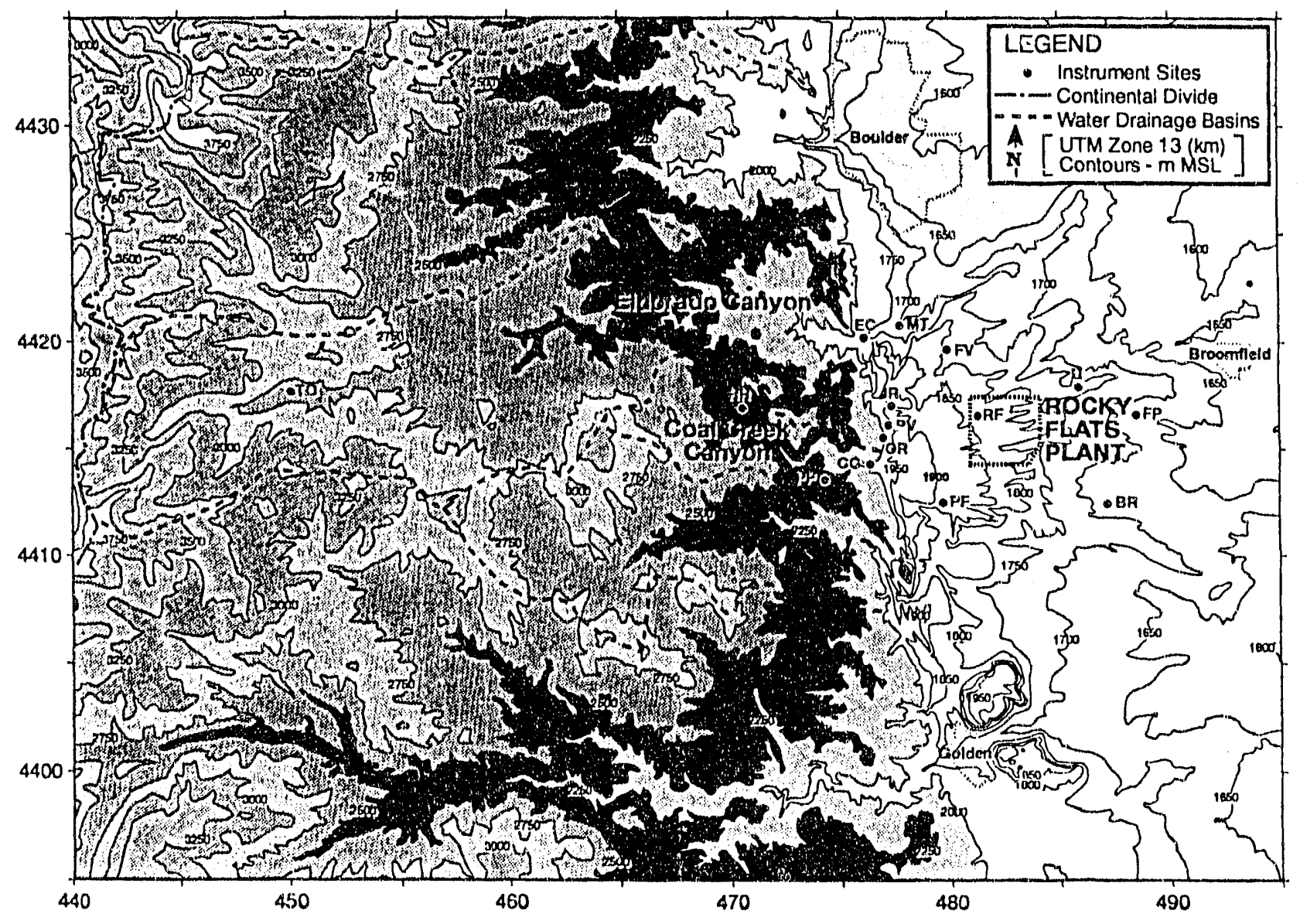

FIGURE 1. Front Range instrument Locations.

Data from meteorological measurement activities other than the ASCOT program's will also be utilized in analyses. Concurrent data will be obtained from the Winter Validation Study Tracer Tests, the Rocky Flats Plant $60-\mathrm{m}$ tower, the PROFS network, and a number of radar profilers and radioacoustic sounding systems operated for EG\&G/ Rocky Flats in the area, as well as routine National Weather Service Data.

During the ASCOT-91 experiment series, six nighttime experiments were conducted. The degree of synoptic forcing varied. At the beginning of the series, a high-pressure cell at the surface moved in from the west with moderate downslope flow ahead of it and strong zonal westerly flow aloft. As the surface high cell centered itself over the Continental Divide and stabilized there for the remainder of the series, it crealed fairly light surface winds except where strong drainage was present. At $500 \mathrm{mb}$, a series of troughs and ridges followed, producing upper-level winds from various directions (SW, W, NW, N, and S), and at light to moderate speeds ( 3 to $28 \mathrm{~m} / \mathrm{s}$ ). Thus, the effects of light, stable boundary layer flow containing streams of modest drainage, interacting with minimal to fairly strong synoptic forcing from different directions over or along the mountain ranges, can be studied through the series of experiments. The network of surface measurements and profiles, together with the Doppler lidar scans focusing on the three-dimensional structure and variability of at. flow, was able to identify interacting layers of wind that changed significantly throughout the night. A first look at one experiment, on the night of February 4-5, 1991, with light winds and stable conditions at the surface (resulting in an air pollution alert in the Denver area) showed the following: 
- A layer of surface-cooled air drained from the mountain valleys toward the east over the adjacent foothills.

- The primary drainage flows were from the Çoal Creek and Eldorado canyons and persisted throughout the night.

- Shallow drainage was detected off the slopes between the canyons; some localized return flows and eddies in the lee of the drainage flows from the canyons were also detected.

- Above the drainage, a layer of regional-scais flow from the south followed the base of the mountains. This layer decreased in depth with time and at one point broke into vortices.

- Still higher, winds in a transitional shear zone veered from south through west to finaily parallel the synoptic-scale winds that prevailed from the north.

- Streams of air from the synoptic flow were channeled by the mountains to move from the north. west through major canyons into the intermediate shear $20 n e$, and impinged on the lower layers.

- These elevated streams of air descending out of canyons reoriented the surface and nearsurface flow from southwest to northwest in a limited area around Rocky Flats and for a limited time around 1:00 a.m. Mountain Standard Time.

- Later, the elevated streams weakened and near-surface flow returned to southerly above thin westerly drainage.

- Drainage from the canyons meandered south of west to north of west with some guidance from the layer above. Eldorado Canyon drainage split into two plumes at times, the lower guided toward the northeast by terrain along the South Boulder Creek and the upper toward the east or southeast by the layer above.

- The range of the drainage flows at the surface was limited to approximately a $15-\mathrm{km}$ radius around Rocky Flats; southerly regional flow persisted beyond. The elevated streams from canyons extended further.

The case chosen for analysis and the results summarized above are not intended to represent typical wind patterns for the area. Rather, they demonstrate how complex and variable the wind field typically is in sface and time around Rocky Flats. Analysis of other experiments in the series will examine the expected canyon drainages and how they are influenced by different conditions. This case study does also demonstrate that, with the mix of diverse measurements made, it is possible to interpret the primary features of the convoluted and evolving flow field over the area. It is clear, however, that the three-dimensional character of the flow can only be defined adequately using multiple, cortinuously profiling instruments, which only a network of remote-sensing equip. ment can provide.

It can be concluded that for conditions of light surface winds with mirimal synoptic forcing, as hypothesized, the surface wind field over the foothills near the mountains is dominated by drainage from canyons rather than off open slopes. Also, the results show that the effects of synoptic- and regional-scale flows, always present to some degree, can never be excluded from consideration.

The observed evolution of surface drainage and the multilayered nature of the flow can be expected to seriously distort the dispersion patterns from tracer releases at the surface. Furthermore, for an elevated release, even more significant distortions of the dispersion will occur.

\section{Coupling/Decoupling of Synoptic and Valley Circulations}

\section{D. Whiteman, K. J. Allwine, and J. M. Hubbe}

In recent years, the Coupling/Decoupling of Synoptic and Valley Circulations project has focused attention on the interactions that occur between circulations of different scales. In FY 1991, in keeping with the Atmospheric Studies in Complex Terrain (ASCOT) program's long-range p!an to move to larger scales and support DOE's emergency response needs, efforts were focused on 1) determining the interactions between synoptic and valley circulations in the Tennessee Valley near Oak Ridge National Laboratory, 2) gaining a better understanding of the meteorological processes that lead to stagnation and ventilation in basins in the Southwesq, and 3) investigating atmospheric dispersion in a basin. Brief reports on these three research efforts follow. 


\section{Fy 1991 Research Highlights}

\section{Oak Ridge Wirrd Climatology}

During FY 1991, climatological investigations were pursued to improve understanding of the relationships between the winds in the Tennessee Valley near Oak Ridge National Laboratory (ORNL) and the geostrophic winds that flow above the valley. The work was begun by hypothesizing four mechanisms that would relate valley winds to the winds aloft. The corisequences of these four mechanisms on joint wind direction frequency patterns is illustrated in Figure 1 for a hypothetical valley having the same norticast-southwest crientation as the Tennessee Valley.

The first hypothesis (thermally driven winds) is that winds in the valley are decoupled trom the winds aloft, so that local winds develop only as a result of thermal contrasts within the valley. In this case, the theory of valley winds implles shat winds will blow along the valley axis, with up-valley winds during the day and down-valley winds during the night.

The second hypothesis (downward momentum transport) is that valley winds are strongly coupled to the winds aloft by the transport of horizontal momenturn downward into the wide valley, so that winds within the valley have the same direction as the winds aloft. The winds are expected to turn slightly toward lower pressure as they near the surface because of triction.

The third hypothesis (forced channeling) is that winds are channeled along the valley's axis by the component of the geostrophic wind that is superimposed along the valley's length. This mechanism implies that winds within the valley would blow up-valley when winds aloft were from southeast, south, southwest, west, or northwest. Otherwise, down-valley winds would occur.

The final hypothesis (pressure-driven channeling) is that winds inside the valley are driven along the valley's axis by the component of the geostrophic pressure gradient that is superimposed along the valley's length. According to this hypothesis, winds blow along the valley axis, with up.valley winds occurring when winds aloft are from the southwest, west, northwest, north, or northeast. Otherwise, down-valley winds would occur. Since geostrophic winds are perpendicular to the pressure gradient (i.e., geostrophic winds blow parallel to the isobars), the joint frequency distribution curve in Figure $i$ is shifted $90^{\circ}$ from the curve for the third hypothesis.

To examine these four hypothetical relationships between winds in a valley and winds aloft, the research approach was to evaluate the extent to which the mechanisms act alone or in combination to produce the winds observed in the Tennessee Valley. This was done by examining actual patterns in joint wind frequency distributions. For this purpose, 5 years of meteorological data were obtained from a 100-m tower (Tower C) at ORNL. Wind data from the 100-m level of this tower were considered representative of winds within the valley. A concurrent 5-year set of twice-daily ( 6 a.m. and 6 p.m. Eastern Standard Time) rawinsonde soundings was obtained from the National Weather Service for four sites surrounding ORNL, and geostrophic winds at the $850-\mathrm{mb}$ pressure level (aboui $1500 \mathrm{~m} \mathrm{MSL}$ ) above the Tower $\mathrm{C}$ site were obtained by interpolation. The joint frequency distributions were based on the hourly averaged tower data nearest in time to the ivice. daily geostrophic winds.

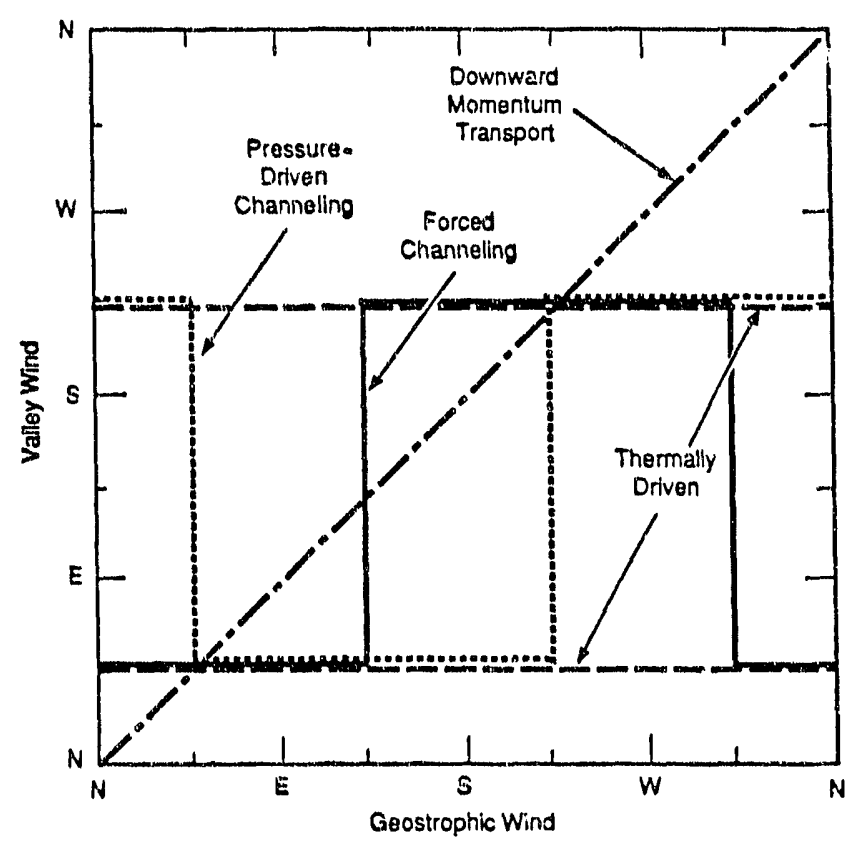

FIGURE 1. Schematic Joint Wind Direction Frequency Distribution Curve for Valley Wind Direction and Geostrophic Wind Direction for a Northeast-Southwest-Oriented Valley, lllusirating the Four Hypothetical Mochanisms Relating Upper Level and Valley Winds. 
Climatological investigations show that Tower $\hat{A}$, winds are very weak. Daytime (and to some exte;it nighttime) winds have a nearly equal probability of blowing up or down the valley, providing little support for the hypothesis of thermally driven winds. The joint frequency distribution in Figure 2 shows that wind directions are predominantly along the valley axis, suggesting that downward iransport of horizontal momentum is net a hiey process. The pattern of joint frequency distributions supports the fourth hypothesis, suggesting that winds in the Tennessee Valley at ORNL are produced predominantly by synoptic-scale pressure gradients that are superimposed along the valley's axis. Despite this strong support for the fourth hypothesis, further work has shown that downward momentum transport does play a minor role in the afternoon and that weak thermally driven flows play a minor role in the morning. A continuing investigation focuses on developing means to quantify the

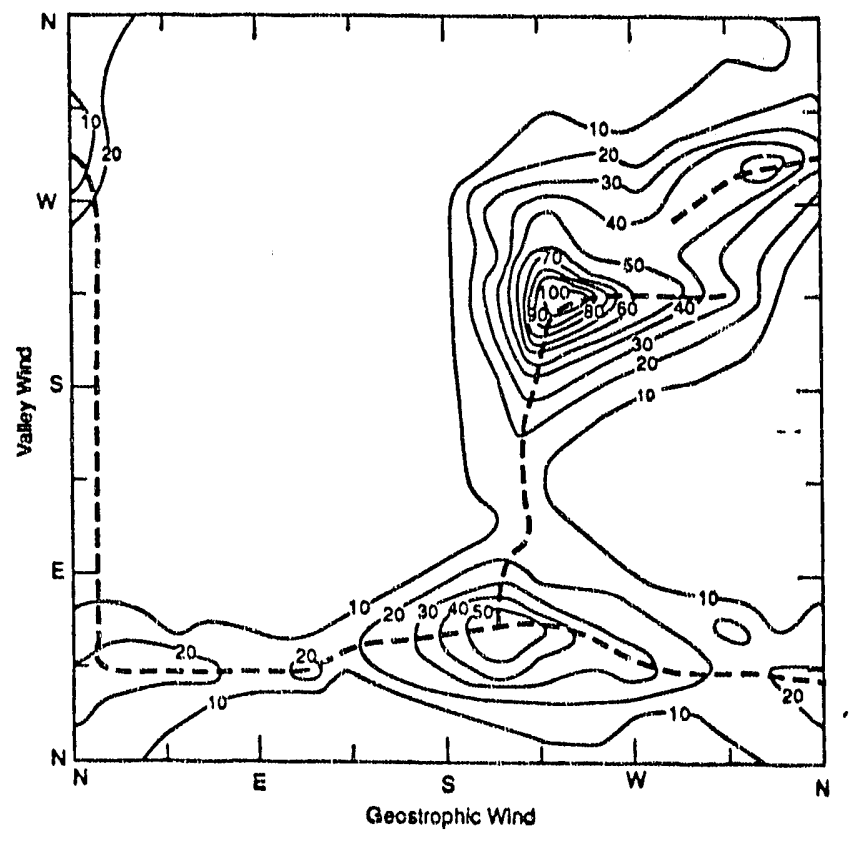

FIGURE 2. Joint Frequency Distribution for Valley and Goo. strophic Winds in the Tennessee Valley. Valley winds are observed at the 100-m level of Tower C at ORNL, while the geostrophic winds are at the 850-mb pressure level over ORNL Contours are the number of cases of winds from the directions indicated; the total number of observations is 3082 . The heavy dashed line is the joint frequency distribution pattern to be compared to the patterns in Figure 1. relative roles of the four alternate hypotheses. The results are expected to prove useful for $\mathrm{im}$. proving wind predictions at ORNL.

\section{Dispersion Moteorology of Valloys and Basins}

During FY 1991, results from two nighttime atmospheric tracer experiments were investigated further. In this summary, we contrast the differing results from the two experiments and point out the important physical effects.

The first experiment was conducted in the Brush Creek Valley of western Colorado during September and October 1984; the second experiment was in the Roanoke Basin of Virginia during January and February 1989. Both experiments were conducted under clear skies with weak synoptic winds, so that local thermally driven flows prevailed. Tracer releases from near ground level were continuous, each lasting for several hours. Ground-level concentrations of the tracer from distances as tar as $8 \mathrm{~km}$ from the source were compared. For the Proanoke Basin and Brush Creek Valley, respectively, the hour-average wind speeds at the release locations were 0.6 arid $1.5 \mathrm{~m} / \mathrm{s}$, values for the standard deviation of the horizontal wind speed $\left(\sigma_{v}\right)$ were 0.20 and $0.38 \mathrm{~m} / \mathrm{s}$, and values for the standard deviation of the vertical wind speed $\left(\sigma_{w}\right)$ were 0.03 and $0.19 \mathrm{~m} / \mathrm{s}$. These wind and turbulence characteristics suggest that the plume in the Brush Creek Valley would be more disperse and so give lower ground-level concentrations than the plume in the Roanoke Basin. This was not shown by the measurements, however (see Figure 3).

Nighttlme average ground-level concentrations $8 \mathrm{~km}$ from the release site in the Brush Creek Valley were greater than those measured in the Roanoke Basin by roughly a factor of 300 . There are several possible reasons why ground-level concentrations for the two similar releases would differ so much: 1) The tracer plume was narrowly confined by the sidewalls in the Brush Creek Valley. 2) The plume centerline follow ed the slope of the valley floor as it moved down-vi lley in Brush Creek Valley. 3) The plume became elevated in the Roanoke Basin as it travelled over the top of a 


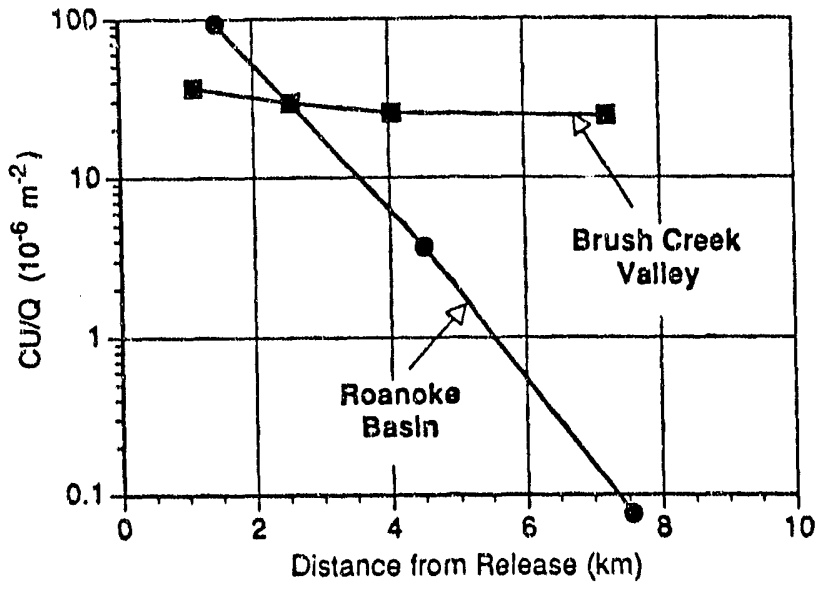

FIGURE 3. Normalized Nighttime Gro!nd-Level Tracer Concentration vs Distanco from the Release Sito for tho 1984 Brush Crook Vialloy and 1989 Roanoke Basin Experiments. The concentrations are 4-hour averages for the period 3 to 7 hours after the start of the release. Concentrations from the two experiments have been normalized by multiplying the measured concentration (C) by wind speod (U), and dividing by the release rate $(Q)$.

cold air pool thai had formed in the basin throughout the evening. The top of this pool anc' thus the bnttom of the plume stabilized at the height of terrain blockages at the down-valley edge of the basin. 4) Lateral dispersion of the plume in the Roanoke Basin was enhanced by vertical variations in the horizontal wind direction.

Research in FY 1991 also concerned the interaction between valley winds and above-ridgetop winds. The information obtained will be useful in regional-air pollution models so that the transport of pollutants between valley flows and regional flows will be better represented. Such information will also provide insights into the vertical transport of heat, moisture, and trace gases that may prove useful in global climate models. A ventilation raie, representing the magnitude and timing of the transfer of material (tracer mass) from the valley atmosphere to the above-ridgetop flows, was determined from the Brush Creek Valley experiment.

Detailed analyses of the Brush Creek tracer experiment showed that ground-level releases of tracer were completely confined within the Brush Creek Valiey in down-valley flows during nighttime. During such conditions, tracer was not detected by samplers on the ridgetops. After sunrise, with the onset of upslope flows and the growth of the convective boundary hyer in the valley, the tracer within the valley was carried into the upper reaches of the valley atmosphere and ventilated from the valley. This was evidenced both by tracer records from the ridgetop samplers and by a tracer mass budget applied to a control volume of the valley atmosphere. The ventilation rate was determined from the tracer mass budget. The budget results were consistent with the magnitude and timing of concentrations measured by the ridgetop samplers. Tracer began to move from the valley shorlly after sunrise, with the maximum ventilation rate occurring within 1 to 1.5 hours after astronomical sunrise. The ventilation rate decayed exponentially to relatively low values within 4 hours following sunrise. Ridgetop concentrations began increasing from background levels within 1 hour of sunrise, peaked within 4 hours of sunrise, and then began to decrease.

\section{Wintertime Meteorology In the Colorado Plateaus Basin}

Activities in FY 1991 inciuded the analysis of data from a large meteorolngical field study conducted in the winter of 1989-90 in the Colorado Plateaus Basin. The data were collected for Arizona's Salt River Project, to investigate the causes of wintertime low-visibility episodes in Grand Canyon National Park.

The Colorado Plateaus Basin of Colorado, Arizona, Utah, and New Mexico is a major geomorphic province of the southwest and includes much of the drainage area of the upper Colorado River, including the Lake Powell Basin and the Little Colorado River. The Colorado Plateaus Basin is an area of mesas and canyons surrounded on all sides by higher mountains. The Grand Canyon is the major channel between the basin and the Basin and Range Province farther to the west.

Analyses of the 1989-90 data show several major meteorological features in the region:

- Deep and persistent temperature inversions form in the Colorado Plateaus Basin in the winter. Dbservations over the upper slopes of the basin show shallow but intense groundbased inversions, with downslope flows feed. ing the basin inversion. Surface energy budget measurements show that the typical wintertime basin inversions are not destroyed by normal daytime sensible heat fluxes at the floor 
of the basin. Rather, they are periodically destroyed by traveling synoptic storm systems. Model calculations show that this situation changes in late winter or early spring, as sen. sible heat flux increases with higher sun angles and longer days.

- Shallow convective boundary layers grow during daytime over the floor of the basin. The convective boundary layers do not grow deep enough to break the wintertime basin inversion. Within the convective boundary layers, upsilope flows develop over inclined surfaces.

- Winds within the basin inversion are often weak, and stagnations and recirculations are important features of the meteorology.

- Winds within the upper two-thirds of the Grand Canyon are channeled along the canyon axis and appear to be driven by synoptic-scale pressure gradients that are superimposed along the channel. This finding suggests that the movement or development of synopticscale pressure systems across the Southwest affects tiie direction of pollutant transport through the Grand Canyon and through other low-lying passes on the western edge of the Colorado Plateaus Basin. The flow through the canyon is from west to east when relatively high pressures occur on the west end of the canyon, and is from east to west when relatively low pressures occur on the west end of the canyon. Thus, when an eastward-moving synoptic-scale low pressure system moves into the Southwest, the flow in the canyon is from east to west, providing a mechanism that moves pollutants into the canyon from the Colorado Plateaus Basin.

\section{Other Technlcal Progress}

The Coupling/Decoupling project participated in the ASCOT-91 meteorological and tracer experiments at the Rocky Flats Plant in Colorado's Front Range in early 1991. Data processing and analysis began in FY 1991 and will be continued for the next two years as other participants provide their data sets to the central database. The Coupling/ Decoupling project will also continue to participate in long-range planning for the ASCOT prograrn.

\section{Futcro Research}

In the next year, this work will be extended. Future work will concentrute on the interaction of circulations at different scales of motion, using the 1991 data set for the Front Range and other data from an experiment to be conducted there in the summer of 1993. Special investigations of valley and basin meteorology will focus on the energetics of the buildup of nocturnal temperature inversions.

\section{Atmospheric Diffusion in Complex Terrain}

\section{J. C. Doran}

The major rbjectlve of the Atmospheric Diffusion in Complex Terrain (ADICT) project has been to Identify and study the forcing mechanisms that determine the structure and evolution of wind and temperaturis fields in regions of complex terrain, so that their effects on the transport and dispersion of atmospheric pollutants can be evaluated and predicted. In FY 1991, two modeling studies and one field study were carried out to address this goal. Accomplishments include

- completion of a 2-week field measurement program in Colorado's Front Range near the Rocky Flats Plant,

- completion of a numerical modeling study of the effects of regional-scale topography on the local wind fields observed over the Hanford Site during winter inversion periods, and

- continuing numerical studies of the dynamic forcing mechanisms for winds in the Tennessee Valley in the vicinity of Oak Ridge National Laboratory.

In addition, development began on a nonhydrostatic mesoscale model that may eventually replace the hydrostatic code used for many of the modeling studies in this project.

\section{Colorado Fleld Study}

In late January and early February 1991, PNL participated in a multilaboratory measurement program in Colorado's Front Range near the Rocky Flats Plant. The experiment was designed to obtain a 
preliminary picture of some of the complex meteorological features of the area that may have an influence on the fate of atmospheric contaminants released in the region. The ADICT project pooled its resources with two other PNL projects, Coupling and Decoupling of Local arid Synoptic Circulations (DECUP) and Direct Simulation of Atmospheric Turbulence (DSAT), to support the measurement effort.

PNL operated a minisodar about $10 \mathrm{~km}$ from the outtlow of a small canyon to the southwest of the Rocky Flats Plant to examine the extent and structure of flows originating in the canyon. In addition, PNL released airsondes from a second site, north of the minisodar site, to obtain wind and temperature profiles during eight nights of the experiment. The airsonde data have been processed, work on the minisodar data has commenced, and analyses are being planned. Additional setails are given in this volume in the report from the DSAT project.

\section{Hanford Site Modeling Study}

A numerical mesoscale model was used to simulate the effects of regional and local terrain, synoptic forcing, and atmospheric stability on the wind fields in the Columbia basin, with particular attention to the Hanford Site. Observations show that, during winter inversion conditions, there is often a shear zone to the lee of Rattlesnake Mountain over the Hanford Site. The temporal evolution of the winds over the northern portion of the Site can vary widely from one day to the next, but the winds over the southern part of the Site show less variability. A series of numerical experiments were carried out that identified major factors that determine the details of the wind field development. In particular, the appearance of northwest flow over the northern portion of the Site with southwest flow over the southern portion seems to be related to channeled flow in the Kittitas Valley and Snoqualmie Pass regions, $75-150 \mathrm{~km}$ to the northwest. An example of a simulated flow pattern is shown in Figure 1. Additional numerical experiments considered the effects of increased wind shear, varying ambient wind directions, and modifications in the thermal structure of the atmosphere; the results agreed well with observations. Numerical experiments such as these, coupled with new atmospheric wind and temperature

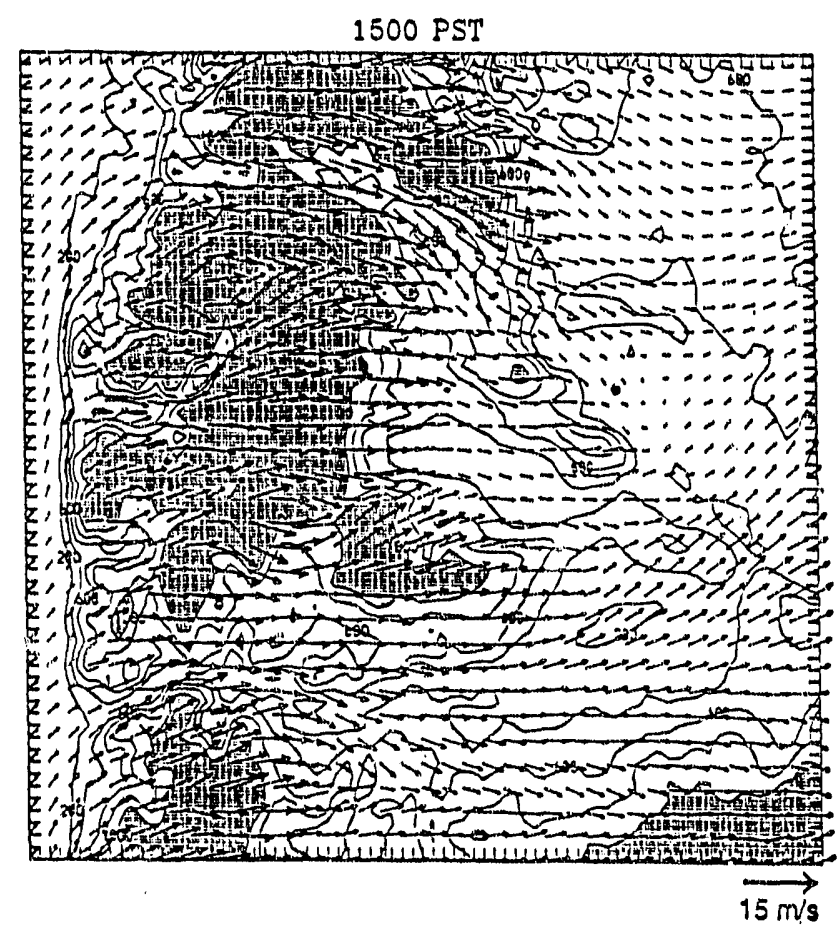

FIGURE 1. Simulated Surface Winds Over the Pacific Northwest for Ambient Winds from $255^{\circ}$ at 3:00 p.m. Pacific Standard Time. Tick marks are $4 \mathrm{~km}$ apart. Stippled areas mark regions with elovations over $1000 \mathrm{~m}$; dot near night center of figure marks location of Hanford Moteorological Station.

profiling instrumentation, may provide opportunities for improved forecasting for operational and emergency uses.

\section{Tennessee Valley Simulations}

The winds in the Tennessee Valley near Oak Ridge National Laboratory are often light and tend to blow either up or down the valley. This tendency does not appear to be reiated to the typical thermally driven wind systems observed in some previous ASCOT (Atmospheric Studies in Complex Terrain) field programs, such as those in the Brush Creek Valley in Colorado. Instead, the directions are apparently related to pressuregradient forces and channeling by the Tennessee Valley. These features were found in a climatological study carried out under the DECUP project. In cooperation with that project, this modeling study was conducted to examine the response of valley winds to various synoptic forcing patterns. The study is still in progress, but results thus far show 
good agreemeil with the climatological data. Simulations suggest that, under stable conditions, synoptic wind directions between $200^{\circ}$ and $360^{\circ}$ will produce valley wind directions that will be generally up-valley; for other synoptic directions the valley winds will flow down-valley. There is also some dependence on synoptic wind speeds and the degree of thermal decoupling of the valley atmosphere from the air aloft. Additional studies of the formation of stagnant zonas in the valley and their relationship to cold air pooling are continuing.

\section{Future Studles}

In FY 1992, Increasing attention will be given to descriptions and analyses of atmospheric disper. sion. Specifically, intensive analyses of the mete. orological and tracer data collected during the 1991 ASC.OT experiment in Colorado will begin. The tracer data will be used ro help idenilfy and characterizu the physical processes that govern diffusion near the Front Range. To support such analyses, ADICT will begin a climatological study of the area, utilizing the data being collected from a network of meteorological instruments in the region. This research will be further supported by initial efforts to incorporate four-dimensional data assimilation techniques into a dynamic mesoscale model.

\section{Interactions Between Surface Exchange Processes and Aimos. pheric Circulations}

\section{J. C. Doran}

The objective of the Interactions Between Surface Exchange Processes and Atmospheric Circula. tions (IBSEPAC) project is to study 1) the effects of surtace exchanges of heat, momentum, and moisture on the generation of cleculation patterns in the atmospheric boundary layer and 2.) possible feedback mechianlsms on the surface processes. The IBSEPAC project will integrate numerical modeling and fleld measurements to increase our understanding of the complex relationships bo. tween these phenomena. Of particular interest to IBSEPAC are the effects of heterogenous surlaces on houndary layer properties and the development of methods to measure and describe such effects. This area of study is closely related to issues of concem to such programs as the
Atmospheric Studies in Complex Terrain (ASCOi and Aimospheric Radiation Measurement (ARM) programs.

The IBSEPAC project was a new project in FY 1991 and comprised only a limited effort (approximately three staft-months total) during its inttial year. Work was begun on two tasks that will continue into FY 1992. The first task was to upgrade FNL's existing capabilities for measuring surface fluxes of momentum, heat, and moisture. Activities included the testing of a new' se nic anemometer used for measuring heat and momentum fluxes, the integration of a new data acquisition system with the sonic anemometer, and the development of algorithms for processing and displaying the data. The second task was a preliminany effort to implement improved modules for describing surface exchange processes in mesoscale models. The intent was to use existing treatments rather than to develop new approaches, so that the resulting model could be used for a variety of numerical experiments.

Work will continue in these areas during FY 1992. The utilty of a fleld measurement program to exam. ine the relationship between sensible heat fluxes and air-surface lemperature differences over semiarid terrain is being evaluated. A modeling siudy of the effects of widely differing vegetation and moisture patterns on circulation patterns in the Pacific Nonthwest will also begin. A substantial effort to install and operate a radar profiler for wind measurements and a radio-acoustic sounding system (RASS) for temperature measurements in the boundary layer is also anticlpated. Delivery of these instruments is expected in 1992; installa. tion, testing, data interpretation, and data display will be major tasks. Research will also begin on combining surface-based flux measuremenis with profile measurements to characterize local boun. dary layer responses to time-varying fluxes.

\section{Direct Simulation of Atmospheric Turbulence}

\section{J. C. Doran}

The objective of the Direct Simulation of Atmospheric Turbulence (DSAT) project is to use advanced numerical models to simulate complex 
nonlinear dynamics in atmospheric flows. In addition, in cooperation with other PNL programs, the DSAT project jointly supports activities of DOE's Atmospheric Studies in Complex Terrain (ASCOT) program in experimental and analytical studies of atmospheric dynamics and their effects on diffusion of atmospheric pollutants. In FY 1991, principal accomplishments of DSAT included

- initial examination of numerical techniques to be used in the direct simulation of stable boundary layer flows,

- a preliminary investigation of the development of small-scale models on massively parallel computers,

- completion of an analysis of the interaction between thermally forced and synoptic winds,

- completion of a two-week field measurement program in Colorado's Front Range near the Rocky Flats Plant,

- a budget study of nighttime air mass and tracer concentrations in Brush Creek Valley, and

- sensitive tracer analyses of samples obtained in the Grand Cunyon area that revealed the presence of aged plumes, suggesting possible significant recirculation episodes during the winter.

\section{Direct Numerical SImulations}

The DSAT project is supporing J. Barnard's graduate research program in direct numerical simula. tions of stable turbulent boundary layer flows at the University of Washington under the direction of Prof. J. Riley. Recent work has involved the selection of a suitable numerical method to carry out the necessary integrations of the governing equations. Although spectral methods are attractive, some modifications are required because the computational domain is not finite nor does it permit the use of periodic boundary conditions. A technique suggested by Spalart et al. (1991) is currently being tested. This technique has shown some promise but its ability to simulate internal gravity waves adequately is unkriown.

\section{Interactlons Between Synoptlc and Thermally Forced Winds}

Analyses of the thermally forced winds and the synoptic wirld field above the Roan Plateau in Colorado were completed, using results from numerical simulations with a nonhydrostatic meso. scale model. Observational data and model results were used to detail the development of the deep nocturnal boundary layer found above the plateau. The shear between the low-level thermally driven flows and the large-scale overlying wind field was found to enhance turbulent mixing of the cold surface layer air upward to form a deep mesoscale boundary layer. A paper by Doran and Skyllingstart (1992) describes the results of the experiment.

\section{Colorado Fleld Study}

In late January and early February 1991, PNL participated in a multilaboratory measurement program (ASCOT) in Colorado's Front Range near DOE's Rocky Flats Plant. As part of that effort, PNL obtained a minisodar and deployed it approximately $10 \mathrm{~km}$ from the mouth of Coal Creek Canyon in Colorado's Front Range in December 1990. The instrument has been operating nearly continuously since that time. The data obtained during the ASCOT experiment revealed the presence of complex layering, shears, and ihermal decoupling in the area. The data obtained in this continuing study will be used to help establish a "climatology" of the area, using funding from a complementary PNL ASCOT project.

\section{Budget Studies}

A budget study was carried out using tracer, lidar, and tethersonde data collected during the 1984 ASCOT experiment in Brush Creek Valley in Colorado. The study sought to demons:-iate a balance between the release rates of tracers emitted in the valley and the amount of tracer passing arcs of samplers located down the valley from the release point. Results show that good agreement can be obtained between the rates of tracer release and the tracer fluxes if the magnitudes of the down-valley winds obtained from the tethersonde results are used in conjunction with cross-valley profile shapes obtained from the lidar data. The use of lidar-derived wind magnitudes, instead of tethersonde-derived values, results in an approximately $25 \%$ discrepancy between the release rates and the fluxes. By using the tethersonde values, it is then possible to estimate subsequent ventilation rates of tracer from the valley during the breakup of the inversion after sunrise. These rates are useful in regional air-quality models because the effects of time-varying source 
terms can be described accurately. These analyses formed part of K. J. Allwine's dissertation research at Washington State University.

\section{Tracer Analyses}

Perfluorocarbon tracer (PFT) samples collected over the Grand Canyon region in another program were analyzed during FY 1991 under the DSAT project. Recent improvements in PNL's gas chromatograph PFT analytical system allowed the measurement of tracer concentrations as low as $10-15$ by volume. Samples obtained on 9 days were analyzed, and for 4 of these days traces of aged prime were detected. Aged plumes contain tracer re. leased one or more days prior to the sampling period. Such findings suggest the possible occurrence of recirculation episodes, l.e., conditions under which material released into the atmosphere may first drift away and then return to an area, thereby increasing the likelihood of poor air quality and limited visibility.

\section{Future Studles}

In FY 1992, the use of numericai models to study nonlinear atmospheric dynamics will continue to be the major focus of this program. Support for the study of direct simulations of stable boundary layer flows by J. Barnard will comtinue. A numerical investigation of the interaction between synoptic and local flows in the Tennessee Valley, begun in PNL's ADICT project, will be shifted to the DSAT project. Additional work will be carried out either to develop a user-friendly nonhydrostatic model or to secure a more powerful model from one of several sources; this new model will replace or supplement codes currently in use at PNL. Work will begin on simulating aspects of the flow fields in Colorado's Front Range, including possible studies of the meso- $\beta$ circulations driven by diurnal heating and cooling over the Front Range and the adjacent plains and examination of wave-turbulence interactions, which may be an important mechanism in turbulent exchange during stable conditions.

\section{References}

Doran, J. C., and E. D. Skyllingstad. 1992. "Multiple-Scale Terrain Forcing of Local Wind Fields." Monthly Weather Review 120(5):817. 825.
Spalart, P. R., R. D. Moser, and M. M. Rogers. 1991. "Spectral Methods for the Navier-Stokes Equations with One Infinite and Two Periodic Directions." Journal of Computational Physics 96:297-324.

\section{The Fifth International Conference on Precipitation Scavenging and Atmosphere-Surface Exchange Processes}

\section{W. R. Barchet, W. G. N. Slinn, and C. E. Elderkin}

The Fifth International Conference on Precipitation Scavenging and Atmosphere-Surface Exchange Processes was organized and hosted by PNL on July 15-19, 1991, in Richland, Washington. As with previous conferences in this series held over the past two decades, the goal of the Fitth Conference was to facilitate the description, discussion, and documentation of current knowledge about the processes involved in scavenging of environmental pollutants by clouds and precipitation and about the atmosphere-surface exchange of pollutants and other trace gases. The conference was especially timely and relevant, as a decade of research on the local and regional problems of acid rain had just been concluded and new investigations of larger-scale problems of pollutant transport, chemical transformation, removal, and interactions with radiative transfer and the blosphere are being initiated.

Specitic themes of the conference concerned the measurement of and models for precipitation scavenging and air-surface exchange processes and their adequacy for applications to future problems, such as those associated with atmospheric oxidants, hazardous wastes, and global environmental change. About 100 podium presentations In 18 technical sessions and about 50 poster pres. entations addressed these topics. Many of the technical sessions were introduced by invited review presesentations.

The conference was attended by 162 scientists. Participation by foreign scientists was strong, with 21 foreign countries represented by 80 scientists 
and students. The co-chairpersons for the conference were W. George N. Slinn (PNL) and Stephen E. Schwartz (Brookhaven National Laboratory). A two-volume set of peer-reviewed papers based on the conference presentations will be published in 1992 by Hemisphere Publishing Corporation of New York.
Financial support for the conference was provided by DOE, the U.S. Environmental Protection Agency, the National Oceanographic and Atmospheric Administration, the Electric Power Research Institute, the Atmospheric Environment Service of Canada, the National Science Foundation, and Battelle Memorial Institute. 
Climate

Research 


\section{CLIMATE RESEARCH}

Climate change research at the Pacific Northwest Laboratory (PNL) is aimed at reducing uncertainties in the fundamental processes that control climate systems that currently prevent accurate predictions of climate change and its effects. PNL is responsible for coordinating and integrating the field and laboratory measurement programs, modeling studies, and data analysis activities of the Atmospheric Radiation Measurements (ARM) program. The ARM program will increase the reliability of predicting regional and global changes in climate in response to increasing atmospheric concentrations of greenhouse gases, including $\mathrm{CO}_{2}$. Improvements in the treatment of radiative transfer in general circulation models (GCMs) under clear sky, broken cloud, and general overcast conditions and improvements in the parameterization of cloud properties, cloud formation, and cloud maintenance in GCMs are the objectives of the multilaboratory effort being led by PNL.

Ocean research related to climate change is examining ocean-atmosphere interaction, ocean circulation and climate modeling, and the technology of making ocean measurements. The program is conducting experimental studies and modeling exchange processes at the air-sea interface for heat, $\mathrm{CO}_{2}$, and other radiatively active gases. Physical, chemical, and biological processes involved in transfer mechanisms at the sea surface, such as bubble plumes and surface microlayer films, are being studied experimentally. The ocean dynamics that transport and redistribute heat and gases captured at the surface are so far not well understood; consequently, PNL is working to improve the parameterizations of the dynamics of the surface mixed layer, transport through the thermocline, and formation of deep water.

Research on greenhouse gas emissions is under way to improve the reliability of forecasts of emissions of $\mathrm{CO}_{2}$ and other radiatively active gases. Model development, validation, and uncertainty evaluations depend on improved and expanded databases, including more definitive information on energy production and consumption practices. The changing technologies and policies of the United States and other countries are being analyzed to anticipate contributions to future emissions of greenhouse gases and their effects on society, particularly on a regional basis.

Methods are being developed and implemented for analyzing the impacts of climate change and $\mathrm{CO}_{2}$ increases on natural resources and society at the regional level. Data are being gathered and examined on climatic, environmental, and societal characteristics for a region of the United States, and approaches are being developed for predicting the consequences of climate change for natural, biological, and human resources.

As part of the U.S. Department of Energy's (DOE's) program to quantify the linkages between changes in atmospheric composition and the temperature of the planet, PNL is studying how clouds and aerosols interact with short-and long-wave radiation to regulate the heating of the planet. Data from a network of surface-based, spectrally resolved direct and diffuse short-wave radiation sensors and ancillary meteorological sensors will be used to improve the parameterization of the radiative effects of clouds and aerosols.

Improvements to climate models that are gained through advances in our understanding of the chemistry and physics of the climate system must be integrated with the rapid pace of advances in computer technology. Therefore, DOE's Computer Hardware, Advanced Mathematics, and Model Physics (CHAMMP) climate modeling program has as its goal the development of models and computing systems that can run from 1,000 to 10,000 times faster than today's systems. Only with such increases in computational speed can climate models become useful policy tools. 
The progress described in the articles that follow was supported by the following research projects:

- Quantltatlve Links

- CHAMMP Detallee Assignment

- Atmospheric Radiation Measurements

- $\mathrm{CO}_{2}$ Energy Systems Research

- $\mathrm{CO}_{2}$ Ocean Research

- $\mathrm{CO}_{2}$ Resource Analysis Research. 


\section{Climate Research}

\section{The Atmospheric Radiation Meas- urement (ARM) Program: Field Measurements for Radiation Forc- ing and Feedbacks in General Circulation Models}

\section{G. M. Stokes and T. S. Cress}

Atmospheric general circulation models (GCMs) are a useful tool for advancing understanding of the global climate system and the impact that human activities have on it. For instance, how different energy scenarios change the atmos. pheric concentration of carbon dioxide can be investigated through the use of GCMs. One of DOE's goals is to improve the performance of GCMs as tools for predicting global climate change. To achleve this goal, DOE initiated a multifaceted research program that concentrates on improved understanding of the physical processes modeled in GCMs that limit GCM performance.

The Atmospheric Radiation Measurement (ARM) Program is the major field portion of DOE's climate change research program. The ARM Program is focused on improving the treatment of cloud radiative forcing and feedbacks in GCMs, because that is currently the major source of uncertainty in the models.

The objective of the ARM Program is to character$i z e$ radiative processes in the atmosphere with improved resolution and accuracy. A key to this characterization is the effective treatment of cloud formation and radiation transfer in climate research models. The experimental design incorporates the following elements:

- up to five permanent measurement sites comprising a highly instrumented central facility and a surrounding network of sensors to document the cloud distribution and morphology in the atmospheric volume above each site,

- a network of meteorological observation stations at each of the five sites to document surface meteorological and radiative conditions over an area comparable in size to the computational grid cell used by a GCM,

- a relocatable facility of ARM instruments,
- airborne in situ measurements for comparison to ground-based remote-sensing instrumentation, and

- satellite data from existing operational and research satellites.

In FY 1991, the ARM Program prepared to begin measurements in FY 1992 with the phased implementation of the first field site. Efforts included

- establishing working priorities for long- and short-term occupation of measurement sites,

- analyzing the scientific objectives of each locale, including the technical and geographic characteristics of the sites that would affect observational strategies,

- establishing a Site Management Plan that delineates responsibilities of the Site Program Manager, Site Scientist, and Site Operator.

- Identifying measurements and measurement strategies required to meet the program objectives,

- selecting instrumentation to produce the required measurements, and

- designing a data management system to acquire instrument and external (e.g., satellite data) data streams and to deliver the data to the individual team members.

Key accomplishments include

- completion of pilot studies of potential site instrumentation,

- selection of Site Program Managers for four of five planned long-term sites,

- selection of Site Scientists for three of five planned long-term sites,

- selection of the site for the first fieldmeasurement program,

- determination of the instrument suite for the first site,

- establishment of distinct measurement strategies, and

- design of the data system. 
The ARM Program involves nine national laboratories whose efforts are coordinated through the ARM Program Office at the PNL. The program consists of three distinct entities: the Science Team, the Instrument Development Program, and the Clouds and Radiation Testbed (CART).

\section{Experimental Approach}

The ARM Program Plan (DOE 1990) outlines the program's basic experimental approach. Fleld measurements will be used to initialize the process models to be evaluated and to provide the data for periodic model comparison and evaluation.

Emphasis is on the data needed to test the radiative models, and secondarily on additional data required to develop and test the performance of radiative parameterizations on the scale of a GCM computational grid cell, or the area included in a satellite observation. Since the single largest impact on atmospheric short- and long-wave radiation is the distribution, type, and morphology of clouds, a third focus is on evaluating how cloud formation, maintenance, and dissipation are treated.

A highly instrumented site will be used to document the radiative properties and fluxes within a column to the top of the atmosphere, document the mean atmospheric properties of the atmos. pheric column, and document the advection of atmospheric properties (e.g., temperature) and constituents (e.g., water vapor) into and out of the grid cell equivalent.

\section{Locale and Site Selection}

Measurement sites for the ARM Program were prioritized based on considerations of global climate regimes on the scales of hundreds of kilometers to considerations of surface homo. geneity on the scale of a few kilometers. This meant proceeding from identifying the southern Great Plains as the highest-priority locale to selecting a specific few kilometers within that locale for the first measurement site. Occupation of the site within the southern Great Plains is planned for April 1992, with data being transmitted from the sito by the end of that month.

The selection process ensured that the primary and supplementary locales would collectively experience the key phenomena controlling the transfer of radiation in the atmosphere, with the primary locales spanning many of the attributes limiting the performance of GCMs. The locales recommended by the site selection team were reviewed in the context of the needs of the Science Team, and of plans for other research programs, because the benefits of coordination or collaboration might influence the priority for occupancy. The primary locales recornmended by the site selection team were reviewed and ultimately prioritized for long-term occupation (7 to 10 years) as follows:

1. Southern U.S. Great Plairs

2. Tropical Western Pacific Ocean

3. North Slope of Alaska

4. Eastern North Pacilic (or Atlantic) Ocean

5. Gulf Stream oft Eastern North America.

With its concentration of related research programs and favorable logistical environment, the southern Great Plains was the clear first choice, both programmatically and scientifically (DOE 1991). Current plans call for a site occupation rate of one every eighteen months.

The supplementary locales recommended for short-term occupancy or for campaigns to study processes characteristic of that locale are Central Australia or Sonoran Desert; Northwest U.S.Southwest Canada Coast; Amazon Basin or Congo Basin; and Beaufort Sea, Bering Sea, or Greenland Sea.

Potential synergies between the ARM Program and other research programs strongly influenced the selection of the southern Great Plains. Because the southern Great Plains is characterlzed by violent weather conditions that periodically threaten life and property, as well as by a wide variety of cloud and meteorological conditions, it is an area of intense interest for atmospheric research and the development of improved operational weather observation and forecasting capabilities. The presence of these programs influenced the selection of specific sites for the central facility and for the vertical profiling measurement facilities.

Figure 1 shows the site with its component central facility and auxiliary, extended, and boundary facilities. Table 1 lists the measurements to be 


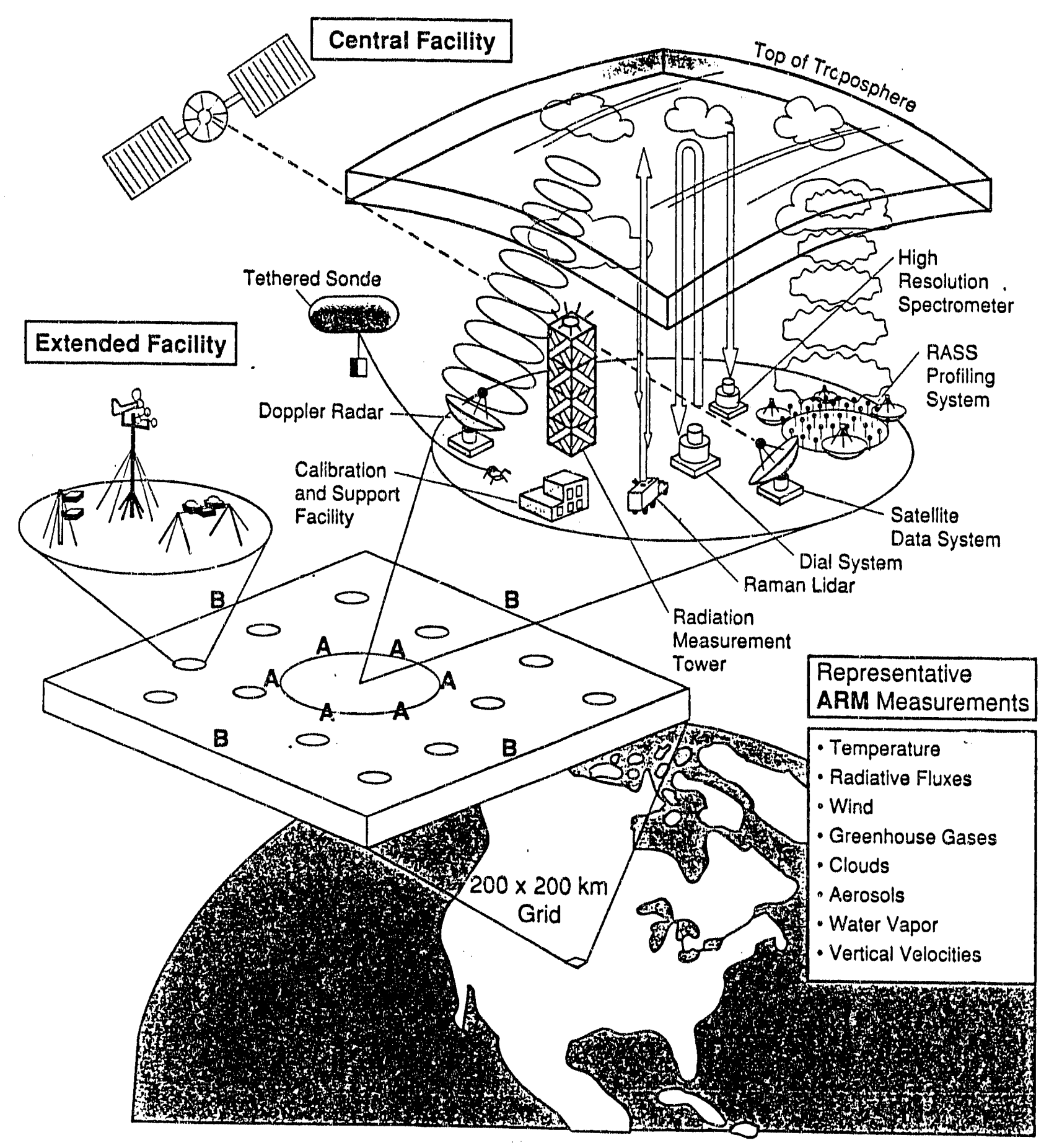

FGURE 1. ARM Sitr. 
TABLE 1. Instruments by Measurement Facility.

Facilities/nstruments

Central Facillty Instruments

915-MHz radar wind profiler and RASS

50-MHz radar wind profiler and RASS

Balloon-bome sounding system

Microwave radiometer

Insirumented 60-m lower

Baseline Solar Padiation Network instruments

Calibration facilities

Aerosol instruments

Instrument Development Program Instruments (for Central Facility)

Ceilometer

Raman lidar

Infrared interferometer spectrometer

Ultraviolet spectral radiometer

35- and 94-GHz radar systems

Lidar systems

\section{Auxillary Sites}

Whole-sky imaging system

\section{Extended Sito Facillites}

Surface flux stations

Wideband solar and infrared sensors: multifitter rotating shadowband radiometer

Surface meteorological sensors

\section{Boundary Facilitios}

Co-location with wind profilers (some with RASS)

Balloun-bome sounding system

Future remote sensor
Property Measured

Vertical profiles of wind velocity components and acoustio virtual temperature in the atmospheric boundary layer

Vertical profiles of wind velocity components and acoustic virtual temperature above the atmospheris boundary layer

Wind speed, wind direction, temperature, and humidity

Integrated columnar amounts of water and liquid

Eddy corrolation measurements of heat, momentum, and molsture fluxes at heights of 60 and $25 \mathrm{~m}$; observations of mean wind comporienis, temperature, and humidity at a height of $60 \mathrm{~m}$; upwelling broadband solar and infrared fluxes at heights of 60 and $25 \mathrm{~m}$

Normal Incident pyranometer; precision spectral pyranometer; pyrgeometer; pyranometer and pyrgeometer for upwelling irradiance; solar specural radiometer

Absolute radiometer; comparison stand; laboratory components

Nephelometer; ozone sensor; CCN counter; aerosol filter pack system with two size cuts; filter sample system for optical absorption; optical particle counting systems

Cloud heights including cimus; aerosol backscatter in the atmospheric boundary layer Vertical profiles of water vapor and ozone concentrations

Infrared radiances at the surface

UV radiances at the surface

Cloud properties

Aerosol and cloud properties

Mapping cloud geometry; possibly radiance observations

Vertical fluxes of heat, moisture, and momentum. Energy-balance Bowen ratio systems will also observe soil heat flux, soil temperature, and soll moisture

Upwelling and downwelling irradiances

Mean wind speed and direction at a height of $10 \mathrm{~m}$; temperature and humidity at a height of $1.5 \mathrm{~m}$; barometric pressure and liquid precipitation

Wind and temperature (with RASS) profiles

Wind, temperature, and humidity profiles

Wind, temperature, and humidity profiles 
made at each of these facilities. The first central facility will be near Lamont, Oklahoma, near the center of the densest part of the Wind Profiler Demonstration Network. Boundary facilities will complement the measurements taken by the six wind profilers shown in the figure at the boundaries of the site. At this time, specific pieces of larid are being examined.

By the end of FY 1991, Site Program Managers for the southern Great Plains, the Tropical Western Pacific, North Slope of Alaska, and the Gulf Stream, and Site Scientists for the Tropical Western Pacific, North Slope of Alaska, and the Gulf Stream were identified. The remaining Site Program Managers and Site Scientists will be named early in FY 1992.

Preparations for site occupation include satisfying the requirements of the National Environmental Protection Act (NEPA). The NEPA process was Initiated during FY 1991 for the southern Great Plains site. The expected impaci of the instrumentation and facilities to be installed at the site appear to require the completion of an Environmental Assessment, which is expected to be completed and approved in time for site occupation in April. To assist in preparation of the Environmental Assessment and for site management, the development of a geographical information system, using Landsat data, was initiated and is expected to be a model for subsequent sites.

An Implementation Review for the ARM Program was held in May 1991. During the review, two teams, representing the views of the Science Team and the recently named Site Program Managers, were requested to provide responses to all aspects of ARM planning. Although the general conclusions from the review were favorable, shortfalls were identified and now the Science Team is playing a larger role both in the design, planning, and execution of the program and in the development of experimental concepts, and the airborne measurements required are being assessed in the context of the ARM obser. vational strategies.

\section{Instrumentation}

The scientific requirements, geographical constraints, and site operating needs will determine what instrumentation will be deployed to each individual ARM measurement site. The current focus is instrumentation for the first site in the southern Great Plains.

The instrumentation for the first ARM/CART site emphasizes observations made at land surface and includes stations to observe air-surface exchange of molsture, heat, and momentum; balloon-borne sounding systems to obtain vertical profiles of wind speed, temperature, and humidity; microwave radiometers to observe amounts of water vapor and liquid in the column above the site; and radar wind profiler systems coupled with acoustic systems to observe vertical profiles of mean wind velocity components and temperature.

\section{Pliot Studles}

Limited pilot studies, in conjunction with other programs, have helped in evaluating the performance of specific instruments. A prime example was a collaborative study with the Winter Icing and Storms Program (WISP) of the Federal Aviation Administration (FAA) and the National Oceanic and Atmospheric Administration (NOAA), conducted in February and March 1991. During this study, the performance of microwave radiometers for the measurement of columnar water vapor and liquid water was evaluated. The study took advantage of the presence of a number of instruments to characterize the moisture distribution in the atmosphere as well as other radiometers. The results are being used in the instrument selection process for the first site.

Similariy, the results of a field experiment during May and June 1991 in the vicinity of Boardman, Oregon, are furnishing valuable guidance for the placement of instrumentation at the southern Great Plains site. The objective of the Boardman study was to acquire data to improve descriptions of values of heat and moisture flux over an area approximately the size of a GCM grid cell. The guidance developed from analysis of the Boardman data will aid in siting instruments for the facilities at the southern Great Plains site.

\section{Data Management System Design}

The software environment of the site and of the experiment center will be capable of receiving, processing, displaying, and storing sizable quantities of data in real time. A software system to support field experimental operations developed by 
the National Center for Atmospheric Research (NCAR) will be the basis for implementation of the site and experiment center data systems. The basic structure of this system is shown in Figure 2. The simplicity of its building block architecture for data processing makes the systern is:pandable to handle virtually any instrument sys

Although team members will receive data directly from the experiment center and access the archive as required, the archive will also make archived data readily available to the wider climate research community, and ultimately to other programs and agencies for research that extends well beyond climate and global change issues.

To determine an appropriate size for the site data system and short-term data archival requirements at the site, instrument data rates, measurement strategies, and the external data stream to be received at the site were evaluated.

\section{Sclence Team Experiment Support}

The ARM Program is focused on improving the treatment of radiative energy in GCMs and, therefore, on the physical processes that impact radiative transport in the atmosphere. The scientific issues facing the ARM Program can be described in the context of three broad topics:

- radiative energy transport in climate models,

- cloud formation, maintenance, and dissipation, and

- the limits of modeling atmospheric processes in GCMs and related models.

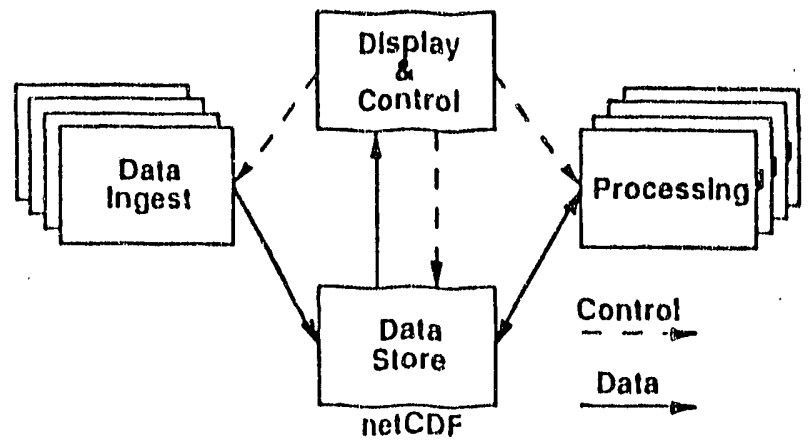

FIGURE 2. NCAR Soltware System.
Within these broad contexts, research generally falls into one of three loosely related groups:

- measurement of the instantaneous radiative flisx under clear, bioken clouds and overcast conditions,

- use of measurements to evaluate process models and parameterizations embodied in GCMs, and

- use of data fusion techniques and fourdimensional data assimilation to address the variability of atmospheric conditions on a scale comparable to a GCM computational grid celf.

Two general measurement strategles have evolved:

- the instantaneous radiative flux experimental concept, and

- the use of a single column of a GCM model to examine process models and parameterizations.

Data fusion techniques and four-dimensional data assimilation are approaches that can be applied in each strategy to use widely spaced and possibly nonsimultaneous measurements to document general and even sometimes specific conditions across the area of a grid cell.

\section{External Program Coordination}

The ARM Program complements related research programs that focus on new observational capabilities and a new generation of predictive models based on the improved understanding of the physical processes that limit model performance.

The complementary programis in the vicinity of the first operational ARM field site in the southern Great Plains include

- The National Weather Service Modernization Program,

- The National Weather Research Program (commonly known as STORM),

- The Global Energy and Water Cycle Experiment (GEWEX),

- Winter Icing and Storms Project (WISP), and

- The Oklahoma Mesonet. 
In February and March 1991, WISP provided the opportunity for A.RM to compare candidate instruments for the first measurement site with instrumentation already in the field for other purposes. Future WISP fleld programs may be located to take advantage of the southern Great Plains site.

The modernization program of the National Weather Service and the development of the Oklahoma Mesonet will directly benefit the ARM Program. About 35 automated weather reporting stations in the Mesonet are within the boundaries of the ARM site; data from these stations will be part of the ARM data base.

The GEWEX and STORM research programs are the most closely coupled with the ARM Program. The GEWEX Continental-Scale International Program will be located near the southern Great Plains site and close collaboration will ensure maximum benefit to both efforts. The ARM Program is also collaborating closely with the STORM Program Office. Care is being taken to ensure compatibility of data systems by using common software and compatible software protocols.

\section{Future Research}

Phased installation of instruments of the first site will begin in April 1992. Initially most instrumentation will be deployed to the Central Facility, but some instruments will go to the boundary facilities, and later more will go to the extended and auxiliary measurement sites. The phased installation process is expected to continue into FY 1993.

Data system testing will begin early in FY 1992 using data sets from recent field programs in which radiometric sensors have been evaluated. The objective is to run test cases to confirm the basic functionality of the planned physical system, gradually adding stress to evaluate system capability.

In FY 1992, the final key personnel (Site Program Managers and Site Scientists) will be named and development of the mobile facility will begin. Assessment of the unique needs of the first ocean environment site in the troplcal western Pacific Ocean will begin. The challenges of this site include not only the type of instrumentation required to address the scientific needs of the site, but also the use of sensitive instrumentation in a hostile environment. The experience here will strongly shape the planning for two more ocean sites. A site on the North Slope of Alaska poses its own problems: stability of instrument platiorms on permafrost and access to remote instrument sites and power.

Interagency and interprogram coordination remain central features of the ARM Program. Involvement of NOAA is substantial and expected to grow; NCAR is involved in instrument and model development with a particular focus on vertical profile specification. The ARM field efforts will continue to be coordinaled with the STORM and GEWEX projects. Other agencies with which ARM Program operations will be coordinated include the National Aeronaufics and Space Administration (NASA), the National Science Foundaiion (NSF), and the Department of Defense (DOD).

\section{References}

U.S. Department of Energy (DOE). 1990. Atmospheric Radiation Measuremení Program Plan. DOE/ER-0441, U.S. Department of Energy, Washington, D.C.

U.S. Department of Energy (DOE). 1991. Identification, Recommendation, and Justification of Potential Locales for ARM Sites. DOE/ER-0495T, U.S. Department of Energy, Washington, D.C.

\section{Tethered-Balloon Sounding System for Obtaining Vertical Radiation Profiles}

\author{
C. D. Whiteman, J. M. Alzheimer, G. A. Anderson, \\ M. R. Garnich, and W. J. Shaw
}

An instrument development project is under way to develop a small tethered-balloon sounding system to collect routine in situ vertical radiometric profiles to heights of $\sim 1500 \mathrm{~m}$ above ground level. The major technical issue of this project is to construct a stable platform that will keep the radiometric instruments level, regardless of the balloon's motion.

FY 1991 was the first year of funding for this project, and emphasis was placed on developing an effective engineering design for the stable platform. The project's key accomplishments are as follows: 
- A mathematical model of an inclined net radiometer was developed to determine the design specifications for the stable platform.

- Two prototype plattorms were designed and built. The first platform, termed the Sky Platform, carries the radiometric sensors and is stabilized by an active control loop. The second platform, termed the Motion Sensing Platform (MSP), is not stabilized and will be used to meas. ure the lateral and angular accelerations to which the Sky Platform will be exposed. Data from the MSP will be used in designing the Sky Platform's control loop.

- Test flights were made with the MSP.

- A working prototype Sky Platform was demonstrated at the Atmospheric Radiation Measurer.:ents (ARM) Sclence Team Meeting in October 1991.

\section{Engineering Design Concepts}

A radiometric platform sultable for deployment on a small tethered balloon should be light, inexpen. sive, and stable. It must be lightweight because of the limited free-lift capacity of small balloons; it must be inexpensive because airborne sensing packages will occasionally be lost; and it must be stable (1.e., kept horizontal) so that the radiometric measurements can be properly interpreted.

During Fr 1991, a large number of designs for the stable platforrn and its sensors were considered by the project team. Platform designs that carried radiometric sensors on or hanging directly from the balloon were rejected because of the diffliculty of stabilizing the platforin in turbulent environments. The tetherline was considered a more suitable location for the platform because its dynamic response to atmospheric turbulence is slower. Designs that relled on mechanical stablization of the platform using counterwelghts were also relected. Aclive control loops allow much better control of frequency response, whthout the penalties of heavy counterwelgits.

Flgure 1 presents an artist's conception of the tethered-balloon radiometric profller. The stable platform is carried on the tetherline below the balloon. In a typical operation, radiometric data would be collected during 45-minute-long balloon ascents to heights of up to $1500 \mathrm{~m}$ above ground level (AGL). A commercial tethered-balloon meteorological-sensing package carried just below the balloon provides supplementary meteorological data, including pressure, temperature, humidity, wind speed, and wind direction.

\section{Modeling of a Tilted Net Radlometer}

The radiometers carried on the ietheriine must be exposed in such a way that the radiometric influ. ences of the balloon, tetheriine, and other obstructlons are negligible. Calculations were performed to estimate the radiometric influence of the balloon on the measurements made at the Sky Platform. These calculations suggest that the short-wave radiometric influence of the balloon will be negli. gible as long as the radiometer is not directly shaded by the balloon and the platiorm is 12 or more balloon diameters (i.e., 30 m or more) below the $7.5 \cdot \mathrm{m}^{3}$ balloon. The inirared radiometric influence of the balloon has not yot been calculated.

A mathematical model of the radiometric signal from a tilted net radiomater was developed to ald in the engineering specifisation of the Sky Platform. This model, which follows the work of Arnfleld (1982), determines the long-wave and short-wave irradiances on the upper and lower sensing elements of a tilted net radiometer by angular integration of long-wave and short-wave radiance distributions from the sky and ground. Various published radiance distributions are uscd in this Integration. Using tilt and azimuth angle probability disiributions, the model can simulate instrument output from oscillations that may be produced by the mean wind, turbulence, or the dynamic response of the tetherline.

The model shows that a nori-level net radiometer can be seriously in error during daytime, when the short-wave radiation stream is directed, but is less susceptlble to error during nighttlme ascents, when the long-wave radiation stream is more isotroplc. The model also shows that oscillations of the radiometer about the horizontal are of less concern than a mean ilit angle. If is therefore important to ensure that the platform is balanced so that wind drag does not produce a mean tilt angle. However, if the ilt and azimuth angles of the radiometer are recorded, partial theoretical correction of the errors is possible. 


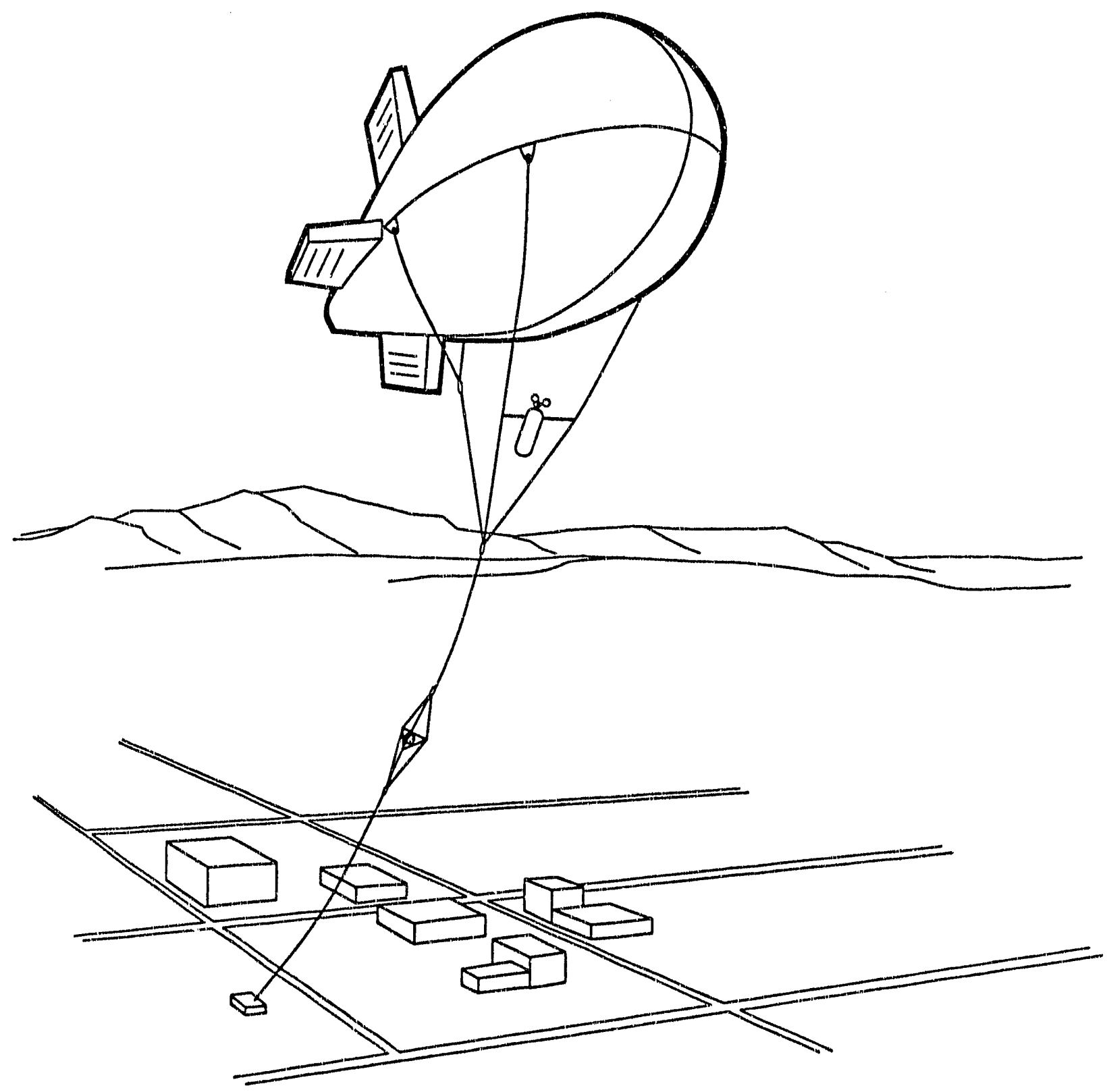

FIGURE 1. Artist's Conception of Tethered-Balloon Radiometer Profiler. A connmercial metaorological-sensing package is carried just under the balloon, and the Sky Plattorm is carried on the tetherline $30 \mathrm{~m}$ or more below the balloon. 


\section{Design of the Stable Platform}

A prototype Sky Platform, as demonstrated at the ARM Science Team Meeting in October 1991, is illustrated in Figure 2. The platform is an equilateral triangle, approximately $65 \mathrm{~cm}$ on a side, formed from aluminum tubing. A mount for radiometric and horizontal sensors is supported at the center of the triangle. The Sky Platform is carried within a 3-m segment of the tetherline that comprises three individual cords at a point $30 \mathrm{~m}$ or more below the balloon, as shown in Figure 1. The fixed corner of the Sky Platform is attached to one of the cords at the center of the 3-m-long section, while the other two corners are attached to the other two cords through pulleys that are driven by small electric motors. An automatic control loop keeps the platform level by interrogating the horizontal sensors (accelerometers) on the Sky Platform and driving the motors, gears, and pulleys at the two mobile comers of the triangle. A flux gate magnetometer provides information on the platform heading.

The Sky Piatform will carry a number of broadband radiometric sensors that are within the weight limitations imposed by the lifting capacity of the balloon. Initial observations will be made using modified net radiometers and/or a silicon cell

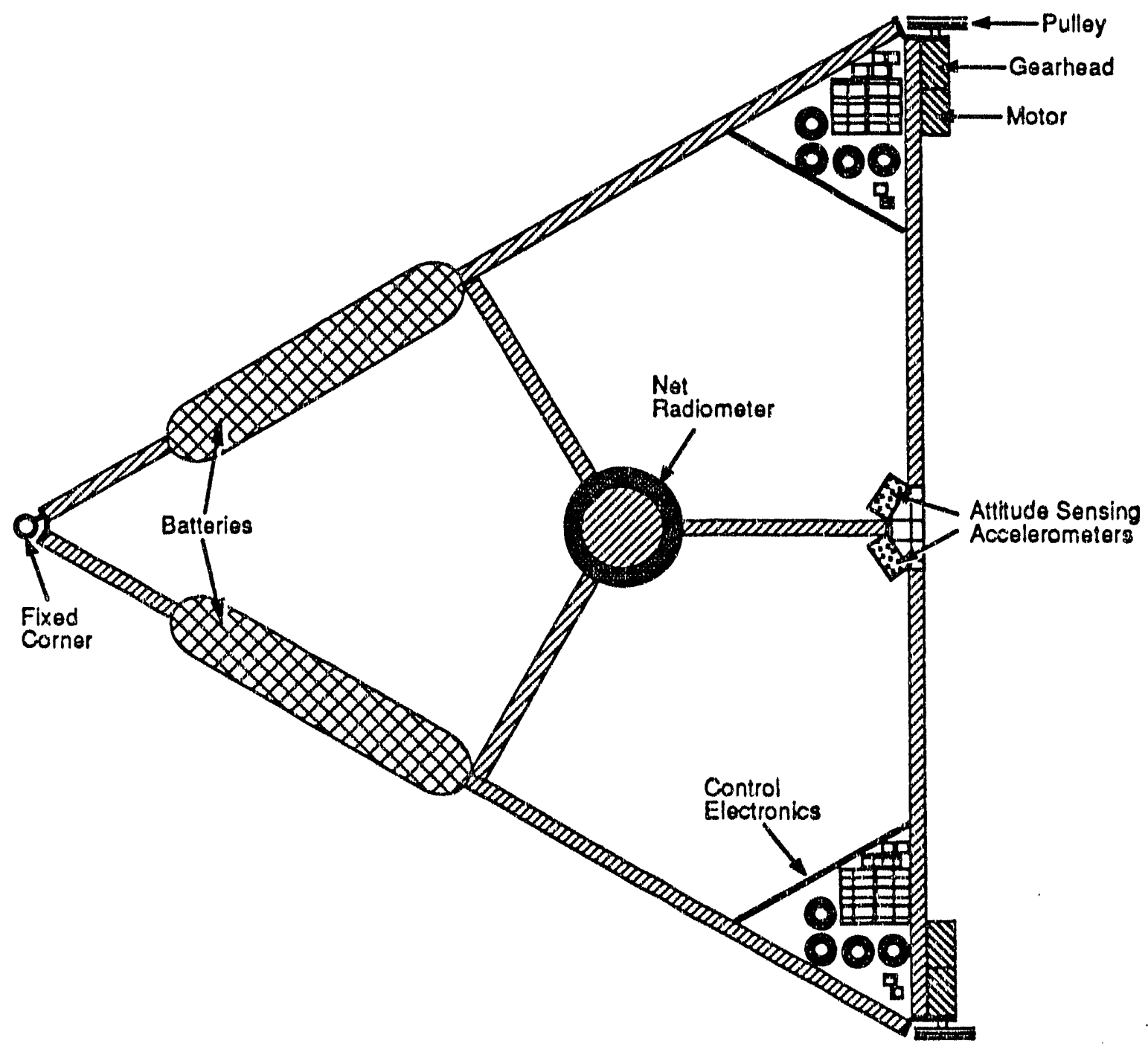

FIGURE 2. Layout of the Problype Sky Platform. 
pyranometer. Modified net radiometers were procured in FY 1991.

\section{Design of the Motion Sensing Platform}

To collect data on the full range of platform motions, including lateral and angular accelera. tions, lateral and angular velocities, and angular orientation, a second airborne platform, the MSP, has been developed to fly in place of the Sky Platiorm. This plattorm is built on a triangular frame identical to the one for the Sky Platform, but the MSP carries no radiometric sensors, control loop, or leveling motors. Rather, the MSP is instrumented to measure the motions to which the Sky Platform will be subjected, and the data obtained will be used in the final design of the control loop and structural elements of the Sky Platform. An array of miniature solid-state accelerometers collects the raw data from which balloon motions are determined.

\section{Flight Testing}

Two flight tests of the MSP were conducted during FY 1991, using an electrical cable suspended from the balloon-borne MSP and a personal computerbased data acquisition system on the ground. However, the heavy electrical cable appeared to affect the dynamic response of the balloon tetherline system, so further tests using a lightweight on-board data acquisition system will be necessary.

\section{Future Work}

The following major tasks are planned in FY 1992:

- The tilted radiorneter model will be tested using radiometric observations collected in a special series of fleld measurements.

- An on-board data acquisition and storage capability will be developed for both the MSP and the Sky Platform.

- A flux gate magnetometer will be installed on the Sky Platiorm.
- A small attitude or rate gyroscope will be installed on both the MSP and the Sky Platform to determine the accuracy of tilt measurements using our present accelerometer method. It will be used to demonstrate the efficacy of the control-loop-stabilized platform.

- Flight tests will be performed during FY 1992 to determine and improve the performance of the prototype MSP and Sky Platform.

- Further effort will be spent on evaluating the performance of various level sensors. We will also investigate the optimal placement of accelerometers on the MSP and methods for distinguishing angular and lateral accelerations.

A final stage in the instrument development program, to be initiated in FY 1993, will be to test radiometric profiles obtained using the Sky Platform against those from an instrumented tower and to strengthen all components of the tethered. balloon system so that it can be run routinely at the ARM Cloud and Radiation Testbed sites. Operating characteristics and operating limits of the instru. ment system must be determined, so that the data can be properly interpreted and safety and operational requirements can be met.

\section{Reference}

Arnfield, A. J. 1982. "Estimation of Diffuse Irradiance on Sloping Obstructed Surfaces: An Error Analysis." Archives for Meteorology, Geophysics, and Bioclimatology, Series B, 30:303-320.

\section{Point-Area Relationships for Global Climate Models}

\section{J. C. Doran}

The objective of this project is to develop methods for relating values of surface fluxes of sensible and latent heat measured at one or more points to area. average values of fluxes that are appropriate for 
use in general circulation models (GCMs). In papticular, we are interested in testing and improving parameterization schemes used in GCMs that describe area-average fluxes in terms of mean quantities, such as air temperatures, surface temperatures, and wind speed. Because surface fluxes of heat and moisture play crucial roles in driving atmospheric circulations, determining ver. tical profiles of water vapor, and forming clouds, it is essential that GCMs be able to represent these processes efficiently and accurately. For that reason, this project is an important component of DOE's Atmospheric Radiation Measurement (ARM) Program.

Application of a combination of field and numerical experiments to address the issue of subgrid-scale parameterizations has been proposed, and in FY 1991, investigators participated in a major field program to collect data needed for the study.

\section{Fleld Study}

During May and June 1991, PNL organized and directed a field study in northeastern Oregon. Participants included scientists from Argonne National Laboratory and Los Alamos National Laboratory, who had also received funding through the ARM Program to pursue objectives closely related to those of this project. In addition, researchers from other institutions participated, including several from the National Oceanic and Atmospheric Administration's (NOAA) Atmospheric Turbulence and Diffusion Division, which had joined PNL in proposing this work to DOE.

The field site chosen featured strong contrasts in surface fluxes over adjacent tracts of land. A steppe area was bordered on the east, northeast, and west by extensive areas of irrigated farmland. The steppe was characterized by large fluxes of sensible heat but small fluxes of latent heat, while the farm areas featured large latent heat fluxes and small sensible heat fluxes. An array of surface flux measurement stations, using eddy correlation or
Bowen ratio energy balance techniques, was de. ployed along a path roughly paraliel to the prevailing winds in the area. These instruments were supplemented with balloon-borne sensors, sodars, and optical scintillation wind and turbulence sensors. An instrumented aircraft flew over the area to measure mean winds and temperatures, radiating surface temperatures, and fluxes of heat, momentum, moisture, $\mathrm{CO}_{2}$, and $\mathrm{O}_{3}$; approximately 91 hours of flight time were achieved. Figure 1 shows a schematic diagram of the experimental area and the instrument locations.

\section{Future Work}

Only a preliminary look at the data was possible in FY 1991, but several interesting cases were obtained during the experiment. The marked contrasts in surface fluxes between the semiarid steppe and the irrigated farmland produced noticeable differences in mean and turbulent atmospheric properties. These differences will be analyzed for their implications for representing area-averaged fluxes in terms of mean quantities, such as wind speed and temperature differences between the surface and the air. Indications of secondary circulations arising from the thermal contrasts of the two basic land types are expected to complicate the analysis.

A second experiment in the same area is tentatively planned. In this experiment, additional instrumentation would be deployed over the farm area to characterize its small-scale variability more completely and to study its effect on the appropriate flux to be assigned to the irrigated area. The flux variations over the farm are expected to be relatively small compared to the differences between the farm and steppe and should be closer to those expected over the ARM Program's Cloud and Radiation Testbed (CART) site in the Great Plains. The results will provide the opportunity for studying and describing surface flux variations on scales on the orders of $1 \mathrm{~km}$ and $10 \mathrm{~km}$. 


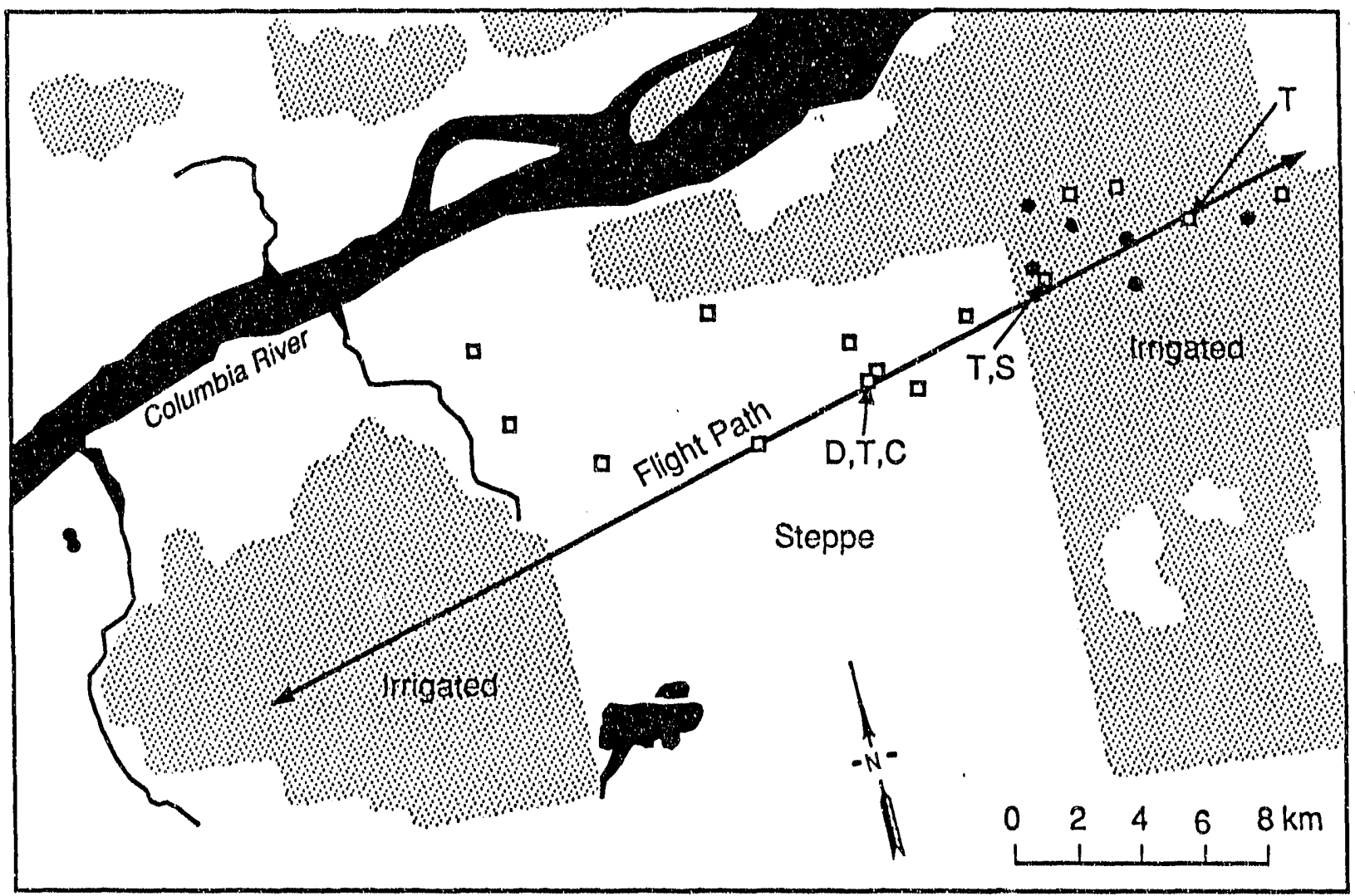

FIGURE 1. Schematic Diagram of Experimental Area. Black areas are bodies of water, stippled areas are imigated familand, and the remaining area is steppe. Squares are eddy correlation instruments, circles are Bowen ratio energy-balance stations, $D$ denotes threecomponent Doppler sodtar. T marks bocations of tethered-balloon launches, $C$ is the location for the converyence ineasurements, and $S$ shows location of minisodars for measurements of intemal boundary-layer development. The primary flight path for the instrumented aircraft is also shown.

\section{Characterization of Cloud/Aerosol Interactions with Solar and Long- Wave Radiation}

\author{
N. S. Laulainen, J. J. Michalsky, (a) L. C. Harrison,(a) \\ N. R. Larson, and J. L. Berndt
}

The Quantitative Links component of DOE's Expanded Carbon Dioxide Research Program attempis to quantify linkages between changes in atmospheric composition and the temperature of the planet. While significant efforts have been made to understand expected changes in climate that may result from an increase in $\mathrm{CO}_{2}$ and other greenhouse gases, there has also been a growing recognition of the role that clouds and aerosols have in the regulation of the planetary energy balance by interacting with incoming solar radiation

(a) Stato University of Now York at Albany. and outgoing infrared radiation. Clouds are important because at any given time they mask about half of the earth's surface. Aerosols can affect climate both directly, through reflection of solar radiation away from the planet, and indirectly, by acting as condensation nuclei for the formation of clouds and altering the structure and optical properties of clouds. Better understanding of these sometimes climatically opposing effects is needed for improving parameterizations of radiative transfer in cloudy, furbid atmospheres for use in general circulation models (GCMs) and other related models.

The Network-Based Solar and Meteorological Characterization of Cloud-Radiation Interaction Project is an element of research in this poorly understood area. The objective of this project is to investigate how clouds and aerosols interact with long-wave 
and short-wave radiation to regulate the heating of the planet. To understand how cloud- and aerosolinduced radiative effects vary in time, with cloud structure and type, for a mid-latitude continental area, a nine-station network is being established in the midwestern and eastern United States. Each station is equipped with a uniquely designed multifilter rotating shadowband radiometer (MFRSR) to measure direct normal, diffuse horizontal, and global horizontal irradiance in six narrow-wave. length passbands. An additional measurement in a broad passband covering a large portion of the short-wave spectrum will approxirnate total shortwave irradiance. Measurements of downwelling long-wave radiation will be made with a broadband infrared radiometer or pyrgeometer, Local ground albedo measurements will be made primarily to identify the presence of snow. Standard meteorological measurements of relative humidity, temperature, and rainfall will supplement these radiation measurements. The study is to be conducted over a minimum of a 5-year period.

Specific objectives accomplished during FY 1991 were 1) the acquisition of equipment and instrumentation; 2) the design, fabrication and testing of the MFRSRs; 3) the selection and preparation of the field sites for the study; and 4) the installation of the instrumentation at the field sites. No analy. ses of the data have been performed, as the installation and system checks were just completed near the end of the year. A major advantage of the ex. periment design is that each station can operate unattended, with only periodic maintenance checks by the site operators. The data will be retrieved automatically by means of telephone and modem through a central data-archiving computer system at PNL.

The project is a cooperative effort between PNL and the Atmospheric Sciences Research Center (ASRC) of the State University of New York at Albany (SUNY-Albany).

\section{Instrumentation}

The primary instrument at each site is the MFRSR, developed jointly at PNL. and SUNY-Albany (Figure 1). It is based on an earlier, single-detector version (LeBaron et al. 1989) but incorporates several innovative design changes. One of them
Is a diffuser/integrating cavity. Because interference filters are used with the detectors, it is necessary for the filter/detectors to be mounted at a sufficient distance from the entrance optics to ensure that no light enters the filter at an angle greater than about five degrees from normal. Othenwise, the filter transmittance and wavelength response will deviate from manufacturer specifica. tions. The combination of a diffuser followed by the integrating cavity maximizes the light through the detector. This diffuser/integrating cavity design further reduces system response asym. metries through multiple scattering of the incident radiation.

Another innovation of the MFRSR is the hexa. gonal packing of six interference filter/detectors around the central unfiltered photodiode that serves as the total short-wave detector. Because the light intensities in each narrow band are very small, and the detectors might be affected by external current sources it leads to the signal conditioning circuitry were long, the amplifiers are mounted near the filter/detectors on a cubic circuit board that serves as the detector mounting platform. In addition, the board is insulated and temperature-controlled at about $40^{\circ} \mathrm{C}$. This stabilizes the performance of the electronics and the filters.

In addition to the microprocessor circuit board that controls data acquisition and shadowband motion, another electronics board amplifies and conditions the signals from all other ancillary instruments that feed into the data acquisition board. In total, the measurements include seven measurements each of direct normal, diffuse horizontal, and global horizontal irradiances, and ancillary data on precipitation, relative humidity, outside air temperature, thermopile output from the precision infrared radiometer $(P \mid R)$ representing infrared irradiance plus dome and case temperatures for correcting this measurement, upwelling short-wave irradiance, detector temperature, battery voltage, and reference voltage for the thermistors that are used in all temperature measurement circuits except outside air. The control unit includes the microprocessor circuit board, the signal conditioning board, modem, electrical surge protector, and power supply. The entire system was tested and calibrated in the laboratory and under ambient outdoor conditions at the ASRC. 


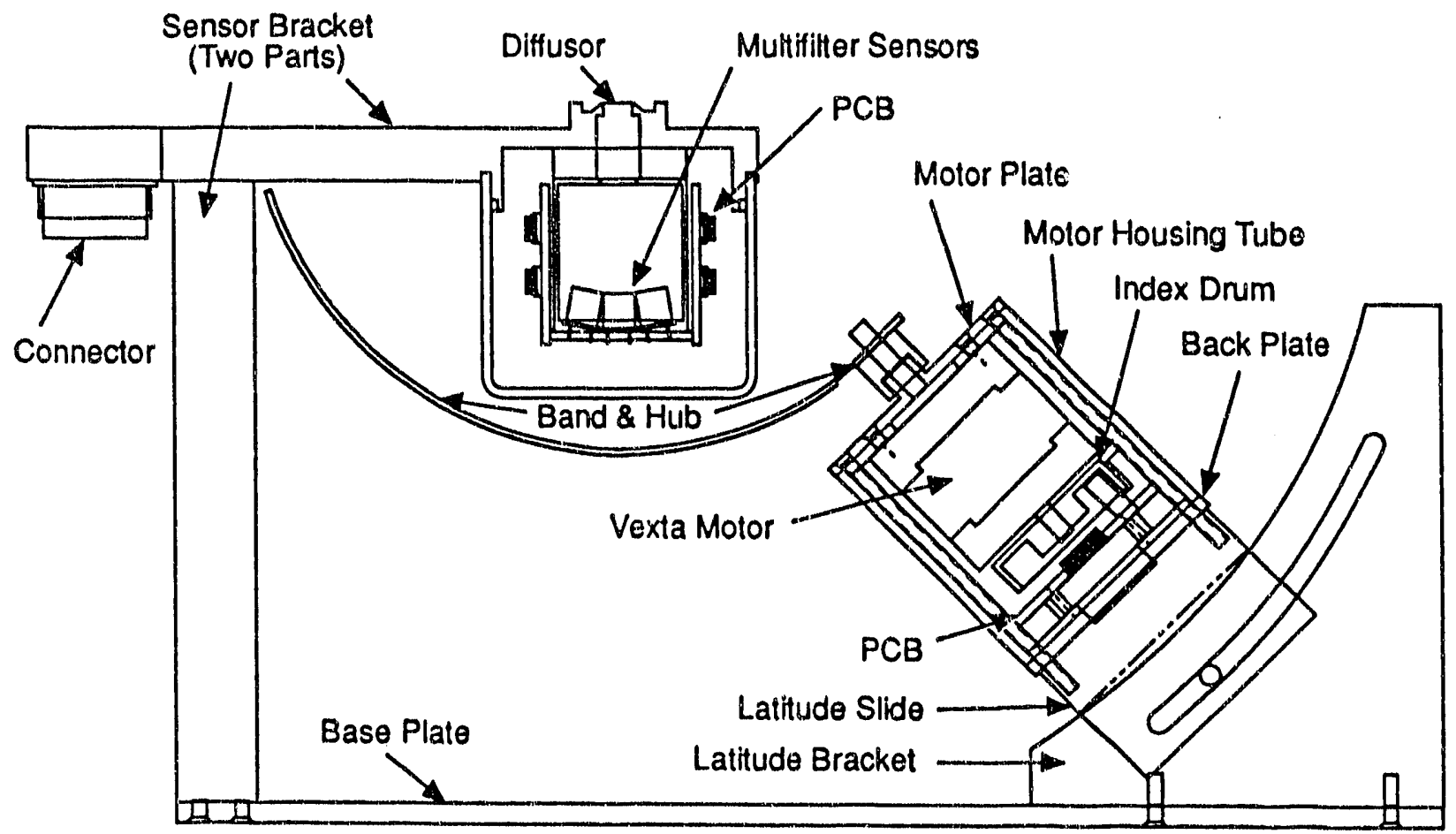

FIGURE 1. Assembly Drawing of the Multifiter Rotating Shadowband Radiometer.

The ancillary instruments installed at the sites include

- pyrgeometer for measuring downwelling infrared radiation between 4 and $50 \mu \mathrm{m}$,

- pyranometer for upwelling shortwave irradiance,

- rain gauge for precipitation rate and amount, and

- weather station for temperature and relative humidity.

In addition, a portable computer, along with a frequency meter for on-board timing calibration and a precision voltage and current source for calibration of current and voltage amplifiers and the analog-todigital converters in the data-acquisition units, are available for instrument maintenance and calibration in the field. An optical radiation calibrator is also being acquired to aid in the calibration of the MFRSR in the laboratory, as well as to facilitate field calibration. Data acquisition, processing, and analysis will be performed on Sun Sparcstation IPC systems, with graphics terminals; these systems are available at both PNL and SUNY-Albany.

\section{Callbratlons and Tests}

An important aspect of proper MFRSR operation is that the receiving optics have a cosine response, i.e., the response decreases as the cosine of the angle of incidence. As part of a separate instrument-development project for the Atmospheric Radiation Measurement (ARM) Program, a cosine test bench was constructed at ASRC that allows measurement of the response from -90 to $+90^{\circ}$ with a step resolution of $0.25^{\circ}$. A normalized response curve for a typical filter/detector is shown in Figure 2 and can be seen to be rearly unity except at high angles of incidence. With this response information, one can correct the direct component. The diffuse contribution at high angles of incidence, while unknown (because the spatial distribution of diffuse radiance is generally not known), is very low because it is weighted approximately by the cosine of the solar-zenith angle. Therefore, the error in global and diffuse horizontal irradiance measurements is small even without correction. Other calibrations involved 1) the amplifier board and analog-to-digital converter using a precision 


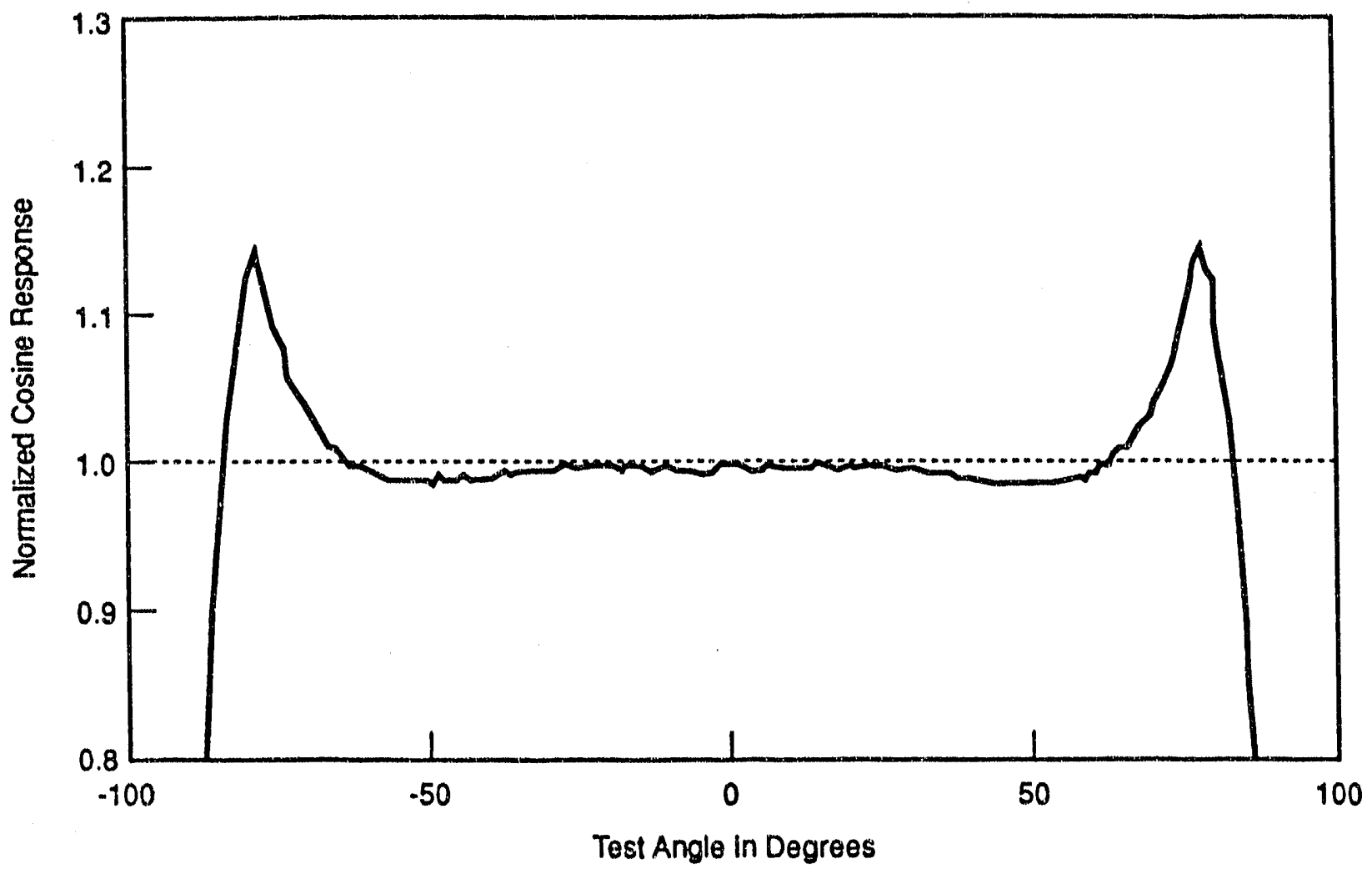

FIGURE 2. Normalized Cosine Respense Curve for a Typical Multifilter Rotating Shadowband Radiometer Filter/Dotector.

voltage and current source; 2) manufacturers' values for precipitation, relative humidity, infrared radiation, and outside air temperature sensors (for the deployment phase); and 3) intercomparison between broadband short-wave radiation instrument and etandard broadband instruments. The filter/detectors will be calibrated and double. checked through instrument calibration in the field as soon as the calibrator is available. Procedures for performing calibrations at each annual visit will be developed during the first half of 1992. An example of data from a MFRSR taken at Rattlesnake Mountain Observatory in southeastern Washington State is shown in Figure 3.

\section{Site Selection and Installation}

Initially, nine sites were selected, but instrumentation has been installed at only eight of them. Selection of the sites was based on availability of electrical power and telephone service, existing research. or monitoring activities, and "regional representativeness," I.e., no influence by local sources of air pollution. The nine sites were

- Ithaca, New York--currently a National Dry Deposition Network (NDDN) and Multistate Atmospheric Power Production Pollution Study (MAP3S! site operated by Cornell University

- Howland, Maine--a remote National Oceanic and Atmospheric Administration-Dry Deposition Research Network (NOAA-DDRN) site operated by the University of Maine

- Pine Grove Mills, Pennsylvania--an ARM Science Team site, in proximity to a MAP3S and a NOAA-DDRN site, operated by Pennsylvania State University

- Oak Ridge, Tennesseo--a NOAA-DDRN slíe operated by the NOAA Atmospheric Turbu. lence and Diffusion Division

- Bluefield, West Virginia--a site with a wellmaintained solar radiation record operated by Bluefield State College 


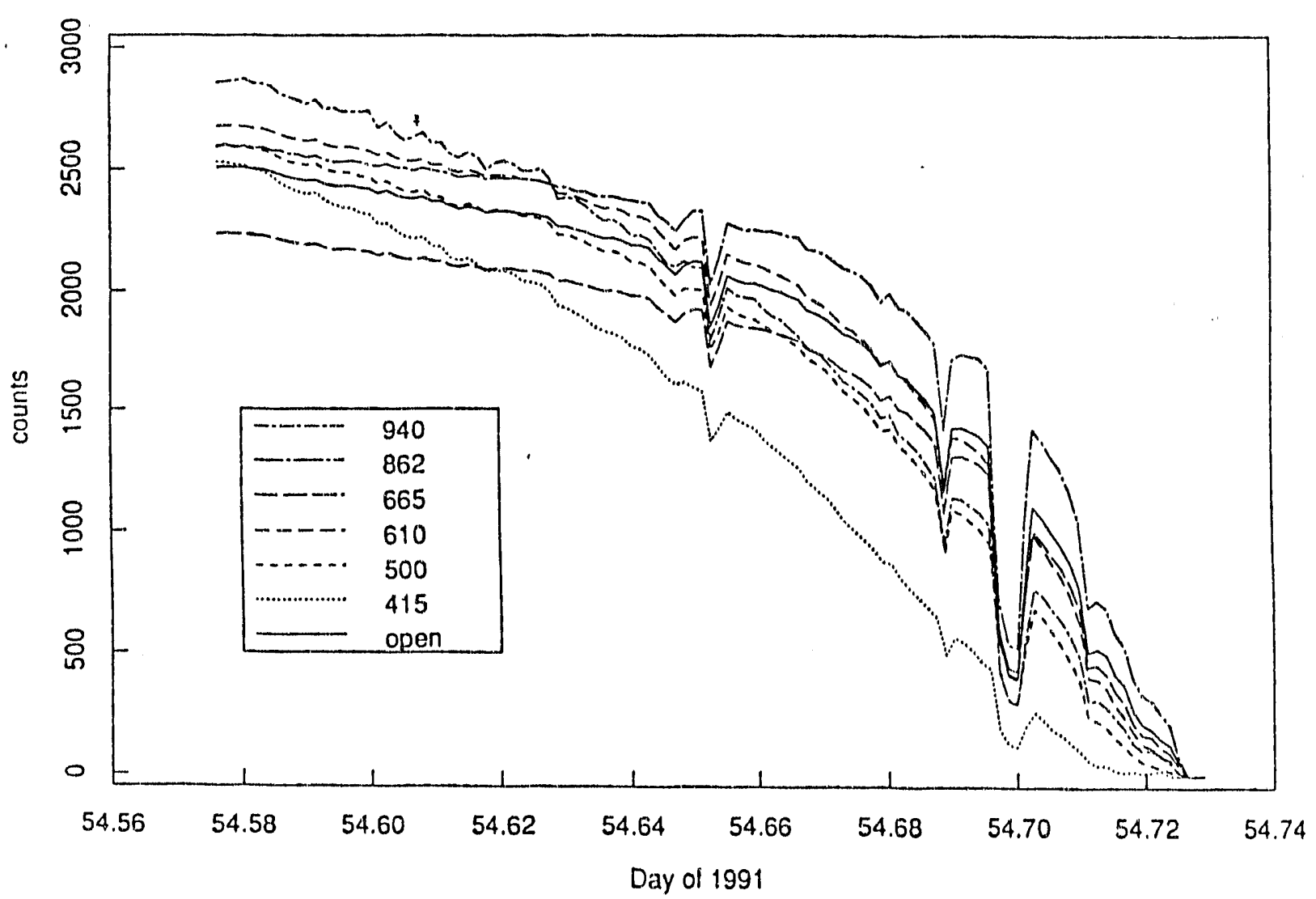

FIGURE 3. Example of Data Taken with the Multifiler Rotating Shadowband Radiometer at Rattlesnake Mountain Observatory.

- Bondville, Illinois--a NOAA-DDRN and MAP3S site operated by the Illinois State Water Survey

- Oxford, Ohio--a NDDN and MAP3S site, with a 10-year solar resource data history, operated by Miami University of Ohio

- Lewes, Delaware--a coastal MAP3S site operated by the University of Delaware's College of Marine Studies

- Huntington Wildlife Forest, Newcomb, New York--a NOAA-DDRN site operated by the State University of New York's College of Environ. mental Science and Forestry.

The Huntington Wildlife Forest site was found to be unacceptable during the installation trip, when it was discovered that the $38-\mathrm{m}$ tower swayed $3^{\circ}$ in azimuth in even light winds. Other sites at the Huntington Wildlife Forest were not acceptable because of the lack of an adequate horizon. A replacement site will be selected in 1992.

\section{Data Acqulsition and Management}

PNL is responsible for primary data collection and management. A PNL-based computer automatically calls each field unit every night to upload the data. An initial set of software for acquiring and processing the data from MFRSR network units was developed and consists of three programs that perform the basic tasks of operating the network and retrieving data, unpacking the data into ASCII format, and sorting the raw unpacked data for each unit by day. Correct mathematical functions for converting the raw output into calibrated engineering units are provided by ASRC/SUNYAlbany. The criteria used for data quality inspection are simple range and singularity checks for the suite of auxiliary instruments connected to the data loggers. The data are then permanently archived at PNL. If the PNL computer goes off-line, a redundant system at SUNY-Albany retrieves the data. 
Once the installation of instruments in the network was completed, the network management program was tested rigorously. Minor revisions to the software removed any computer operating system malfunctions to ensure consistently reliable daily operation. The data system manager performs regular checks of network status. Data are formatted for archiving daily, and file system backups are performed weekly. Analysis software is being evaluated while the data archive is assembled. This procedure allows for active feedback on the suitability of the data-reduction techniques.

The processed data files serve as the master data files to be used by the investigators. The master data files will be available for on-line use by onsite (PNL) investigators. Offsite investigators will be able to receive copies of the master data files from the data system manager via magnetic storage tapes and disks, or via electronic mail.

\section{Data Analysis and Interpretation}

Because the network was installed late in 1991, no analyses of the data have performed. It is expected, however, that several analysis techniques that have been applied to similar data sets can be used in this project. For example, the anal$y$ sis techniques used on stratospheric aerosol data from the El Chichon eruption (Pearson et al. 1988) will be applied to aerosol data from the Mt. Pinatubo eruption. Also, initial work has begun on evaluating analysis software routines that are to be interfaced with the graphics/statistical software package known as "New S."

A paper describing the design and operation of the MFRSR was presented at the Biennial Congress of the International Solar Energy Society (Harrison 1991). In the near term, a paper is planned that describes the cosine test bench and results from measurements on several types of sensors. Another paper will describe automated techniques for reducing direct beam data from the MFRSR for the determination of aerosol optical depth.

\section{Future Work}

Because FY 1991 was spent on getting the instru. mentation into the field, only preliminary looks at test data were possible. From early indications, it appears that the MFRSRs and data systems are performing satisfactorily and that the data will indeed be useful for studying cloud/aerosol effects. As a result of the Mt. Pinatubo eruption in June 1991, there is also a unique opportunity to observe the evolution and decay of the stratospheric aerosol cloud from the eruption. Major efforts in 1992, however, will focus on the analysis and interpretation of network data as a function of meteorological (cloudiness, relative humidity, temperature) and haze (aerosol optical depth) conditions. Tests will be performed on various schemes for characterizing cloud/aerosol effects on radiative transfer with respect to the cloud parameters (cloudiness and cloud brightness) introduced by Perez et al. (1990), cloud and aerosol optical depths, and solar zenith angle. The aim of this project is to extend the statistical sample on cloud/aerosol radiative effects for continental, midlatitude areas beyond what can be accomplished in short, intensive campaigns. The five-year data set should allow investigations of how the frequency distributions in the measured and derived parameters vary from year to year. Additional work will be performed relating the observations from the MFRSR network to similar observations obtained at the ARM Cloud and Radiation Testbed (CART) sites.

\section{References}

Harrison, L. C. 1991. "Multi-Spectral Automated Rotating Shadowband Radiometry in the Atmos" pheric Radiation Measurements (ARM) Program." In Proceedings of the Biennial Congress of the International Solar Energy Society Meeting. eds. M. E. Arden, S. M. A. Burley, and M. Coleman, pp. 893-898, Pergamon Press, New York.

LeBaron, B. A., J. J. Michalsky, and L. C. Harrison. 1989. "Rotating Shadowband Photometer Measurement of Atmospheric Turbidity: A Tool for Estimating Visibility." Atmospheric Environment 23:255-263.

Pearson, E. W., B. A. LeBaron, and J. J. Michalsky. 1988. "Decay of the El Chichon Perturbation to the Stratospheric Aerosol Layer: Multispectral Ground-Based Radiometric Observations." Geophysical Research Letters 15:24-27.

Perez, R., P. Ineichen, R. Seals, J. Michalsky, and R. Stewart. 1990. "Modeling Daylight Availability and Irradiance Components trom Direcl and Global Irradiance." Solar Energy 44:271-289. 
The Computer Hardware, Advanced Mathematics and Model Physics (CHAMMP) Climate Modelling Program

\author{
D. C. Bader, M. C. MacCracken, (a) and R. C.
} Malone(b)

Improved methods for predicting the world's future climate and the potential olimate change caused by human activities are needed to guide formulation of domestic and international energy policies. The World Meteorological Organization (WMO)/United Nations Environment Programme's Intergovernmental Panel on Climate Change (IPCC) stated in its 1990 scientific assessment (IPCC 1990) that "Improved prediction of climate change depends on the development of climate models, which is the objective of the climate modelling programme of the World Climate Research Prograrnme." Current general circulation models (GCMs) of the atmosphere and ocean that form the basis for climate projections are useful, but nonetheless inadequate in many ways. The deficiencies include the limited treatment of interactions among the atmosphere, ocean, cryosphere, and land surface; the inadequate representation of such key processes as radiative transfer and cloud development; and relatively coarse spatial resolution. The demands that must be met by future climate models have been established in the development of the U.S. Global Change Research Program (USGCRP), and their impirtance is evidenced by the designation of climate modeling and prediction as one of the program's four highpriority integrating themes (CEES 1991). DOE's participation in the USGCRP is directed at accelerating progress toward more reliable and accurate predictions, with reduced uncertainty, of 10- to 100-year climate change on regional scales.

Two primary factors will speed the development of better climate models. First, the scientific basis on which the various submodels of climatic processes are formed must be improved and verified. This is the goal of many of the USGCRP experimental and modeling activities, including DOE's Atmospheric Radiation Measurement (ARM) Program and the Program for Climate Model Diagnosis and Intercom. parison (PCMDI). Second, advances in computer

(a) Lawrence Livermore National Laboratory.
(b) Los Alamos National Laboratory. technology, and the accompanying advances in numerical algorithms and software that use the technology, must be applled to the climatic modeling problem. Progress in these areas will be sub. stantially enhanced by the U.S. High Periormance Computing and Communications (HPCC) Program. The DOE Computer Hardware, Advanced Mathematics and Model Physics (CHAMMP) Program will bulld on these research programs by providing an interdisciplinary focus, which has been identifled as a computational "Grand Challenge" to be addressed by the HPCC Program (CPMES 1991).

\section{History}

During 1990, a program plan for CHAMMP was drafted, distributed for review, and published. The broad objective was development of a program to rapidly apply the recent and projected advances in massively parallel computer architectures to the problem of climate modeling. Within 10 years, a computer may be avallable that will perform modeling calculations at a rate that is $10^{3}$ to $10^{4}$ times faster than is possible today. As part of the review process, a long-term technical oversight committee recommended that more powerful climate models would not be useful policy tools unless more emphasis was placed on research into the theoretical limits of climate predictability.

To get a fast start on the problem and to keep abreast of the fast evolution in computer hardware, several 18-month pilot projects were slarted in early 1990 at DOE laboratories and the National Center for Atmospheric Research (NCAR). Collaborative piojects among climate modelers, mathematicians, and computer scientists in different institutions were encouraged. Many of these projects form the basis for current CHAMMP research activities. A compilaticn of final reports from. the pilot activities is available (DOE 1991).

\section{Objectlve}

The goal of the CHAMMP Program is to develop, verify, and apply a new generation of climate models within a coordinated framework that

- Incorporates the best avallable scientific and numerical approaches to represent physical, biogeochemical, and ecological processes,

- makes full use of the hardware and software capabilities of new computer architectures, 
- probes the limits of climate predictability, and

- can be used to address the problem of understanding the greenhouse climate issue through the ability of the models to simulate time. dependent climatic changes over extended times and with regional resolution.

To meet this goal, the CHAMMP program will be conducted in three phases over the next 10 to 12 years. The initial phase will last from 2 to 4 years. The program's primary emphasis is the transfer of existing atmospheric and ocean GCMs to massively parallel computing platiorms and the initiation of a research program to develop new methods and explore predictability issues for climate modeling on time scales of the decade to the century. The second phase will include the development of useful coupled atmosphereocean climate models. This phase will overlap with the end of the first phase and will last 3 to 5 years. In the third and final phase of the program, fully coupled climate system models with even faster performance will be developed and available for conducting long simulations of climate change on decade to century time scales with regional spatial resolution. Research results on the limits of climate predictability will give more definitive estlmates of model uncertainty and will be useful in interpreting model output for policy formulation.

\section{Initlal Research Focus}

Four research areas have been identifled ior the CHAMMP Program's first phase:

- understanding of the theoretical limits to climate predictability on decade to century time scales,

- development of new algorithms and techniques for atmospheric and ocean GCM modeling that exploit massively-parallel computers,

- development of more accurate process parameterizations that fit with model resolution, and

- improvements of computer software to dramatically increase model throughput and performance.

Proposals were solicited in these areas from private industry and universities. Once again, collaborative, multidisciplinary projects were encouraged. Eight projects were selected from 48 proposals to recelve research grants totaling over $\$ 1 \mathrm{M}$ for $\mathrm{FY} 1991$. An additional $\$ 1 \mathrm{M}$ will soon be awarded in external grants from the same pool of proposals. A separate proposal solicitation for DOE and other government laboratories re. sulted in selection of eight projects from DOE laboratories and one joint project from NCAR and the Navy from 39 proposals submitted.

Collectively, the laboratory, university, and industry projects span the research areas outlined above and provide a broad and deep base of research talent on which to build the program. Principal investigators from these projects will form the CHAMMP Science Team. In addition to performing research, the Science Team will provide input to DOE on scientific priorities for the CHAMMP Program to enable the program to meet its objectives. Meetings and workshops will be designed to encourage further collaborations among Science Team members as their research progresses.

\section{Model Development Program}

The model development component of the CHAMMP Program is designed to be evolutionary and flexible to achieve short-term results. It will provide a support structure for collaborations both within the CHAMMP Program and with other national and international climate modeling programs. These collaborations are most effective at the technical level, as DOE laboratory investigators work joiritly with modelers at other institutions, such as NCAR and the Geophysical Fluid Dynamics Laboratory (GFDL), on problems associated with the development of climate models on massively parallel computers. To accelerate progress in the field, advances from research done by the Science Team will be implemented swiftly through a framework supported by the model development program and made available to the larger climate modeling community.

The primary focus of the initial model development effort is the full implementation of the NCAR spectral model and two finite-difference atmospheric models [the University of California, Los Angeles (UCLA) - Colorado State University (CSU) GCM (Randall et al. 1985; Arakawa and Lamb 1977) and the GFDL SKY.HI GCM (Fels et al. 1980)] on parallel architectures. Plans are also proceeding to port three ocean models, the Semtner-Chervin model (Semtner and Chervin 1988), the GFDL's new Modular Ocean Model (Pacanowski et al. 1991), and the German isopycnic-coordinate global ocean model used at Scripps Institution of Oceanography 
(Oberhuber 1990) to the parallel machines. In all cases, model developers and users are working with CHAMMP team members to maintain the codes' integrity through the transfer.

Two programming strategles are being adopted to port these models to parallel scientific computers. In the first, a single programming thread is exe. cuted simultaneously on all processors. Such a "data parallel" programming style is conveniently expressed with the array syntax features of the new FORTRAN 90 language standard. In the second, each processor has its own program thread and information is explicitly passed between processors through coding instructions. The architectures that exploit these two programming models may converge as advences are made in the hardware. Nevertheless, CHAMMP investigators make use of both so that they understand what each programming style provides in terms of ease of code development, debugging, efficiency, portability, and compatibility with language standards.

Through DOE's component of the HPCC Program, the CHAMMP Program will provide access and computer time on leading-edge computer platforms to Science Team members and collaborators. Model development team members at DOE laboratories will work with scientists addressing other "Grand Challenge" applications and will help guide the development of enabling techriologies that are common to many of these computational problems. These technologies include tools for data analysis and display, programming language standards, mass data storage and retrieval, and high-speed distributed computing applications.

\section{References}

Arakawa, A., and V. R. Lamb. 1977. "Computational Design of the Basic Dynamical Processes of the UCLA General Circulation Model." Methods in Computational Physics 17:174-265.

CEES (Committee on Earth and Environmental Sciences). 1991. Our Changing Planet: The FY 1992 U.S. Global Change Research Program. Committee on Earth and Environmental Sciences, Washington, D.C.

CPMES (Committee on Physical, Mathematical, and Engineering Sciences). 1991. Grand
Challenges: High Performance Computing and Communications. The FY 1992 U.S. Research and Development Program. Committee on Physical, Mathematical, and Engineering Sciences, Washington, D.C.

Fels, S. B., J. D. Mahlman, M. D. Scwarzkopf, and R. W. Sinclair. 1980. "Stratospheric Sensitivity to Perturbations in Ozone and Carbon Dioxide: Radiative and Dynamical Response." Journal of the Atmospheric Sciences 37:2265-2297.

IPCC (Intergovernmental Panel on Climate Change). 1990. Climate Change. The IPCC Scientific Assessment. Cambridge University Press, Cambridge, England.

Oberhuber, J. M. 1990. Simulation of the Atlantic Circulation with a Coupled Sea Ice - Mixed Layer, Isopycnal General Circulation Model. Report 59, Max Planck Institut für Meteorology, Hamburg, Germany.

Pacanowski, R., K. Dixon, and A. Rosetti. 1991. A GFDL Modular Ocean Model User's Guide, Version 1.0. GFDL Ocean Group Technical Report No. 2, Geophysical Fluid Dynamics Laboratory, Princeton, New Jersey.

Randall, D. A., J. A. Abeles, and T. G. Corsetti. 1985. "Seasonal Simulations of the Planetary Boundary Layer and Boundary Layer Stratocumulus Clouds with a General Circulation Model." Journal of the Atmospheric Sciences 42:641-676.

Semtner, A. J., and R. M. Chervin. 1988. "A Simulation of the Global Ocean with Resolved Eddies." Journal of Geophysical Research 93:15502. 15522, 15767-15775.

U.S. Department of Energy (DOE). 1991. CHAMMP Pilot Project Final Report. U.S. Department of Energy, Washington, D.C.

\section{Carbon Dloxide Ocean Research}

J. P. Downing, W. E. Asher, D. W. Denbo, E. D. Skyllingstad, and M. C. Richmond

The objective of the $\mathrm{CO}_{2}$ Ocean Research project is to improve understanding of the role of the ocean in $\mathrm{CO}_{2}$-induced climate change. Staft at 
both PNL and the Battelle/Marine Sciences Laboratory (Battelle/MSL) provide technical support to the Environmental Sciences Division (ESD) and conduct research into the exchange of $\mathrm{CO}_{2}$ at the air-sea interface, deep water formation (in ocean general circulation models), and surface-layer processes, including air-sea exchanges of mass, heat, and momentum. Direct support io ESD includes development of aqueous $\mathrm{CO}_{2}$ standards and administration of the science team for the Global Survey of $\mathrm{CO}_{2}$ in the Oceans project.

For the $\mathrm{CO}_{2}$ Ocean Research project, FY 1991 progress included

- further study, Including laboratory experiments, of the relationship between ocean whitecap coverage and the air-sea exchange of $\mathrm{CO}_{2}$,

- continued study of deep convection in the ocean,

- development of a iwo-dimensional model of convection, and

- numerical experiments on ocean surface-layer dynamics.

In addition, the project provided technical oversight for the development of advanced sensor technologies for ocean measurements for DOE.

\section{Activities and Accompllshments}

\section{Alr-Sea Exchange of Carbon Dloxide}

Laboratory Experiments. Extensive labora. tory experiments to study the effect of bubbla plurnes on gas exchange in the Whitecap Simula. tion Tank (WST) were completed during FY 1991. These are described briefly below.

In the oxygen transport experiments, the effects of seawater temperature on bubble-plume-governed gas exchange were investigated for oxygen eva. sion and invasion.

In a series of carbon dioxide transport experiments, a gas chromatograph equipped with a thermal-conductivity detector was used for meas. uring gas-phase $\mathrm{CO}_{2}$ concentrations. Combined with measurements of $\mathrm{pH}$ in the WST, this instru. ment allows $\mathrm{CO}_{2}$ irvasion and evasion to be meas. ured as a function of water temperatura.
Preliminary measurements of depth-dependent bubble-size distributions were made with the laser phased-doppler anemometer (LPDA) in the WST. Bubble populations produced in the WST by the tipping-bucket method were compared to bubble populations generated by oceanic breaking waves. The LPDA bubble measurements were also used to model air/water gas transport in the WST.

Field Experiment. The Nantucket Shoals microwave/whitecap experiment was conducted In February 1991, in collaboration with E. C. Monahan and P. S. Smith. Two variables were measured simultaneously over Nantucket Shoals ( $30 \mathrm{nmi}$ south of Cape Cod) from an aircraft using a high-resolution video camera and a $19 \cdot \mathrm{GHz}$ dualpolarization radiometer. Dr. Smith was responsible for analysis of the passive microwave data and Dr. Monahan analyzed the video records for white. cap coverage.

New Facllitles/Instrumentation. To further expand our research capabilities in the area of air/sea gas exchange, we have

- Installed and calibrated an LPDA for measuring aqueous-phase turbulence velocities and bubble-size distributions in a WST.

- Built a second laboratory with a WST to be used for bulk-phase chemical studies. Use of this laboratony will permit concurrent chemical and optical/spectroscoplc measurements while minimizing potential safety problems with the LPDA high-power laser.

- Bullt a purgo-and-trap gas chroinatograph system for dirrethylsulfide (DMS) analysis. This system will allow lurther measurements for the radiatively important trace species DMS and will be used to study evasion rates of DMS as a func. tion of temperature.

\section{Deep Convectlon}

Construction of a two-dimerisional convection model that uses the nonhydrostatic, Boussinesq, Incompressible Navier-Stokes equations was compieted. The model resolves iurbulent eddies and includes thin effects of sub-grid motlons using a sophisticated furbulent kinetis energy (TKE) 
model. It was necessary to use this model to compute the transport of temperature, salinity, TKE, and tracers without generating numerical artifacts.

Results from two simulations performed using oceanic temperature-salinity profiles taken in regions where deep convection occurs were presented at the 1991 IUGG/IAPSO meeting in Vienna, Austria.

The first simulation was initialized with data taken in January 1987 from the Medoc region of the Mediterranean Sea, the second with dala taken during the winter of 1988 in the Greenland Sea. Analysis of the two temperature-salinity profiles indicates that the Greenland Sea profile is more likely to become thermobarically unstable after cooling than the Medoc profile.

From these simulations we have learned that plumes are much more efficient at transporting heat than turbulent eddies, and that when plume formation ceases, the heat fluxes for the Medoc and the Greenland Sea are similar in magnitude. These results have provided new insight about the importancs: of thermobaric instabilities in deep water formation.

\section{Surface Mixed Layer (Two-Dimenslonal Model)}

To adapt a deep convection model to the surface mixed layer (SML) problem, an open lower boundary condition was needed because of the limited depth of the surface layer. The open lower boundary also allowed for vertical propagation of internal gravity waves so that wave energy would not in. crease over time as a result of wave reflection. The boundary we selected is a version of the radiative method devised by Klemp and Durran (1983). Their method is widely used in atmospheric models of mountain waves where the upper boundary must allow similar gravity wave propagation. Other features added to the two-dimensional model specifically for the SML research are the inclusion of vertical shear in the horizonial velocity, surface wind stress, and the parameterization of turbulent energy flux at the model top.

Simulations of the SML were performed for two sites: one near the Bahamas using measurements from Shay and Gregg (1986), and the other from an equatorial location reported on by Moum et al. (1989). The Shay and Gregg data represent a case of shallow convection $(100 \mathrm{~m})$ in a region with very small horizontal current velocities. These measurements are ideal for testing the model's ability to simulate purely convective mixing. The Moum et al. data represent a more challenging problem involving convective interaction with a strong thermocline shear zone and, to date, we have not been able to simulate these intricate processes.

The model reveals that the evolution o: mixing begins with convection at the surface caused by nighttime cooling and that convective plumes interact with the underlying thermocline when Internal waves are generated. During daylight hours, surface heating suppresses convection, leading to significantly reduced mixed-layer eddy energy and wave growth. The model agrees qualitatively with measurements of turbulent kinetic energy dissipation taken by Shay and Gregg (1986).

A significant problem with the two-dimensional results concerns the depth of the surface mixed layer during the daytime heating period. The observed surface layer exhibits a 20-m mixed layer throughout the day. In contrast, the model generates a strong temperature increase at the surface without significant downward heat transport. The $20-\mathrm{m}$ depth of the observed mixed layer is likely to be a result of Langmuir circulations and surface turbulence caused by wave motion. The model cannot simulate these effects because of its two. dimensional structure. These results indicate that a three-dimensional model is necessary to accurately simulate important mixing processes such as Lanymuir circulations.

Many of the same processes may be active in the vicinity of the equatorial undercurrent. For example, the generation of internal waves by colnvection could lead to unstable gravity wave modes in the strong vertical shiear associated with the equatorial undercurrent. We plan to continue modeling the equatorial region to test model performance for regions with strong vertical shear in the nearsurface current. 
Based on the FY 1991 experiment, we have better estimates of vertical eddy viscosities in convectively mixed surface layers and of entrainment at the mixed-layer base. In addition, the simulations provided model data needed to complete an accurate kinetic energy budget for the ocean surface.

\section{Plans for Future Research}

\section{Alr-Sea Exchange of Carbon Dloxlde}

Laboratory and field experiments are planned for FY 1992 to refine the empirical model and improve understanding of the mechanisms by which bubble plumes promote gas transport.

Laboratory Experiments. Measurements using phased-doppler anemometry will include bubble-size spectra and turbulence velocities in the WST as a function of water temperature. The results will be used in models of bubble-mediated gas exchange.

Additional gas transport experiments will be performed using the gas chromatograph.

A DOE-owned coulometer, on loan from Brookhaven National Laboratory, will be used to measure $\mathrm{CO}_{2}$ gas-exchange rates in the WST. The coulometer will provide faster measurements and more accurate analyses than the chromatograph.

Fleld Experlments. Planning will continue for experiments to be conducted in a large outdoor wave basin. The basin will allow a known wave field to be generated with concurrent measurements of several variables. This project will be conducted in collaboration with P. S. Smith and E. C. Monahan.

\section{Deep Convection}

Two-Dimensional Model. Our experiments with the two-dimensional convection model led us to believe that deep convection can be treated in ocean general circulation models by a one. dimensional parcel model algorithm, as is done in atmospheric models. Planned three-dimensional experiments should provide the data required to devolop an accurate, one-dimensional parcel model to be included in ocean general circulation models to produce realistic quantitios of dense water at reasonable depths.
Three-Dimenslonal Convectlon Model. The numerical methods developed for and tested with the two-dimensional model will be used in the first version of the three-dimensional model. A simplified implementation of the advection scheme and TKE model will be used initially. The model grid will be organized into vertical sections to enable us to take advantage of computers with parallel architectures and will provide greater flexibility in the choice of computers for run.ing the model.

Initial test simulations that can be directly compared to existing two-dimensional model results will be run. This test will ensure that the two-dimensional model has been converted to a three-dimensional model correctly. Verification of the complete threedimensional model is expected to begin by the end of FY 1992.

\section{Surface Mixed Layer}

The three-dimensional model development effort will be shared between the SML and Deep Convection projects. As part of the model development, a suriace boundary condition will be implemented for parameterizing the effects of wave motion.

\section{Reterences}

Klemp, J. B., and D. R. Durran. 1983. "An IJpper Boundary Condition Permitting Internal Gravity Wave Radiation in Numerical Mesoscale Models." Monthly Weather Review 111:430-445.

Moum, J. N., D. R. Caldwell, and C. A. Paulson. 1989. "Mixing in the Equatorial Surface Layer and Thermociline." Journal of Geophysical Research 94:2005-2021.

Shay, T. J., and M. C. Gregg. 1986. "Convectively Driven Turbulent Mixing in the Upper Ocean." Journal of Physical Oceanography 16:1777-1798.

\section{Second-Generation Model}

\section{J. A. Edmona's}

The Second-Generation Model (SGM) is a new model designed to produce estimates of global greenhouse gas emissions for multiple regions of the workd at five-year time steps extending as far 
into the future as the year 2100 . The now greenhouse gas emissions model is being developed in phases. The first phase consists of constructing model Version 0.0, developing the underlying database to support this version, and then exercis. ing the model.

The heart of the Version 0.0 model will be a new, computable, general equilibrium modeling tramework. Most of the detail will be found in the energy sector description. in addition to the energy sector, the new model will include four other highly aggregated sectoral modules (agriculture, other production, households, and government) along with a price preprocessor, a demographic module, a solution algorithm, and an emissions postprocessor. The initial prototype has been completed and tested for a single-period, single-region case. Evolutionary extensions and refinement of parameterization resulting in a complete full-scale model, Version 1.0, will be accomplished progressively over approximately the next 2 years. However, increasingly useful output will be available in the interim.

\section{FY 1994 Accomplishments}

A major accomplishment for the project was the formation of a project team, including the hiring of an exceptionally well-qualified team leader.

The overall goal for FY 1991 was to have Version 0.0 fully operational, and significant progress was made toward that end. A dernographic module that accepts user-specified rates and provides forecasts of population by region, gender, and age group as input for other modules of the model has been developed and tested. Plans call for feeding back information from other model modules (e.g., education level) to explore effects on population and resulting impacts on other economic processes.

A Generic Production/Cost Module that can be readily adapted to the individual modules by specifying such parameters as number of sectors and subsectors and by providing a tallored database with information such as resources, vintages, and production function coefficients, has been devel. oped and coded. Currently, three rudimentary production modules have been incorporated: Agriculture, Energy, and Other Production. In addition, two final-demand modules, Households and Government, have been designed and coded.

To clear the various markets, a robust set of solution algorithms is being developed and tested with very encouraging results so far. Finally, a price preprocessor and a crude report writer have been included.

In sumnary, much progress has been made toward the FY 1991 goal; however, much additional work remains before Version 0.0 can be said to be operating reliably and efficiently. Highest-priority work includes a) expanding the number of regions from one to eleven; b) irmproving the quality of input data, which are mostly artificial at present; and c) exercising the model to refine the solution algorithm for greater efficiency.

\section{FY 1992 Actlvitles}

Activities in FY 1992 will focus on completing Version 0.0 , improving model data, exercising the model, and initially developing Version 1.0.

From October 1, 1991, through January 1, 1992 , the Generic Production/Cost Module will be modified to Include the following:

- energy (and potentially other) production frorn a depletable resource base,

- energy (and potentially other) production from a renewable resource base,

- time delay between initial investment and initial production for an economic activity, and

- coefficients for greenhouse gas emissions.

In addition, the model will be extended to run for 11 regions and 23 five-year periods to the year 2100.

From January 1 through July 1, 1992, collection of economic and energy data will continue. Work will proceed toward a final implementation of the inodel. The development of the required data sets has been supported by the participation of a number of international energy experts, who have visited PNL through the Advanced International Studies Unit's visiting scholars program. By July 1 , 1992, Version 0.0 will be fully implemented. 
During the final quarter of FY 1992, the model will be exercised and a series of analyses will be conducted. These analyses will include the effects of local, regional, and global carbon and of taxes based on emissions weighted by their global warm. ing potential (GWP), to examine the direct and indirect effects of these measures on emissions reductions, national income, and international trade. Results will be compared to those reported in the literature.

Beginning about April 1, 1992, work will begin in the development of SGM Version 1.0. This work will include the following activities:

- The Agriculture Module will be extended from a single product to as many as ten markets. A biome scheme will be implemented that will reflect changes in land productivity. Modeling of gradations of water availability will be explored.

- The Other Producis Module will be separated into the following sectors: Manufacturing (both materials-intensive and other manulacturing), Transportation, Health and Other Services, and Education.

- Although the basic structure of the Households Module will remain the same, increasingly sophisticated modeling of the labor supply and educational services demand functions will be incorporated. Savings supply will be made sensitive to interest rates. Labor supply will be made sensitive to the education and age structure of the population.

- In the Government Module, the decisionmaking processes will be refined to include infrastructures, tax rates, and regulatory policies.

- The Energy Module will be expanded to permit a wider range and more flexibility in choices of technologies.

- As the individual production sectors are increasingly disaggregated, the Emissions Calculation Module can provide finer-grained summations of greenhouse gas emissions.

- Mechanisms will be explored for modeling the behavior of nonmarket economies.

- The role of research and development in the rate of technical progress will be investigated with a view toward research and development
Investment in energy-saving and emissionsreduction efforts.

- As an adjunct to model development, ways to enhance user-friendliness (e.g., graphic user interface) will be explored to maximize access to the final product.

To work in conjunction with the SGM within an internally consistent, integrating framework, PNL is seeking multisponsor iunding for a computer model of the effects of global change on human systems.

\section{The Regional Effects of Climate Change and $\mathrm{CO}_{2}$ Fertilization on the Natural and Human Environ- ment: the MINK Study}

\section{J. Scott}

General circulation models (GCMs) indicate that human-caused increases in greenhouse gases may raise the average temperature of the earth's atmosphere during the next century to levels not experienced in the last 100,000 years. The cost of stabilizing the Earth's climate is believed to be high (Lashof and Tirpak 1990; National Research Council 1990), so the research community increas. ingly is focusing on improving methodologies to analyze the impact of climate change on natural resources and the human economic and social systems that depend on them.

At the initiation of the Resources Analysis Research Project in FY 1989, it was determined that methodological advances were needed in four specific areas:

- analyses must be forward-looking in addressing the sutte of technologies available in the future, which may be as important to determining consequences as will future atmospheric $\mathrm{CO}_{2}$ and cilimate;

- methods must be developed for addressing the interactions of human and natural systems, Including methods to analyze simultaneously the interaction of multiple resources within a systems framework;

- analysis must recognize that natural resource effects may transcend political boundaries and that human migration and interregional trade 
and competition may affect the size or even the direction of net climate impacts; and

- more efficient means of generating distributions of uncertain potential outcomes from modelbased analyses are required.

The Resources Analysis Research Project was initiated to address all of these issues and develop the scientific information base and the analytical tools necessary to understand the regional consequences of $\mathrm{CO}_{2}$ /climate change, including descriptions of their nature, timing, magnitude, and associated uncertainties. The program focused on a single region of the United States [Missourl, lowa, Nebraska, and Kansas (MINK)], employed a historical analog climate (the Dust Bowl period of the 1930 s), and analyzed the interactions of all of the resources within that region as they might evolve under current and changing $\mathrm{CO}_{2}$ /climate conditions over the next 50 years.

\section{Accomplishments}

During the third year of the project (FY 1991), based on results of an international peer review conducted in Interlaken, Switzerland, in November 1990 , final analysis was conducted. The computer models adapted in previous years to simulate the impacts of climate change were used to simulate the effects of both the 1930s analog climate change and increased aimospheric $\mathrm{CO}_{2}$ on four natural resource sectors and the MINK regional economy. A comprehensive report, in eight volumes, was written describing the impact of analog climate, human adaptation, economic growth, and technological change on the MINK resource sectors and the regional economy.

The analysis was conducted in four stages: 1) the analog climate change first was imposed on today's economy with mid-1980s technology and no adap. tation by economic actors in the reglon; 2) today's economic system was then allowed to make low. cost adaptations to climate change, and the effects of enhariced $\mathrm{CO}_{2}$ on photosynthesis and water utilization were allowed to occur in the agriculture and forestry sectors; 3 ) future economic growth and foreseeable technological change without climate change were estimated for the year 2030; and finally, 4) analog climate change, $\mathrm{CO}_{2}$ effects, and economic adaptation were all combined for the year 2030 and the effect on each sector and the region's economy analyzed.
The impacts of climate change on "typical" agricultural cropping systems (including yields, profit, energy, and water use) were analyzed using a version of the Erosion-Production Impact Calculator (EPIC) computer code (Williams et al. 1984), while forest products yields were calculated using a version of the FORENA code (Solomon et al. 1984; Solomon and West 1987). In validation runs, EPIC produced close approximations of current crop yields and water use for today's climate, while FORENA results for today's climate closely matched today's actual Missouri forests. Water supply and demand balances were calculated in part using U.S. Army Corps of Engineers' simulations of the Missouri River Basin reservoirs. Finally, the overall impact on the regional economy was calculated using the IMPLAN computer code (U.S. Department of Agriculture 1989).

\section{Program Findings}

Some of the key empirical findings of the MINK study are as follows:

- Future technological change would Increase the yields of the individual major crops grown in the MINK region from $65 \%$ to $90 \%$ by the year 2030 in the absence of climate change.

- Given a 1930 s analog climate, crop yields in the year 2030 would decline by between $1 \%$ and $28 \%$ relative to the future baseline if farmers do not react to climate change. The net value of MINK crop production in the worst case would be reduced by an average $22 \%$, while irrigation requirements would increase. However, the combination of $\mathrm{CO}_{2}$ effects, technological change, and low-cost farmer adaptations could reduce these losses considerably. Effective methods already available include earlier planting, longer-season varieties, conservation tillage, and more drought-resistant crops and cultivars. Additional adaptations could take advantage of $\mathrm{CO}_{2}$ fertilization and warmer climates in the year 2030. The combined net value of farm production of the four key crops--wheat, corn, soybeans, and sorghum-increased $3 \%$ above baseline (more than $65 \%$ above today's values) in the best scenario.

- The intensive mining of groundwater for irrigation in the MINK region and growing competition for surface water to sustain recreation and wildlife is likely to result in significant future water demand-supply imbalances and stress on 
water management institutions early in the next century even without climate change. If water management priorities were changed, adapta. tlons to future climate could force a general return to dryland agriculture in the two western states to conserve groundwater, while irrigation would increase sharply in the eastern states (a decline of about $30 \%$ in Irrigated farm land in Nebraska and $58 \%$ in Kansas and a $300 \%$-plus increase in lowa and Missouri). Dam operations on the Missouri River could be changed to deemphasize navigation and emphasize fish and wild life and recreation requirements for surface waters, increasing regional incomes dependent on these activities.

- The region's marginal forest products sector would decline under the analog climate, with biomass production declining between $20 \%$ and $60 \%$ in the long run and with significant reductions in both standing stock and harvest. Salvage logging could support the industry for some time; however, in the absence of new wood processing methods that utilize lower quality stock, the region's forest products industry would likely migrate to other regions that are relatively better off under climate change. Plantation forestry to support biomass production is possible in the region but would require a significant subsidy.

- Total energy demand in agriculture would be increased by about $3 \%$ to $4 \%$ by the analog climate, increases in irrigation demand for energy being partially offset by decreases in energy for crop drying. Impacts of climate change on thermal energy supply were generally of minor importance. Little hydropower is currently generated in the MINK region; how. ever, major declines could occur in hydropower production in the upper reaches of the Missourl basin, adversely affecting power imports.

- A simple decision anaiysis model analyzed farmer decisions to switch crops under climate uncertainty. If farmers were relatively impervious to risk, it was found that they would be attracted to crops with higher average profita. bility, such as corn, even if climate change tended to significantly increase the variability of yields. If farmers were highly averse to risk, they would likely adopt crops such as sorghum, which have lower average but less variable profitability under the analog climate.
- The regional economic impacts of a 1930s analog climate in the MINK region were projected to be modest. Regional impacts were calculated for agriculture and water-based recreation, both of which are large enough and vulnerable enough to climate change to make a difference in the overall economy. If farmers are unable to adjust to the changed climate, and only agricultural exports are affected, then the impact on regional production was projected to be a decline of only $0.3 \%$ to $1.3 \%$. In the worst case (considered less likely), the feedlot and livestock industry could also decline because of a lack of feed grains, and the decline in regional economic output could be as large as $10 \%$. However, projected technological and management responses by farmers could also lead to net increases in regional product. The impact of a climate-related decline in water-based recreation was calculated as a decline in regional output of probably less than $1 \%$.

\section{Future Work}

The study identffied water supply and demand as the most critical climate-related issue in the region. However, the analysis was limited in that, for reasons of time and budget, it could not deal with the water supply and demand of all of the river basins contributing to water supply for the MINK region. An important extension of the MINK region analysis would reflect water supply and demand (and Institutions) in the Upper Missouri River Basin to see how climate change effects in one region affect downstream water users in another region. There are numerous analogies elsewhere in the world with trans-boundary river flows. Comparative analysis needs to be done with other resources and other resource management institutional settings.

Despite the fact that the MINK study dealt with uncertainty, within the multiple-model analytical methodology it is not simple to directly assess the effects of a wide range of alternative climate scenarios or impacts in other regions. However, the methods used in the study could be generalized for other regions to identify effective and flexible technical and institutional responses to climate change. In particular, based on the results and lessons learned in the MINK study, it appears feasible to Jevelop a generic regional model designed to capture in a reduced form the essential 
climate-sensitive features of the sectoral and regional economic models used in the MINK study. Extensive sensitivity analysis could then be done with this model to look at a full range of uncertain potential climate change effects in a region dominated by agriculture.

One of the findings of two recent workshops on the regional effects of climate change (The Inter. national Workshop on the Natural Resources and Economic Consequences of Global Climatic Change in Interlaken, Switzerland, in November 1990 and The 1991 Woodlands Conference at The Woodlands, Texas, in March 1991) is that some of the more important effects of global change may occur through interregional linkages provided by global markets and migration. A worldclimate-effects model or a global-linking methodology would place regional impacts analysis in a global context. The concept of this linking method. ology would be to begin with a simple world-effects model containing major population, trade, and resource effects of climate change to determine the relative importance of such linkages, then expand the reduced-form modeling of individual regions as time and budget permit.

\section{Acknowledgments}

The study team and their respective roles consisted of Resources for the Future (RFF), with the assistance of Texas A\&M University (analysis), Oak Ridge National Laboratory (ORNL) (data integration and quality control), PNL (project coordination and analysis of uncertainty iseues), and Sigma Xi (outreach and uncertainty issues). The study team also includes Jae Edmonds and Al Liebeirau of PNL; Norman Rosenberg, Bill Easterling, Mary Mckenney, Pierre Crosson, Michael Bowes, Ken Frederick, Joel Darmstadter, Roger Sedjo, Kathleen L.emon, and Laura Katz of RFF; Robert
Cushman, Carolyn Hunsaker, and Linda Allison of ORNL; and Gary Yohe and Tom Malone from Sigma Xi.

\section{References}

Lashof, D. A., and D. A. Tirpak, eds. 1990. Policy Options for Stabilizing Global Climate. Report to Congress. U.S. Environmental Protection Agency, Washington, D.C.

National Research Council. 1990. Confronting Climate Change: Strategies for Energy Research and Development. National Academy Press, Washington, D.C.

Solomon, A. M., et al. 1984. Response of Unmanaged Forests to $\mathrm{CO}_{2}$-Induced Climate Change: Available Information, Initial Tests, and Data Requirements. U.S. DOE TR009, NBB-0053, U.S. Department of Energy, Washington, D.C.

Solomon, A. M., and D. C. West. 1987. "Simulating Forest Ecosystem Responses to Expected Climate Change in Eastern North America: Applications to Decision Making in the Forest Industry." In The Greenhouse Effect, Climate Change, and U.S. Forests, ed. W. E. Shands. Conservation Foundation, Washington, D.C.

U.S. Department of Agriculture. 1989. Micro IMPLAN Release 89-03 (A Computer Program). U.S. Department of Agriculture, Forest Service, Land Management Planning, Ft. Collins, Colorado.

Williams, J. R., C. A. Jones, and P. T. Dyke. 1984. "A Modeling Approach to Determining the Relationship Between Erosion and Soll Productivity." Transactions of the American Society of Agricultural Engineers 27:129-144. 


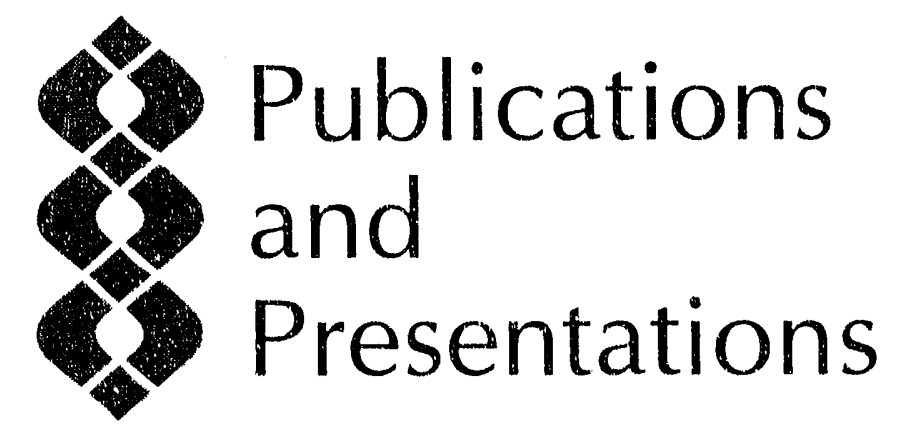




\section{PUBLICATIONS}

Allwine, K. J., B. K. Lamb, L. Bamesberger, and R. Eskridge. 1991. 1989 Roanoke Tracer Study. PNL-7567, Pacific Northwest Laboratory, Richland, Washington.

Asher, W. E., E. C. Monahan, R. Wanninkhof, and T. S. Bates. 1991. "Correlation of Fractional Foam Coverage with Gas Transport Rates." In Air-Water Mass Transfer, eds. S. C. Wilhelms and J. S. Gulliver, pp. 536548. American Society of Civil Engineers, New York.

Asher, W. E., and J. F. Pankow. 1991. "The Effect of Surface Films on Concentration Fluctuations Close to a Gas/Liquid Interface." In Air-Water Mass Transfer," eds. S. C. Wilhelms and J. S. Gulliver, pp. 68-80. American Society of Civil Engineers, New York.

Asher, W. E., and J. F. Pankow. 1991. "Prediction of Gas/Water Mass Transport Coefficients by a Surface Renewal Model." Environmental Science and Technology 25:12,94-1300.

Bowes, M. D., and R. Sedjo. 1991. Processes for Identifying Regional Influences of and Responses to Increasing Atmospheric $\mathrm{CO}_{2}$ and Climate Change--The MINK Project. Report III--Forestry. DOE/RL/01830T-H9, U.S. Department of Energy, Washington, D.C.

Crosson, P. R., and M. Bowes. 1991. Pro. cesses for Identifying Influences of and Responses to Increasing Atmospheric $\mathrm{CO}_{2}$ and Climate Change--The MINK Project. Report VI--Consequences of Climate Change for the MINK Economy: Impacts and Responses. DOE/RL/01830T-H12, U.S. Department of Energy, Washington, D.C.

Crosson, P. R., L. A. Katz, and J. Wingard. 1991. Processes for Identifying Regional Influences of and Responses to Increasing Atmospheric $\mathrm{CO}_{2}$ and Climate Change--The MINK Project. Report Ila--Agricultural Production and Resource Use in the MINK Region Without and With Climate Change.
DOE/RL/01830T-H7, U.S. Department of Energy, Washington, D.C.

Darmstadter, J. 1991. Processes for Identifying Regional Influences of and Responses to Increasing Atmospheric $\mathrm{CO}_{2}$ and Climate Chango--The MINK Project. Report V.Energy. DOE/RL/01830T-H11, U.S. Department of Energy, Washington, D.C.

Doran, J. C. 1991. "The Effects of Ambient Winds ori Valley Drainage Flows." BoundaryLayer Meteorology 55:177-189.

Doran, J. C., and E. D. Skyllingstad. 1992. "Multiple-Scale Terrain Forcing of Local Wind Fields." Monthly Weather Review $120(5): 817-825$.

Easterling, W. E., M. S. McKenney, N. J. Rosenberg, and K. A. Lemon. 1991. Processes for ldentifying Regional Influences of and Responses to Increasing Atmospheric $\mathrm{CO}_{2}$ and Climate Change--The MINK Project. Report IIb--A Farm-Level Simulation of the Effects of Climate Change on Crop Productivity in the MINK Region. DOE/RL/01830T. $\mathrm{H} 8$, U.S. Department of Energy, Washington, D.C.

Frederick, K. D. 1991. Processes for Identifying Regional Influences of and Responses to Increasing Atmospheric $\mathrm{CO} 2$ and Climate Change--The MINK Project. Report IV.Water Resources. DOE/RL/01830T-H1O, U.S. Department of Energy, Washington, D.C.

Frysinger, G. S., W. E. Asher, G. M. Korenowski, W. R. Barger, M. A. Klusty, N. M. Frew, and R. K. Nelson. 1991. "Study of Ocean Slicks by Nonlinear Laser Processes, Part 1: Second-Harmonic Generation." Journal of Geophysical Research (in press).

Hales, J. M. 1991. "Source-Receptor Linearity: Definitions, Measurement, and Practical Implications." Atmospheric Environment (in press). 
Hubbe, J. M., and K. J. Allwine. 1991. ASCOT 91 Field Experiment: PNL Airsonde Data Summary. PNL-7809 (ASCOT-91-3), Pacific Northwest Laboratory, Richland, Washington.

Luecken, D. J., C. M. Berkowitz, and R. C. Easter. 1991. "Use of a Three-Dimensional Cloud-Chemistry Model to Study the Transatlantic Transport of Soluble Sulfur Species." Journal of Geophysical Research (in press).

Quinn, P. K., W. E. Asher, and R. J. Charlson. 1991. "Equilibria of the Marine MultiPhase Ammonia System." Journal of Atmospheric Chemistry (in press).

Rosenberg, N. J., P. R. Crosson, K. D. Frederick, W. E. Easterling III, M. S. McKenney, R. A. Sedjo, M. D. Bowes, J. Darmstadter, L. A. Katz, and K. M. Lemon. 1991. Processes for Identifying Influences of and Responses to Increasing Atmospheric $\mathrm{CO}_{2}$ and Climate Change--The MINK Project. Report I Background and Baselines. DOE/RL/01830T-H6, U.S. Department of Energy, Washington, D.C.

Rosenberg, N. J., and P. R. Crosson. 1991. Processes for Identifying Influences of and
Responses to Increasing Atmospheric $\mathrm{CO}_{2}$ and Climaie Change--The MINK Study. An Overvlew. DOE/RL/01830T-H5, U.S. Department of Energy, Washington, D.C.

Stockle, C. O., J. R. Williams, N. J. Rosenberg, and C. A. Jones. 1992. "Estimating the Effect of Carbon Dioxide-Induced Climate Change on Growth and Yleld of Crops I. Modification of the EPIC Model for Climate Change Analysis." Agricultural Systems $38: 225-238$.

Stockle, C. O., J. R. Williams, N. J. Rosenberg, and C. A. Jones. 1992. "Estimating the Effect of Carbon Dioxide-Induced Climate Change on Growth and Yield of Crops II. Assessing the Impact on Maize, Wheat, \& Soybean in the Midwestern U.S.A." Agricultural Systems 38:239-256.

Yohe, G. W. 1991. "Uncertainty, Climate Change, and the Economic Value of Information: An Economic Methodology for Evaluating the Timing and Relative Efficiency of Alternative Responses to Climate Change, with Application to Protecting Developed Property from Greenhouse-Induced Sea Level Rise." Policy Sclences 24:245-269. 


\section{PRESENTATIONS}

Asher, W. E., P. J. Farley, R. Wanninkhof, E. C. Monahan, and T. S. Bates. 1991. "Laboratory and Field Results on the Corre. lation of Fractional Area Whitecap Coverage with Air/Sea Gas Transport." Presented at the Fifth International Conference on Particle Scavenging and Atmosphere-Surface Exchange Processes, July 10-14, 1991, Richland, Washington.

Asher, W. E., E. C. Monahan, T. S. Bates, and R. Wanninkhof. 1991. "Correlation of Whitecap Coverage with Air-Sea Gas Transport Piston Velocities Deduced from Laboratory and Field Results." Presented at the IUGG XX General Assembly, August 11-24, 1991, Vienna, Austria.

Davis, W. E., M. T. Dana, R. N. Lee, W. G. N. Slinn, and J. M. Thorp. 1991. "Scavenging Ratios Based on Inflow Air Concentrations." Presented at the Fifth International Conference on Precipitation Scavenging and Atmospheric Surface Exchange Processes, July 15 19, 1991, Richland, Washington.

Edmonds, J., D. Weubbles, and W. Chandler. 1990. "Greenhouse Gases: What is Their Role in Climate Change?" Presented at the Dahlem Workshop on Limiting the Greenhouse Effect: Options for Controlling Atmospheric $\mathrm{CO}_{2}$ Accumulation, December 9-14, 1990 , Berlin, Germany.

Hauser, R. K., C. D. Whiteman, and J. L. Sutherland. 1991. "Surface Meteorological Conditions During the Winter 1990 Navajo Generating Station Visibility Impairment Study." Paper 91-47.9, 84th Annual Meeting and Exhibition, Air and Waste Management Association, June 16-21, 1991, Vancouver. British Columbia.

Kleinman, L. I., P. H. Daum, and C. M. Berkowitz. 1991. "Effects of In-Cloud Pro. cesses upon the Vertical Distribution of Aerosol Particles: Observations and Numerical Simulations." Presented at the Fifth International Conference on Precipitation Sca. venging and Atmospheric Surface Exchange
Processes, July 15-19, 1991, Richland, Washington.

Llebetrau, A. M., and M. J. Scott. 1990. "Methods for Estimating the Uncertainty of Climate Change Effects in a Crop Model." Presented at the International Workshop on the Natural Resource and Economic Implications of Global Climate Change, November 5-9, 1990, Interlaken, Switzerland.

Llebetrau, A. M., M. J. Scott, W. Easterling, and M. MoKenney. 1990. "Sensitivity and Uncertainty Analysis of Crop Yield Estimates Computed Using the EPIC Model." Presented at the Third Interdisciplinary Conference on Natural Resource Modeling, October 11-13, 1990, Cornell University, Ithaca, New York.

Luecken, D. J., C. M. Berkowitz, and R. C. Easter. 1991. "Influence of Clouds and Rain on the Large-Scale Transport and Deposition of Sulfur." Presented at the Fifth International Conference on Precipitation Scavenging and Atmospheric Surface Exchange Processes, July 15-19, 1991, Richland, Washington.

Rosenberg, N. J., P. R. Crosson, W. E. Easterling III, M. S. McKenney, and K. D. Frederick, 1991. "Developing a Methodology for Identifying Regional Influences of and Responses to Increasing Atmospheric $\mathrm{CO}_{2}$ and Climate Change." Presented at The Regions and Global Warming. 1991 Woodlands Confarence, March 3-6, 1991, The Woodlands, Texas.

Ruffleux, D. C., and C. D. Whiteman. 1991. "Wintertime Surface Energy Budget in the Grand Canyon Region." Paper 91-47.4, 84th Annual Meeting and Exhibition, Air and Waste Management Association, June 16-21, 1991, Vancouver British Columbia.

Skyllingstad, E. D., and D. W. Denbo. 1991. "A Two-Dimensional Model of Mixed Layer Growth and Thermobaric Plume Instability." Presented at the IUGG XX General Assembly, August 11-24, 1991, Vienna, Austria. 
Whiteman, C. D. 1991. "Thermally Driven Wind Systems." Presented at National Fire Weather Forecasters Course, April 2.11, 1991, Boise, Idaho.

Wolfe, D. E., D. C. Welsh, and C. D. Whiteman. 1991. "Wind Structure within the Grand Canyon as Observed by a Low-Level Wind Profiler." Paper 91-85.2, 84th Annual Meeting and Exhibition, Air and Waste Management Assoclation, June 16-21, 1991, Vancouver, British Columbla.

Yohe, G. W. 1990. "Imbedding Dynamic Responses with Imperfect Information into
Static Portraits of the Regional Impact of Climate Change." Presented at the International Workshop on the Natural Resource and Economic Implications of Global Climate Change, November 5-9, 1990, Interlaken, Switzerland.

Yohe, G. W. 1990. "Toward a General Criterion for Selecting Interesting Scenarios with Which to Analyze Adaptive and Averting Response to Potential Climate Change." Presented at the International Workshop on the Natural Resource and Economic Implications of Global Climate Change, November 5-9, 1990, Interlaken, Switzerland. 
Author

Index 


\section{AUTHOR INDEX}

Abbey, O. B.; 9

Allwine, K. J.; 16

Alzheimer, J. M.; 35

Anderson, G. A.; 35

Asher, W. E.; 49

Bador, D. C.; 47

Barchet, W. R.; 24

Berkowitz, C. M.; 3, 9

Berndt, J. L.; 41

Busness, K. M.; 9

Chapman, E. G.; 3

Cress, T. S.; 29

Dana, M. T.; 3

Daum, P. H.; 9

Denbo, D. W.; 49
Doran, J. C.; 20, 22, 39

Downing, J. P.; 49

Easter, R. C.; 3

Edmonds, J. A.; 52

Elderkin, C. E.; 12, 24

Garnich, M. R.; 35

Hales, J. M.: 3, 9

Hannigan, R. V.; 9

Harrison, L. C.; 41

Hubbe, J. M.; 16

Larson, N. R.; 41

Laulainen, N. S.; 41

Luecken, D. J.; 3
MacCracken, M. C.; 47

Malone, R. C.; 47

Michalsky, J. J.; 41

Richmond, M. C.; 49

Scott, M. J.; 54

Shaw, W. J.; 35

Skyllingstad, E. D.; 49

Slinn, W. G. N.; 24

Stokes, G. M.; 29

Tomich, S. D.; 9

Whiteman, C. D.; 16, 35 
Distribution 


\section{DISTRIBUTION}

\section{OFFSITE}

DOE/Otfice of Scientific

and Technical Information

(12)

R. E. Alexander
ORPBR, NL
U.S. Nuclear Regulatory
Commission
Washington, DC 20585

E. L. Alpen

Donner Laboratory

University of California

Berkeley, CA 94720

D. R. Anderson

ENVIROTEST

1206A North 185th

Seattle, WA 98133.4020

Assistant Secretary

Environment, Safety \& Health

EH-1, FORS

U.S. Department of Energy

W'ashington, DC 20585

\author{
J. A. Auxier \\ IT Corporation \\ 312 Director's Drive \\ Knoxville, TN 37701 \\ F. Badgley \\ 1374941 st Street, NE \\ Seattle, WA 98125 \\ R. E. Baker \\ 8904 Roundleaf Way \\ Gaithersburg, MD 20879-1630 \\ D. Baldocchi \\ Atmospheric Turbulence \\ and Diffusion Laboratory \\ National Oceanic and \\ Atmospheric Administration \\ P.O. Bo× 2456 \\ Oak Ridge, TN 37830
}

R. W. Barber

EH-131, GTN

U.S. Department of Energy

Washington, DC 20585
A. D. Barker
Battelle Columbus Division
505 King Avenue
Columbus, $\mathrm{OH} \$ 3201$

\section{H. M. Bames \\ AREAL (MD-39) \\ U.S. Environmental \\ Protection Agency \\ Research Triangle Park, NC 27711}

N. F. Barr

ER-72, GTN

U.S. Department of Energy

Washington, DC 20585

S. Barr
Environmental Studies Group
MS-F665
Los Alamos Natinnal Laboratory
P.O. Box 1653
Los Alamos, NM 87545
J. F. Boatman
NOAAR/E/AR4
325 Broadway
Boulder, CO 80303

L. C. Brazley, dr.

NE-22, GTN

U.S. Department of Energy

Washington, DC 20585

J. C. Brown

Environmental Studies Group

MS-A114

Los Alamos National Laboratory

P.O. Box 1663

Los Alamos, NM 87545
P. Buhl

FE-232, GTN

U.S. Department of Energy

Washington, DC 20585

G. Buriey

Office of Radiation

Programs (ANR-458)

U.S. Environmental

Protection Agency

Washington, DC 20460

W. W. Burr

Medical \& Health Sciences

Division

Oak Ridge Associated

Universities

P.O. Box 117

Oak Ridge, TN 37830

L. K. Bustad

College of Veterinary Medicine

Washington State University

Pullman, WA 99164-7010

R. J. Catlin

U.T. Health Science CenterHouston

13307 Queensbury Lane

Houston, TX 77079

J. S. Chang

Atmospheric Sciences

Research Center

State University of New York at Albany

100 Fuller Road

Albany, NY 80307

A. J. Charison

Department of Atmospheric

Sciences, AK-40

University of Washington

Seattle, WA 98195 


\author{
J.K.S. Ching \\ AREAL (MD-80) \\ U.S. Environmental \\ Protection Agency \\ Research Triangle Park, \\ NC 27711
Council on Environmental
Quality \\ 722 Jackson Place, NW \\ Washington, DC 20503 \\ T. V. Crawiord \\ Westinghouse \\ Atomic Energy Division \\ Savannah River Laboratory \\ Aiken, SC 29808 \\ J. B. Cunning \\ NOAAVERL. \\ 325 Broadway \\ Boulder, CO 80303 \\ P. H. Daum \\ Brookhaven National \\ Laboratory \\ Upton, Long Island, NY 11973 \\ J. F. Decker \\ ER-3, FORS \\ U.S. Department of Energy \\ Washington, DC 20585 \\ K. Demerjian \\ Atmospheric Sclences \\ Research Center \\ State University of New York \\ at Albany \\ 100 Fuller Road \\ Albany, NY 80307 \\ R. L. Dennis \\ AREAL (MD-80) \\ U.S. Environmental \\ Protection Agency \\ Research Triangle Park, \\ NC 27711
}

G. DePlanque, Director

Environmental Measurements

Laboratory

U.S. Department of Energy

375 Hudson Street

New York, NY 10014

M. H. Dickerson

Lawrence Livermore National Laboratory

L-262

P.O. BOX 808

Livermore, CA 94550

R. R. Dickerson

Department of Meteorology

University of Maryland

College Park, MD 207.42

H. Drucker

Argonne National Laboratory 9700 South Cass Avenue

Argonne, IL 60439

A. P. Duhamel

ER-74, GTN

U.S. Department of Energy

Washington, DC 20585

C. W. Edington, Director

Board on Padiation Effects

Research

National Research Council

2101 Constitution Avenue, NW

Washington, DC 20418

R. J. Engelmann

1170 i Karen

Potomac, MD 20854

G. J. Foley

AREAL (MD-75)

U.S. Environmental

Protection Agency

Research Triangle Fark,

NC 27711
D. J. Galas

ER-70, GTN

U.S. Department of Energy

Washington, DC 20585

T. F. Gesell

Idaho Operations Office

U.S. Department of Energy

785 DOE Place

Idaho Falls, ID $83402-4149$

R. D. Gilmore

Environmental Health

Sciences, Inc.

Nine Lake Bellevue Building

Suite 104

Bellevie, WA 98005

G. H. Groenewold

Energy and Mineral

Research Center

University of North Dakota

Box 8213, University Station

Grand Forks, ND 58202

T. Gross

ER-74, GTN

U.S. Department of Energy

Washington, DC 20585

D. A. Hansen

Electric Power Research

Institute

3412 Hillview Avenue

Palo Alto, CA 94303

W. Happer

ER-1, FORS

U.S. Department of Energy

Washington, DC 20585

J. W. Healy

51 Grand Canyon Drive

White Rock, NM 87544

B. B. Hicks

NOAA-Air Resource Laboratory

1325 East-West Highway

Room 9348

Silver Spring, MD 20910 
T. W. Horst

Surface and Sounding Systems Facility

Atmospheric Technology

Division

National Center for

Atmospheric Research

P.O. Box 3000

Boulder, CO 80307-3000

F. Hutchinson

Department of Molecular

Biophysics and Biochemistry

Yale University

260 Whitney Avenue

P.O. Box 6666

New Haven, CT 06511

H. Ishikawa

Nuclear Salety Research

Association

P.O. Box 1307

Falls Church, VA 22041

A. W. Johnson

Vice President for

Academic Affairs

San Diego State University

San Diego, CA 92128

L. J. Johnson

Idaho National Engineering

Laboratory

IRC MS 2203

P.O. Box 1625

ldaho Falls, ID 83415

G. Y. Jordy

ER-30, GTN

U.S. Department of Energy

Washington, DC 20585

F. Koomonoff

ER-12, GTN

U.S. Department of Energy

Washington, DC 20585

R. Kornasiewicz

Mail Stop 1130-55, ONRR

U.S. Nuclear Regulatory

Commission

Washington, DC 20555
D. Lal

Geological Research

Division A-020

Scripps Institute of

Oceanography

La Jolla, CA 92093

T. V. Larsen

Department of Clvil Engineering

University of Washington

Seattle, WA 98195

L. Levin

Electric Power Research

Institute

3412 Hillview Ave.

Palo Alto, CA 94303

Librarian

Brookhaven National

Laboratory

Research Library, Reference

Upton, Long island, NY 11973

Librarian

Colorado State University

Documents Department

The Libraries

Ft. Collins, CO 80521

Librarian

Electric Power Research

Institute

3412 Hillview Avenue

Palo Alto, CA 94303

Librarian

Atmospheric Sciences

Library, AK-50

University of Washingion

Seattle, WA 98195

Librarian

Los Alamos National

Laboratory

MS P364

P.O. Box 1663

Los Alamos, NM 87545
Librarian

National Oceanic and

Atmospheric Administration

Atmospheric Turbulence

and Diffusion Laboratory

P.O. Box 2456

Oak Ridge, TN 37831

Librarian

Washington State University

Pullman, WA 99164-6510

Library

Serials Department

(\#80-170187)

University of Chicago

1100 East 57th Street

Chicago, IL 60637

I. R. Linger

ER-63, GTN

U.S. Department of Energy

Washington, DC 20585

D. J. Luecken

11 Willowbridge Drive, \#46

Durham, NC 27707

D. L. Lundgren

Lovelace - ITRI

P.O. Box 5890

Albuquerque, NM 87185

O. R. Lunt

Laboratory of Nuclear Medicine and Radiation Biology

University of California

900 Veteran Avenue

West Los Angeles, CA 90024

M. C. MacCracken

Lawrence Livermore National

Laboratory

P.O. Box 808 (L-262)

Livermore, CA 94550

W. J. Madia

Battelle Columbus Division

$505 \mathrm{King}$ Avenue

Columbus, $\mathrm{OH} 43201$ 


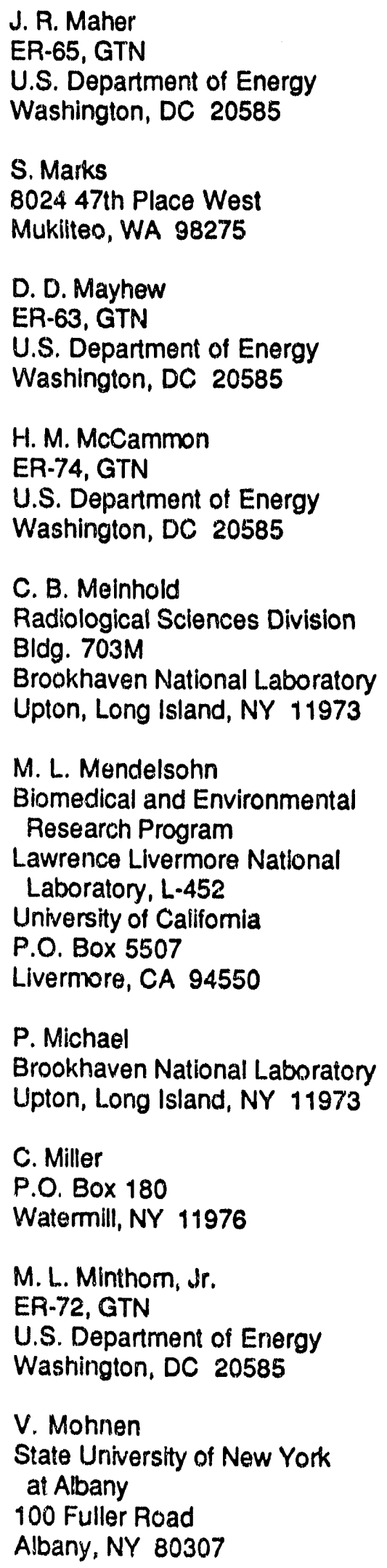

B. Morgan

Environmental Division

DOE - Savannah River

Operations Office

P.O. Box A

Alkon, SC 29801

H. Moses

ER-74, GTN

U.S. Department of Energy

Washington, DC 20585

P. K. Mueller

Environmental Science

Department

Electric Power Research

Institute

3412 Hillviow Avenue

P.O. Box 10412

Palo Alto, CA 94304

R. Nathan

Battelle Project

Management Division

505 King Avenue

Columbus, OH 43201

W. Noff

Wave Propogation Lab, NOAA

325 Broadway

Boulder, CO 80303

L. Newmarı

Brookhaven National Laboratory Upton, Long Island, NY 11973

W. R. Ney

National Council on Radiation

Protection and Measurements

Sulte 1016

7910 Woodmont Avenue

Bethesda, MD 20814

Nuclear Regulatory Commission

Advisory Committeo on

Reactor Safeguards

Washington, DC 20555

M.J. O'Brien

Radiation Safety Office

GS-05

University of Washington

Seattle, WA 98105
A. A. Patrinos

ER-74, GTN

U.S. Department of Energy

Washingion, DC 20585

R. Pawr

AREAL (MD-44)

U.S. Environmental

Protection Agency

Research Triangle Park, NC 27711

K. E. Pickering

Research Scientist

Universities Space Research

Association

NASA Goddard Space Flight

Center

Code 916

Greenbelt, MD 20771

A. A. Pitrolo

Morgantown Energy

Research Center

U.S. Department of Energy

P.O. Box 880

Morgantown, WV 26505

D. P. Rall

NIEHS

P.O. Box 12233

Research Triangle Park, NC 27709

M. R. Riches

ER-74, GTN

U.S. Department of Energy

Washington, DC 20585

C. R. Richmond

Oak Ridge National Laboratory

4500N, MS-62523

P.O. Box 2008

Oak Ridge, TN 37831-6253

M. C. Richmond

University of Washington

Seattle, WA 98195

S. L. Rose

ER-72, GTN

U.S. Department of Energy

Washington, DC 20585

Distr.4 


R. D. Rosen
Environmental Measurements
Laboratory
U.S. Department of Energy
376 Hudson Street
New York, NY 10014
P. Samson
Atmospheric and Oceanic
Sciences
University of Michigan
Ann Arbor, MI 48109
R. A. Scarano
Mill Licensing Section
U.S. Nuclear Regulatory
Commission
Washington, DC 20585
F. A. Schiermeler
Atmospheric Sciences
Modeling
Division (MD-80)
U.S. Environmental
Protection Agency
Research Triangle Park,
NC 27711

M. Schulman

ER-70, GTN

U.S. Department of Energy

Washington, DC 20585
R. B. Setlow
Brookhaven National Laboratory
Upton, Island, NY 11973
R. Shikiar
Battelle - Seattle
4000 NE 41st Street
Seattle, WA 98105
P. Silverman
Lawrence Berkeley Laboratory
Bidg. 50A/5104
Berkeley, CA 94720
W. K. Sinclair
National Council on Radiation
Protection and Measurements
Suite 1016
7910 Woodmont Avenue
Eethesda, MD 20814

D. Sisterson

Argonne National Laboratory

Building 203, ER

Argonne, IL 60439

C. Spicer

Battelle Columbus Division

505 King Avenue

Columbus, $\mathrm{OH} 43201$

J. N. Stannard

17441 Plaza Animado \#132

San Diego, CA 92128

R. J. Stern

EH-10, FORS

U.S. Department of Energy

Washington, DC 20585

J. F. Stevens

Dayton Area Office

DOE - Albuquerque

Operations Office

P.O. Box 66

Miamisburg, OH 45342.

E. T. Still

Kerr-McGee Corporation

P.O. Box 25861

Oklahoma City, OK 73125

P. Stone

ER-6, FORS

U.S. Department of Energy

Washington, DC 20585

G. M. Sverdrup

Battelie Columbus Division

505 King Avenue

Columbus, OH 43201

J. Swinebroad

EH-43, GTN

U.S. Department of Energy

Washington, DC 20585

Technical Information

Service

Westinghouse

Savannah River Laboratory

Room 773A

Aiken, SC 29801
R. G. Thomas

ER-72, GTN

Department of Energy

Washington, DC 20585

U.S. Department of Energy

Environment, Safety and

Health Division

P.O. Box 5400

Albuquerque, NM 87115

E. J. Vallario

15228 Red Clover Drive

Rockville, MD 20853

C. R. Vest

Marymount University

2807 North Glebe Road

Arlington, VA 22207

B. W. Wachholz

Radiation Effects Branch

National Cancer Institute

EPN, Room 530

8000 Rockville Pike

Bethesda, MD 20892

R. A. Walters

Los Alamos National Laboratory

MS-A114

P.O. Box 1663

Los Alamos, NM 87545

C. G. Welty, Jr.

EH-123, GTN

U.S. Department of Energy

Washington, DC 20585

I. Wender

Department of Chemical

Engineering

1249 Benedum Hall

University of Pittsburgh

Pittsburgh, PA 15261

M. L. Weseiy

Argonne National Laboratory

Building 203, ER

Argonne, IL 60439 
PNL-8000 Pt. 3

UC.402

W. W. Weyzen

Electric Power Research Institute

3412 Hillview Avenue

P.O. Box 10412

Palo Alto, CA 92665

D. Winstanley

National Acid Precipitation

Assessment Program

722 Jackson Street

Washington, DC 20006

R. W. Wood

ER-71, GTN

U.S. Department of Energy

Washington, DC 20585

Zhu Zhixian

Laboratory for Energy-

Related Health Research

University of Califomia

Davis, CA 95616

\section{FOREIGN}

\section{W. A. Asman}

National Environmental

Institute

P.O. BoX 1

NL-3720 BA Bilthoven

THE NETHERLANDS

D. C. Aumann

Institut für Physikalische

Chemis

Der Universităt Bonn

Abt. Nuklearchemie

Wegelerstran $\theta 12$

5300 Bonn 1

GERMANY

J. K. Basson

Raad Op Atomic

Atoomkrag Energy Board

Privaatsk $X 256$

Pretoria 0001

REPUBLIC OF SOUTH AFRICA
A. M. Beau, Librarian

Commissariat à l'Energìe

Atomique

Départment de Protection

Sanitaire

BP No. 6

F-92260 Fontenay-aux-Roses

FRANCE

G. Bengtsson

Statens Stralskyddsinstitut

Box 60204

S-104 01 Stockholm

SWEDEN

D. J. Beninson

Gerencia de Protection

Radiologica y Seguridad

Comision Nacional de

Energia Atomica

Avenida del Libertador 8250

1429 Buenos Aires

ARGENTINA

R. Berkowicz

Air Pollution Laboratory

National Agency for

Environmental Protection

Riso National Laboratory

DK-4000 Roskilde

DENMARK

Cao Shu-yuan, Deputy Head

Laboratory of Radiation

Medicine

North China Institute of

Radiation Protection

Tal-yuan, Shan-xi

THE PEOPLE'S REPUBLIC OF

CHINA

M. Carpentier

Commission of the E.C.

200 Rue de la Lol

J-70 6/16

B-1049 Brussels

BELGIUM
CEC

DG XII Library

SDM8 R1

200 Rue de la Lol

B-1049 Brussels

BELGIUM

Chen Xing-an, M.D.

Laboratory of Industrial

Hygiene

Ministry of Public Health

2. Xinkang Street

Deshengmanwal, Beijing

THE PEOPLE'S REPUBLIC OF

CHINA

G. H. Clark

Australian Nuclear Science

and Technology Organization

Environmental Science Division

Private Mail Bag 1

Menai NSW 2234

AUSTRALIA

R. Clarke

National P.adiological

Protection Board

Hanwell, Didcot

OXON OX11 ORQ

ENGLAND

P. Crutzen

Atmospheric Chemistry

Max-Planck-Institut

für Chemie

Postfach 3060

D-6500 Mainz

GERMANY

F. A. A. M. de Leeuw

Laboratory for Air Research

RIVM Laboratory for Air

Research

P.O. Box 1

NL-3720 BA Bitthoven

THE NETHERLANDS 
Deng Zhicheng

North China Institute of

Radiation Protection

Tai-yuan, Shan-xi

THE PEOPLE'S REPUBLIC OF

CHINA

Director

Commissariat à l'Energie

Atomique

Centre d'Etudes Nucléaires

Fontenay-aux-Roses (Seine)

FRANCE

Director

Commonwealth Scientific

and Industrial Research

Organization

Aspendal, Victoria

AUSTRALIA

Director

Laboratorio di

Radiobiologia Animale

Centro di Studi Nucleari

Della Casaccia

Comitate Nazionale per

I'Energia Nucleare

Casella Postale 2400

00100 Roma

ITALY

D. Djuric

Institute of Occupational

and Radiological Health

11000 Beograd

Deligradoka 29

YUGOSLAVIA

H. Dovland

Director

Norwegian Institute for

Air Research

Elvegaten 52

$\mathrm{N}-2001$ Lilleström

NORWAY
L. Feinendegen, Director

Institut für Medezin

Kernsforschungsanlage

Jülich

Postfach 1913

D-5170 Jülich

GERMANY

R. M. Fry

Office of the Supervising

Scientist for the

Alligator Rivers Region

P.O. Box 387

Bondi Junction NSW 2022

AUSTRALIA

G. B. Gerber

Radiobiology Department

Commission of European

Communities

200 Rue de la Loi

B-1049 Brussels

BELGIUM

A. R. Gopal-Ayengar

73-Mysore Colony

Mahul Road, Chembur

Bombay-400 074

INDIA

P. Grennifelt

Swedish Environmental

Research Instilute

P.O. Box 47086

S-402 58 Göteborg

SWEDEN

S. E. Gryning

Physics and Meteorology

Riso National Laboratory

DK-4000 Roskilde

DENMARK

G. F. Gualdrini

ENEA

3 v. le Ercolani

I-40138 Bologna

ITALY
J. L. Head

Department of Nuclear

Science \& Technology

Royal Naval College,

Greenwich

London SE10 9NN

ENGLAND

O. Hov

Department of Geophysics

University of Bergen

Allegaten 70

N-5007 Lilleström

NORWAY

P. Hummelshoej

Physics and Meteorology

Riso National Laboratory

DK-4000 Roskilde

DENMARK

K. E. Lennart Johansson

Radiofysiska Inst.

Regionsjukhuset

S-901 82 Umeá

SWEDEN

G. N. Kelly

Commission of the

European Communities

Directorate-General

Joint Research Centre

200 Rue de la Loi

B-1049 Brussels

BELGIUM

J. Kjems

Director of Research

Riso National Laboratory

DK-4000 Roskilde

DENMARK

H. J. Klimisch

BASF Aktiengesellschaft

Abteilung Toxikologie

Z470

D-6700 Ludwigshafen

GERMANY 
PNL-8000 Pt. 3

UC-402

L. Kristensen

Physics and Meteorology

Riso National Laboratory

DK-4000 Roskilde

DENMARK

\section{A. Lacser \\ Israel Institute of \\ Biological Research \\ Department of Mathematics \\ P.O. Box 19 \\ 700450 \\ Ness-Ziona \\ ISRAEL.}

\section{S. E. Larsen \\ Physics and Meteorology \\ Riso National Laboratory \\ DK-4000 Roskilde \\ DENMARK \\ H. P. Leenmouts \\ National Institute of \\ Public Health and \\ Environmental Hygiene \\ P.O. Box 1 \\ NL-3720 BA, Bilthoven \\ THE NETHEPILANDS \\ Li De-ping \\ Professor and Director \\ of North China Institute \\ of Radiation Protection, NMI \\ Tai-yuan, Shan-xi \\ THE PEOPLE'S REPUBLIC OF \\ CHINA}

\section{Librarian \\ Centre d'Etudes \\ Nucléaires de Saclay \\ P.O. Box 2, Saclay \\ Fig-sur-Yvette (S\&O) \\ FRANCE}

Librarian

Commonwealth Scientific

and Industrial Research

Organization

314 Albert Street

P.O. Box 89

East Melbourne, Victoria

AUSTRALIA
Librarian

Commonwealth Scieritific and Industrial Research

Organization

Division of Atmospheric

Research

Station Street

Aspendale, Vic. 3195

AUSTRALIA

Librarian

ECN

3 Westerdiunweg

NL-1755 ZG Petten

THE NETHERLANDS

Librarian

ENEA (OECD) Health and

Safety Otfice

38, Blvd. Suchet

Paris

FRANCE

Librarian

HCS/EHE

World Health Organization

$\mathrm{CH}-1211$ Geneva 27

SWITZERLAND

Librarian

Kernforschungzentrum

Karlsruhe

Institut pür Strahlenbiologio

D-75 Karlsnuhe 1

Postfach 3640

GERMANY

Librarian

Max-Planck-Iristitut für

Blophysics

Forstkasstrassis

D-6000 Frankfurt/Main

GERMANY

Librarian

Ministry of Agriculture,

Fisheries and Food

Fisheries Laboratory

Lowestoft, Suffolk

NR33 OHT

ENGLAND
Librarian

National Institute of

Radiological Sciences

9-1, Anagawa 4-chome

Chiba-shi 260

JAPAN

Library

Riso National Laboratory

DK-4000 Roskilde

DENMARK

Library, Periodicals

Atomic Energy Commission of

Canada, Lid.

Pinawa, Manitoba ROE ILO

CANADA

Library

Department of Meteorology

University of Stockholm

Arrhenius Laboratory

S-106 91 Stockholm

SWEDEN

A. M. Marko

Atomic Energy Commission of

Canada, Ltd.

Biology and Health Physics

Division

Chalk River Nuclear

Laboratories

P.O. Box 62

Chalk River, Ontario KOJ 1JO

CANADA

H. Matsudaira,

Director-General

National Institute of

Radiological Sciences

9-1, Anagawa-4-chome

Chiba-shi 260

JAPAN

Meng Zi-Qiang

Department of Environmental

Science

Shanxi University

Tai-Yuan, Shan-xi

THE PEOPLE'S REPUBLIC OF CHINA 


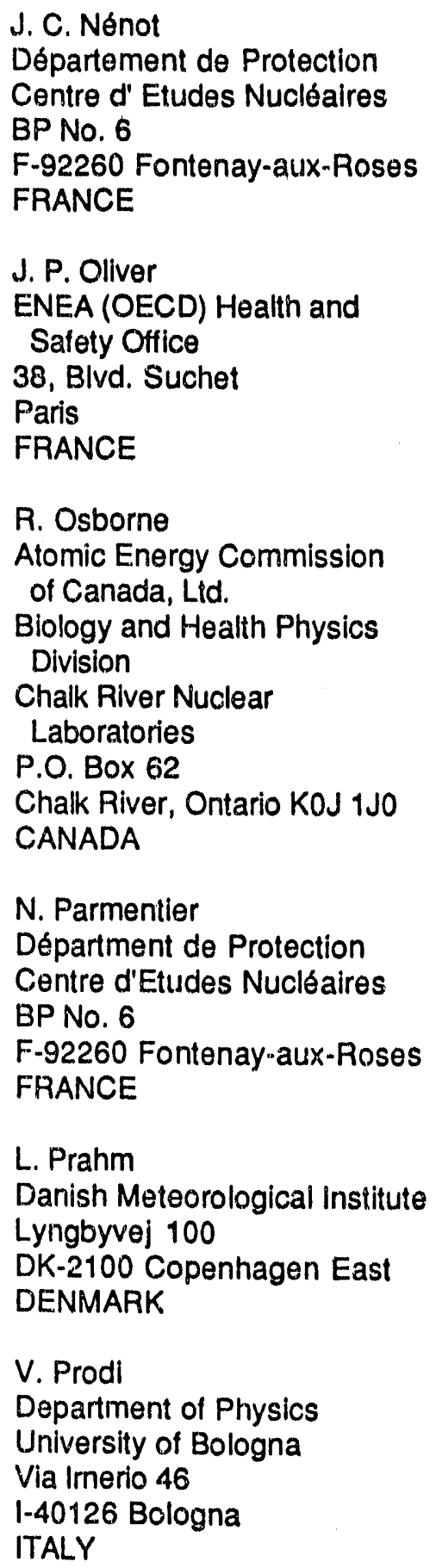

\author{
P. J. A. Rombout \\ Inhalation of Toxicology \\ Department \\ National Institute of \\ Public Health and \\ Environmental Hygieno \\ P.O. Box 1 \\ NL-3720 BA, Bilthoven \\ THE NETHERLANDS \\ M. Roy \\ Institut de Protection ef \\ de Sureté Nucléaire \\ Department de Protection \\ Sanitaire \\ Service d'Etudes \\ Apliquées de Protection \\ Sanitaire \\ BP No. 6 \\ F-92260 Fontenay-aux- \\ Roses \\ FRANCE \\ M. Rzekiecki \\ Commissariat à l'Energie \\ Atomique \\ Centre d'Etudes \\ Nucléaires de Cadarache \\ BP No. 13-St. Paul \\ Les Durance \\ FRANCE
}

G. Schnatz

Battelle-Europe eV

Am Rómerhof 35

P.O. Box 900160

D-6000 Frankfurt a.M.

GERMANY
R. Skogstrom Meteorological Institute University of Stockholm Arrhenius Laboratory S-106 91 Stockholm SWEDEN

J. Slanina

ECN

3 Westerduinweg NL-1755 ZG Petten THE NETHERLANDS

\author{
H. Smith \\ Biology Department \\ National Radiological \\ Protection Board \\ Chilton, Didcot \\ OxOn OX11 ORO \\ ENGLAND
J. W. Stather
National Radiological
Protection Board
Building 383
Hanwell, Didcot
OXON OX11 ORQ \\ ENGLAND
}

Sun Shi-quan, Head

Radiation-Medicine Department

North China Institute

of Radiation Protection

Tai-yuan, Shan-xi

THE PEOPLE'S REPUBLIC OF

CHINA

\section{J. W. Thiessen \\ Foundation \\ 5-2 Hijyama Park \\ Minami - Ward \\ Hiroshima 732 \\ JAPAN}

Radiation Effects Research
M. Thorne
International Commission
on Radiological Protection
Clifton Avenue
Sutton, Surrey
ENGLAND

\author{
United Nations Scientific \\ Committee on the Effects \\ of Atomic Radiation \\ Vienna International Center \\ P.O. Box 500 \\ A-1400 Vienna \\ AUSTRIA \\ D. Van As \\ Atomic Energy Board \\ Private Bag X256 \\ Pretoria 0001 \\ REPUBLIC OF SOUTH AFRICA
}




\begin{tabular}{|c|}
\hline $\begin{array}{l}\text { Vienna International } \\
\text { Centre Library } \\
\text { Gifts and Exchange } \\
\text { P.O. Box } 100 \\
\text { A-1400 Vienna } \\
\text { AUSTRIA }\end{array}$ \\
\hline $\begin{array}{l}\text { Wang Renzhi } \\
\text { Institute of Radiation } \\
\text { Medicine } \\
11 \# \text { Tal Ping Road } \\
\text { Beiling } \\
\text { THE PEOPLE'S REPUBLIC OF } \\
\text { CHINA }\end{array}$ \\
\hline $\begin{array}{l}\text { Wang Ruifa } \\
\text { Laboratory of Industrial } \\
\text { Hyglene } \\
\text { Ministry of Public Health } \\
2 \text { Xinkang Street } \\
\text { Deshengmanwai, Beljing } \\
\text { THE PEOPLE'S REPUBLIC OF } \\
\text { CHINA }\end{array}$ \\
\hline $\begin{array}{l}\text { Wang Yibing } \\
\text { North China Institute } \\
\text { of Radiation Protection } \\
\text { P.O. Box } 120 \\
\text { Tai-yuan, Shan-xi } \\
\text { THE PEOPLE'S REPUBLIC OF } \\
\text { CHINA }\end{array}$ \\
\hline $\begin{array}{l}\text { Wei Luxin } \\
\text { Laboratory of Industrial } \\
\text { Hygiene } \\
\text { Ministry of Public Health } \\
2 \text { Xinkang Street } \\
\text { Deshengmanwal, Beijing } \\
\text { THE PEOPLE'S REPUBLIC OF } \\
\text { CHINA }\end{array}$ \\
\hline $\begin{array}{l}\text { B. C. Winkler } \\
\text { Raad Op Atomic } \\
\text { Atoomkrag Energy Board } \\
\text { Privaatsk X256 } \\
\text { Pretoria 0001 } \\
\text { REPUBLIC OF SOUTH AFRICA }\end{array}$ \\
\hline
\end{tabular}

\author{
Wu De-Chang \\ Institute of Radiation \\ Medicine \\ 11\# Tal Ping Road \\ Beijing \\ THE PEOPLE'S REPUBLIC OF \\ CHINA
}

Yao Jiaxiang

2 Xinkang Street

Deshengmenwal

Beijing 100011

THE PEOPLE'S REPUBLIC OF

CHINA

ONSITE

DOE Richland Fleld Offlce (5)

\author{
R. D. Freeberg A5-19 \\ P. W. Kruger A5-90 \\ E. C. Norma i A5-10 \\ Public Readi.ig Room A1-65 \\ M. W. Tiernan A5-55
}

\section{Trl-Citles Universliy Center}

J. Cooper, Librarian H2-52

Hanford Environmental Health Foundation

M. J. Swint H1-02

Westinghouse Hanford

Co. (4)

W. E. Davis S6-70

G. L. Laws H4-57

C. J. Perkins $\times 0-21$

D. E. Simpson B3-55
Paclflc Northwest

Laboratory (122)

O. B. Abbey K6-04

R. C. Adams K6-52

K. J. Allwine, Jr. K6-11

W. E. Asher Sequim

R. W. Baalman K1-50

D. C. Bader BWO

J. F. Bagley K1-64

W. J. Bair K1-50 (15)

C. A. Baldwin P7-58 (10)

M. Y. Ballinger K6-03

W. R. Barchet K6-11 (5)

E. M. Baroni K1-74

C. J. Brandt K6-04

N. M. Burleigh K1-29

K. M. Busness K6-04

E. G. Chapman K6-08

T. D. Chikalla P7-75

J.F. Clarke BWO

T. T. Claudson B1-40

E. A. Crecellus Sequim

T. S. Cress K1-74

M. T. Dana K6-08

D. W. Denbo Sequim

J. C. Doran K6-11

J.P. Downing Sequim

R. C. Easter K6-08

J. A. Edmonds BWO

C. E. Elderkin K6-11

J.W. Falco K6-78

B. H. Fimiani BWO

S. J. Ghan K6-08

C. S. Glantz K6-96

W. A. Glass K4-13

J. A. Glissmeyer K6-03

D. W. Glover K6-81

M. J. Graham K7-80

R. H. Gray K I-33

L. K. Grove K6-86

R. K. Hadlock K6-03

J. M. Hales K1-74

R. V. Hannigan K6-04

M. S. Hanson K1-51

P. C. $\mathrm{H}$ ys $\mathrm{KG-86}$ 
C. S. Hillock K6-98

D. J. Hoitink K6-07

L. A. Holmes K1-29

J. R. Houston A3-60

J. M. Hubbe K6-11

J. R. Johnson K3-53

R. A. Keefe K6-11

E. W. Kleckner K6-84

M. L. Knotek K1-48

W. W. Laity K2-50

N. S. Laulainen $\mathrm{K} 6-11$

R. N. Lee K6-08

A. M. Liebetrau K7-3

J. C. Liljegren K1-74
J. A. Mahaffey P7-82

J. F. Park P7-52

W. T. Pennell K6-04

J. V. Ramsdell, Jr. K6-03

D. R. Roth K6-11

B. C. Scott K6-08

M. J. Scott K6-57

W. J. Shaw K6-11

B. D. Shipp K1-73

R. L. Skaggs K6-77

E. D. Skyllingstad Sequim

W. G. N. Slinn KG-08

G. M. Stokes K1-74 (5)

J. A. Stottlemyre K6-75
T. S. Tenforde K1.50 (2)

J. M. Thorp K6-08

L. L. Wendell K6-07 (2)

R. B. Westerberg K4-16

C. D. Whiteman K6-11

R. E. Wildung P7-54

W. R. Wiley K1-46

L. D. Williams K1-41

J. D. Zimbrick P7-58

Health Physics Dept. Library

Life Sciences Library (2)

Publishing Coordination

Technical Report Files (5) 

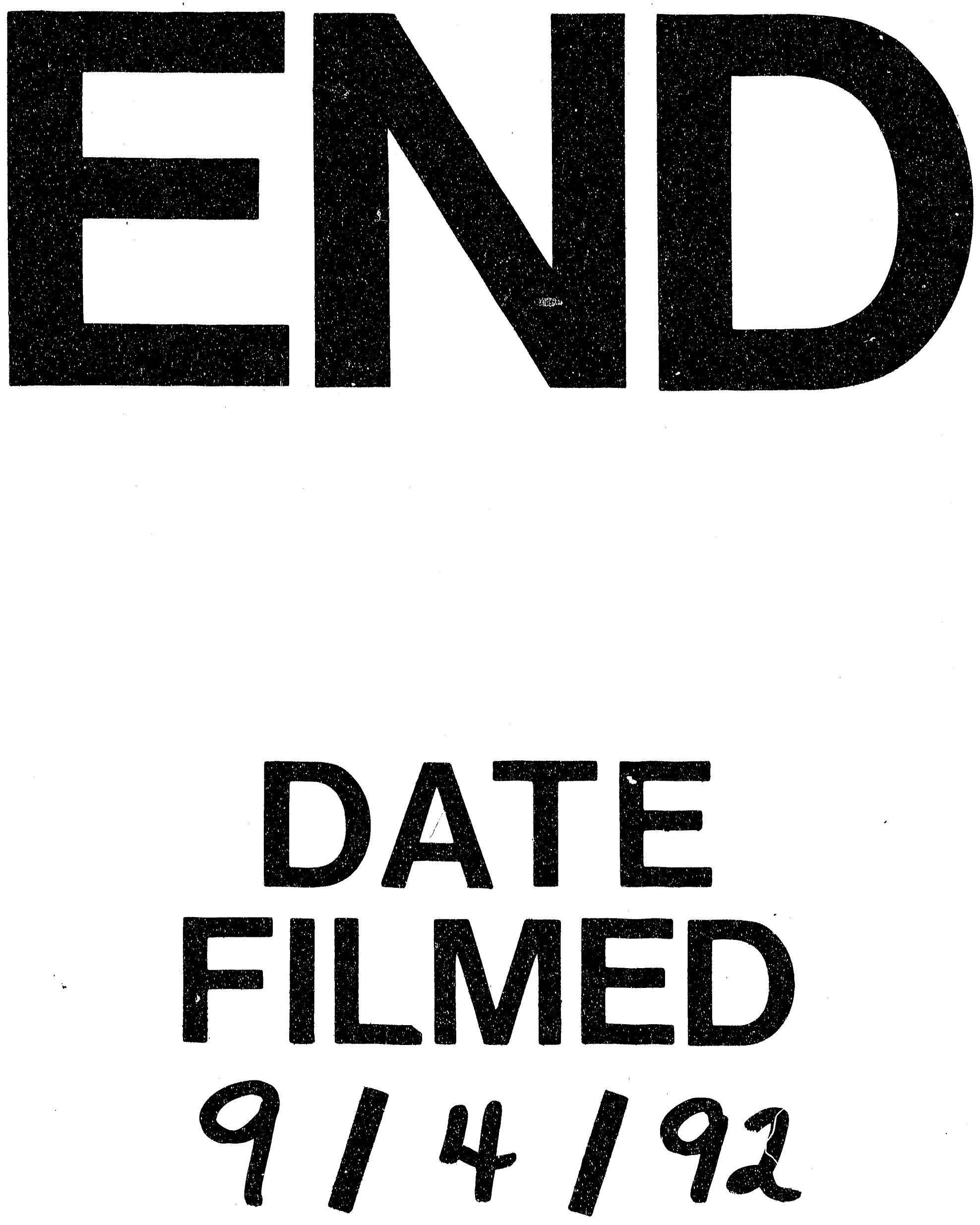